University of Rhode Island

DigitalCommons@URI

Open Access Dissertations

2017

\title{
Speaking Truth to Power: Stand-Up Comedians as Sophists, Jesters, Public Intellectuals and Activists
}

Jillian Belanger

University of Rhode Island, jillianbelanger@my.uri.edu

Follow this and additional works at: https://digitalcommons.uri.edu/oa_diss

\section{Recommended Citation}

Belanger, Jillian, "Speaking Truth to Power: Stand-Up Comedians as Sophists, Jesters, Public Intellectuals and Activists" (2017). Open Access Dissertations. Paper 610.

https://digitalcommons.uri.edu/oa_diss/610

This Dissertation is brought to you for free and open access by DigitalCommons@URI. It has been accepted for inclusion in Open Access Dissertations by an authorized administrator of DigitalCommons@URI. For more information, please contact digitalcommons-group@uri.edu. 
SPEAKING TRUTH TO POWER: STAND-UP COMEDIANS

AS SOPHISTS, JESTERS, PUBLIC INTELLECTUALS AND ACTIVISTS

BY

JILLIAN BELANGER

A DISSERTATION SUBMITTED IN PARTIAL FULFILLMENT OF THE

REQUIREMENTS FOR THE DEGREE OF

DOCTOR OF PHILOSOPHY

IN

ENGLISH WITH A SPECIALIZATION IN RHETORIC AND COMPOSITION

UNIVERSITY OF RHODE ISLAND

2017 


\section{DOCTOR OF PHILOSOPHY DISSERTATION}

OF

JILLIAN BELANGER

APPROVED:

Dissertation Committee:

Major Professor

Renee Hobbs

Caroline Gottschalk Druschke

Rachel DiCioccio

Nasser H. Zawia

DEAN OF THE GRADUATE SCHOOL

UNIVERSITY OF RHODE ISLAND

2017 


\begin{abstract}
Stand-up comedians are rhetors who use humor as a rhetorical tool to inform and persuade mass audiences in the classical rhetorical tradition. In this dissertation, I work to recover the rhetorical motives of stand-up comedy, just as rhetoric and composition scholars before me have reread and recovered the legacy of the Sophists. To that end, I align stand-up comedians first with the historical heritage of Sophists and jesters, and then with the more contemporary tradition of public intellectuals and social activists. Using excerpts from stand-up comedy performances, I demonstrate how stand-up comedians are able to persuade and educate with humor. Moreover, I argue that standup comedians represent a shift in access to messages, away from the prerequisite of formal education required by many forms of rhetoric and toward a more innately compelling method of information sharing, available to wide, diverse audiences.

I ask the overarching question: What kinds of messages are stand-up comedians sharing - about what, to whom, and how? To answer, I've used two data sources as evidence: (1) analysis of stand-up performances, and (2) interviews, both recorded interviews I've studied as well as those I've conducted myself. I've anchored my arguments about the important role of stand-up comedians to an evolutionary theory of humor recently advanced by scholars who believe humor is a computational tool humans have developed in order to detect and correct errors in their thinking. With that explanation in mind, the work of stand-up comedians starts looking less like jokes for joking's sake and more like an intentional, effective, and enjoyable form of rhetorical persuasion.
\end{abstract}




\section{ACKNOWLEDGMENTS}

That writing a dissertation is one of the hardest things I've ever done makes me feel spoiled and aware of my privilege, but it's the truth. If you saw the movie Akeelah and the Bee, you might remember the exquisitely amazing Angela Bassett telling the talented, young Keke Palmer, "You know, Akeelah, you ain't short on people who want to help you. I bet if you just look around, you got 50,000 coaches. Starting with me.” And then there's a heartwarming montage of all the people in their neighborhood helping Akeelah study for the spelling bee. That's a long setup to say that I feel like I've had 50,000 coaches and I'm so thankful for every single one of them. While I probably can't cover all of them before there's some grad school version of the music that plays when your speech is too long at the Grammy's, I'm going to cram as many thanks in as I can before I'm led offstage.

To my husband Joe James and our son Giuseppe David James: Nothing in this world would ever be worth having if I didn't have you two by my side, and that includes a Ph.D. For everything from Gus saluting me on his way to bed and saying, "Good luck, sergeant” to Joe figuring out how to remove the line breaks in my header that were making me lose my mind, I am grateful. You know that very cheesy Bryan Adams song, "Everything I do, I do it for you”? That.

My first coaches were my parents, Lisa and David Vieira, and they’ve been my strongest supporters and my biggest role models my whole life, so it's safe to say that even if I wrote an entire dissertation on how much I have to be thankful to them for, it'd 
only cover up 'til like third grade. They have not only told me I could do anything I put my mind to, but they made me feel that way too, and I'm forever indebted to them for their endless supply of love, encouragement, and Sunday dinners. While we're on the topic of family, my little brother Michael David has cheered me on for as long as he’s been on this planet, and bro, I got your back too, and Anga's and Luca's! Deb, Jim, Matthew, Aimee, Greg and Crosby, thank you for being there too! My family comes first in all things for me, including acknowledgement sections.

Dr. Renee Hobbs has come to feel like family to me over the past four years-I still can't believe I landed that research assistantship with you when you were but a farawayseeming scholar on Twitter; that felt like winning the lottery. You are still my academic role model, someone who is able to focus all your energy and attention on the task at hand, but also warmly and effortlessly make those around you feel listened to and included. Getting to have you as my major professor has felt like hitting the jackpot a second time. Dr. Jeremiah Dyehouse, when you told me in Swan Hall that I had gotten into the program... it's hard for me to explain what an important moment that was for me, but where should I try if not in the acknowledgements section of my dissertation, right? You are the first professor I had at URI, and if you hadn't made the comment about stand-up comedians being rhetors, I might be writing an entirely different dissertation, so I cannot thank you enough for your initial idea and continued support!

Dr. Caroline Gottschalk Druschke, you are awesome. In your WRT 647 Research Methods class, we talked about tacking your research boat to a fleet already in the field or staking out a course on your own, and while I know exactly nothing about sailing, my big takeaway was that even if our colleagues might not be talking about stand-up 
comedy too much at the moment, that doesn't mean I can't steer my ship in that direction and charter the territory, so thank you for strengthening my resolve to take on a subject I feel passionately about. And now every time I go to the Mews Tavern, I will look for the dollar bill you added to the wall for our class. Dr. Rachel DiCioccio, do you know how amazing it has been for me to have someone at URI who has studied and written about comedy? Très amazing. Your Humor Communication: Theory, Impact, and Outcomes was formative and invaluably instrumental to me as I developed my own identity as a scholar of comedy. And then to top that off, you're fun and funny to boot? It's a dream come true! Dr. Carolyn Betensky, thank you for all that you taught me, for your generosity of spirit, and for being on my oral comprehensive exams committee. I am so looking forward to sharing a cup of tea at Coffee Exchange with you once this is all over! And Dr. Norbert Mundorf, I am incredibly grateful to you for jumping in as the chair of my defense committee. Thank you for your kindness - and for being environmentally conscious!

To my classmates, Lindy, Krysten, Jenna, Clarissa, Alyson, Bridget, Karen, Eileen, and Adrienne: My learning was enhanced by listening to your comments, reading your work, laughing with you, and figuring it all out together, and I'm very fortunate to have worked alongside such smart, amazing women. Dotted along the timeline of my experience in this program are these bright spots — a brunch with Krysten here, a lunch with Clarissa there, some tea with Lindy, a walk with Karen, a writing boot camp with Jenna... you kept me going, and I thank you for that. To comedians Dan Martin, Patton Oswalt, Myq Kaplan, Erin Judge, Will Luera, W. Kamau Bell, John Fugelsang, and 
Aparna Nancherla: Thank you for your generous time and expert insight as I worked on this project!

You know how Zuzu Bailey tells her dad in It's a Wonderful Life that every time a bell rings, an angel gets his (or her) wings? Well every time I self-indulgently whined on Twitter about how hard it was to write this dissertation, and Amma or Amanda or Krystafer or any number of kind souls replied with a pep talk, a paragraph was born. And as far as acknowledging pep talks, the queen of talking pep to me is without question the one, the only Katydid Retzleff, who's been my pen-pal since we were seven. Our morning chats start my days off right, and our BE FRI, ST ENDS tattoos are coming soon to a ribcage near you.

I would be remiss not to offer my gratitude to Nutella, green tea, white cheddar cheez-its, and almonds for being my constant companions and fuel for working. Likewise, Mariam Makeba, Norah Jones, Frédéric Chopin, and the 3-hour brain waves video on YouTube all deserve my heartfelt thanks for making up the soundtrack to my writing days and nights, and Beyoncé for being the soundtrack to my life, obvs. Last as well as first, and the furthest thing from least, I must return to Joe and Gus, as I always will, to say thank you and I love you and this diss is for you. 


\section{TABLE OF CONTENTS}

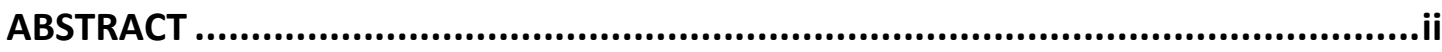

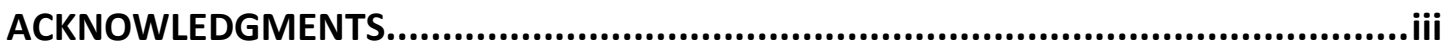

TABLE OF CONTENTS

CHAPTER 1

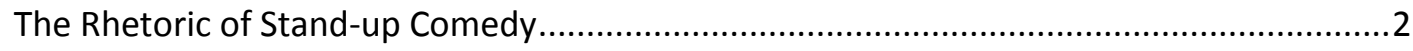

Interdisciplinary Literature Review.............................................................................

The Evolutionary and Computational Theory of Humor .................................................15

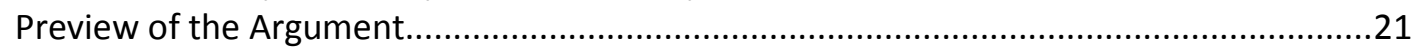

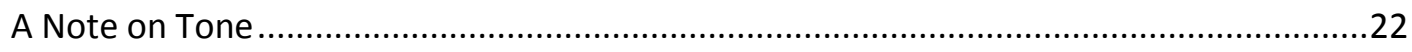

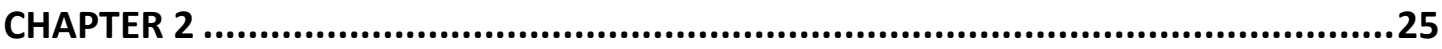

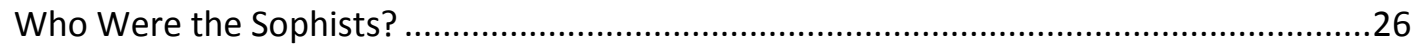

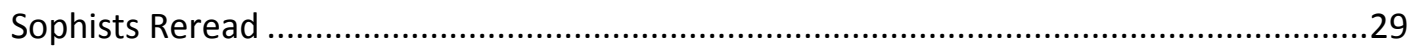

Similarities Between Sophists and Stand-up Comedians ………………………………....33

Argument to Reread the Stand-ups........................................................................47

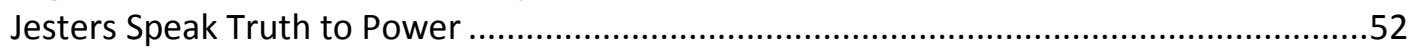

Stand-up Comedians as Jesters …………………………………………………...56

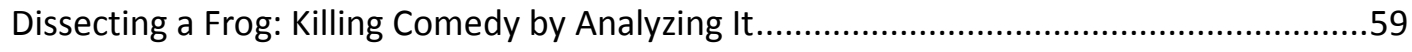

Stand-up Comedy as Resistance ...............................................................................

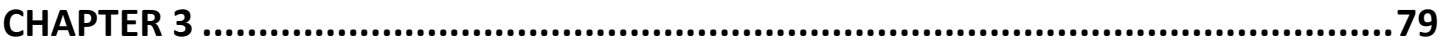

Comedians as Public Intellectuals............................................................................79

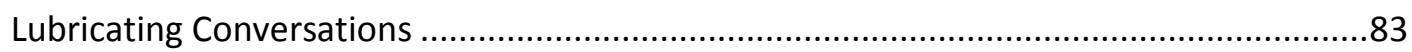

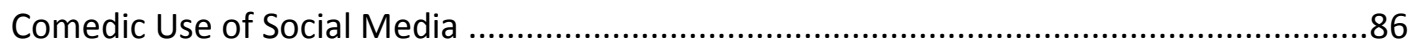

Working Within the Language of the People ...............................................................90

Comedians as Social Activists .................................................................................93

Poverty and Racism Are (Not) Funny .......................................................................96

Funny Formulas for Entertainment Education .............................................................102

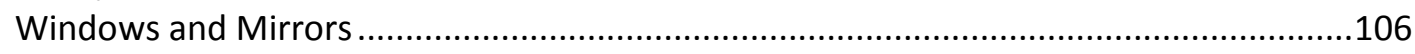

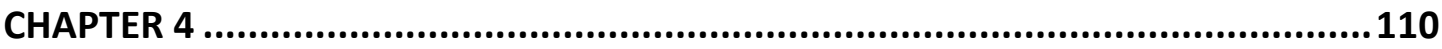

The Importance of Including Comedians' Voices in a Study of Stand-Up Comedy as

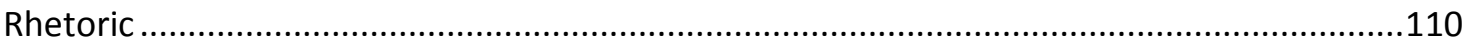

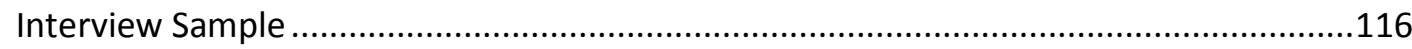

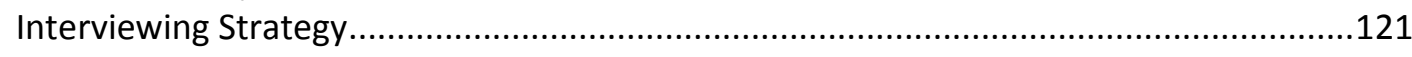

Preparing for the Interviews.....................................................................................122

W. Kamau Bell: A Comedy Rhetorician for Emerging and Established Activists ................123

John Fugelsang: A Comedy Rhetorician Devoted to the Process ........................................129

Aparna Nancherla: A Comedy Rhetorician Growing Into Her Political Identity ................136

Speaking Seriously About the Craft ............................................................................139

Examining the Human Experience ...............................................................................

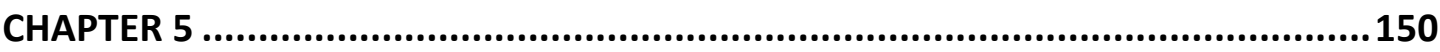




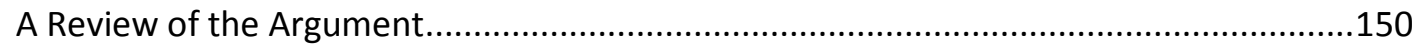

My Identity as a Writer, Researcher, and Comedy Consumer ......................................154

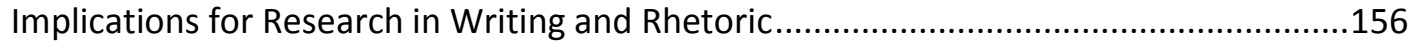

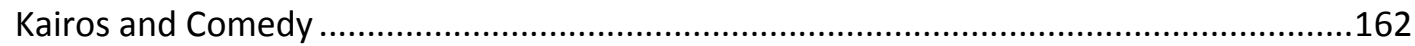

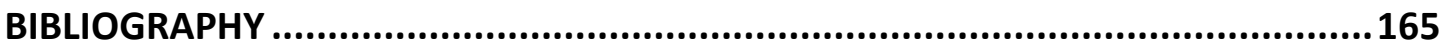




\section{CHAPTER 1}

THE SETUP

Stand-up comedians are rhetors who use humor as a rhetorical tool to inform and persuade mass audiences in the classical rhetorical tradition. Taking a page from Kenneth Burke’s book A Rhetoric of Motives, we will be identifying “a rhetorical motive... present where it is not usually recognized, or thought to belong.” Comedians are not often recognized as having a rhetorical motive; stand-up comedy is often enjoyed and appreciated as performance, but seldom analyzed or respected as persuasion. The following work aims to recover the important rhetorical function of stand-up comedians' work, aligning them first with the historical heritage of Sophists and jesters, and then with the more contemporary tradition of public intellectuals and social activists. Explicitly highlighted throughout will be voices of the comedians themselves, both in the form of their stand-up performances and their firsthand reflections on their own roles and agency.

American humorist Mark Twain famously told us, "Against the assault of laughter, nothing can stand.” American humorist Abe Burrows less famously told us, "With comedy we make much more serious points than we do with anything... serious." So why then, is it true that "any scholar who wants to study comedy occasionally encounters individuals who see only frivolity in their endeavors"? (Quirk). Competing approaches alternatively suggest that either laughter and comedy represent peak persuasion or are of little import and count only as frivolity. I am not an American 
humorist, but I am not-at-all famously telling us that a little levity can go a long way, so as a scholar who wants to study comedy, if I encounter an individual who sees only frivolity in my endeavors, I might remind said individual that if frivolity is a lightheartedness or a lack of seriousness, I'm happy to be light of heart, and seriousness is not the only way to make a point.

\section{The Rhetoric of Stand-up Comedy}

Stand-up comedians present points along the same lines as other persuasive speakers, generally following the five canons of rhetoric: invention, arrangement, style, memory, delivery. By employing these classically rhetorical strategies, stand-up comedians achieve rhetorical authority in their performances (Greenbaum) and spread knowledge and information to mass audiences in the tradition of what Apel and Habermas call open communication and embodied, enacted discourse. The comedians themselves are rarely given credit for this rhetorical work, or at least, the fruits of their labor come more in the form of laughs from ephemeral audiences in comedy clubs or on couches at home. If we were to imagine removing the humor from what they do, however, and picture a group of people who develop arguments, make thoughtful, stylistic and organizational decisions to optimize effect, memorize those stylized arguments, and then regularly deliver them to large audiences, we'd probably take that group pretty seriously as rhetors.

When we throw in the fact that the arguments comedians develop make people laugh, the significance of those arguments should be increased, because that in and of itself is no small feat. Humorists will work tirelessly to produce just the right combination of words to get people to laugh, and their process has been compared with 
science, as they all develop their own formulas by experimenting bit by bit and gauging the results (McGraw and Warner). What makes their process even more experimental is that in the imagined group of people who create and perform material as often as comedians but not humorously, they can experiment mainly through customary composition practices of editing, on the written page or computer screen, whereas comedians mainly do their experimenting onstage with live audiences, in order to gauge responses and determine whether a phrase needs to be shortened or a word needs to be louder the next time they try that material out.

The Greek concept of Kairos takes into account timing, setting and context, and plays a major role in how successful a stand-up comedian's material will be. In addition to practicing and editing before a live audience, comedians must be fluid and responsive to the crowd before them in an interactive way not expected of other speech makers, which demands that they stay up on their rhetorical toes a little more. A commencement speaker can typically expect to make it through a fifteen- or twenty-minute speech just as she’s prepared it, without any major heckling from the audience, but we couldn't say the same for comedians, who must be more improvisational in their delivery. Kairos is much more a factor in their endeavors. Although the basis of their acts are memorized, "they must be prepared for the exigencies of the moment, which is part of what makes live comedy so exciting in the first place” (Greenbaum 40). Even the physical act of standing in a room full of people who are seated facing toward you can be interpreted as both uniquely powerful and uniquely vulnerable, an embodied act of gaining attention and social prominence (Meier and Schmitt). 
Taken as a whole, a stand-up comedy performance is "a decidedly oratorical spectacle" and "remains one of the last remnants of the rhetorical tradition in contemporary culture” (Meier and Schmitt). The experimentation in stand-up comedy may qualify as science, but overall, the use of the five canons, Kairos, and embodied authority combine to make stand-up comedy, in Greek terms, a techne, or true art and discipline. Mike Rose says rhetoric and composition has taken a "public turn" and this research reveals that stand-up comedians are practicing rhetoricians who have taken a "public turn" by delivering carefully prepared speeches outside of the academy (Huckin, et. al. 109).

\section{Interdisciplinary Literature Review}

A thorough literature review captures major voices and perspectives from multiple fields on the topic of how comedy can be and has been wielded as a rhetorical tool. As historical anchors, I include Erasmus's Praise of Folly and Otto's Fools Are Everywhere in order to assist in examining the role of humor in past communities and conversations. Sanders too offers examples reaching back to the ancient Hebrews of laughter's age-old power to subvert authority. Many of the texts, however, are more contemporary explorations of comedy’s rhetorical power, offered by sociologists, anthropologists, psychologists, comedians, some rhetoricians, and one juggler. I have called upon writings from all of these groups in order to review, compare, and analyze what representatives from each have to contribute to the question of how stand-up comedians utilize humor to inform and persuade.

An interdisciplinary area of research, humor studies have been conducted and documented by linguists, anthropologists, sociologists, psychologists, and performers 
themselves. Rhetoricians are adding their perspective to the pot in recent years, and we have a lot more to add to a thorough examination of stand-up comedians' intentional production of humor in order to inform and persuade. The many intersections of rhetoric and composition and stand-up comedy are explored preliminarily by Tarez Samra Graban in a chapter for Victor Raskin’s Primer of Humor Research. Graban reports, "Humor has invited—no, enticed—a growing number of rhetoric and composition scholars to consider its bearing on cultural production and inquiry.” What, though, have all the rhetoric and composition scholars that Graban writes are "invitedno enticed... to consider [humor's] bearing on cultural production and inquiry” been studying, if not stand-up comedy, which seems to me the most clearly and compellingly connected to rhetoric and composition?

As a broad overview of the connections between comedy studies and rhetoric and composition, Graban provides a starting point from which we can look for specific links between stand-up comedy, specifically, and rhetoric. Graban chronicles references to humor in the field of rhetoric and composition that can be traced back to rhetoric's forefathers, along with other key intersections between humor and rhetoric to date. Cicero, Aristotle, and Quintilian have given considerable thought to humor and its rhetorical applications. In Book 6 of Institutio Oratoria, Quintilian wrote, “Though laughter may be regarded as a trivial matter, and an emotion frequently awakened by buffoons, actors or fools, it has a certain imperious force of its own which it is very hard to resist" and Cicero wrote, "Humor is a way the speaker can undermine his opposition, revealing his opposition’s weakness while concealing his own” (Graban). In the 
examples cited above, Quintilian and Cicero's treatment of humor demonstrates that they considered it to be a valuable, serious tool with powerful possibilities.

Aristotle lends his opinion about jests, in a manner befitting the rest of the topics on which he lends opinions, which is to say, presents as if a fact:

As to jests. These are supposed to be of some service in controversy. Gorgias said that you should kill your opponents' earnestness with jesting and their jesting with earnestness; in which he was right. Jests have been classified in the Poetics. Some are becoming to a gentleman, others are not; see that you choose such as become you. Irony better befits a gentleman than buffoonery; the ironical man jokes to amuse himself, the buffoon to amuse other people. (145)

According to Aristotle's confident claim, then, a stand-up comedian is automatically a buffoon for seeking to amuse other people. However, given that Aristotle also uttered the infamous definition of rhetoric as "the faculty of observing in any given case the available means of persuasion” (7) and further elaborated that “[p]ersuasion is clearly a sort of demonstration, since we are most fully persuaded when we consider a thing to have been demonstrated” (5), we should also be able to entertain a more nuanced opinion of stand-up comedians, whereby their jests are not ungentlemanly buffoonery, but rather, a demonstration of an especially effective available means of persuasion. However, this strategic act of persuasion is not as often the subject of humor studies as the act of consuming humor (Miczo). Researchers and philosophers have done plenty of thinking and writing about audience members, readers or viewers on the receiving end of comedy. Much of this writing isn’t broken down into genre-specific 
comedy. "Humor" and "comedy" are often presented as homogenous categories that intend to entertain and make people laugh. While psychologists have written extensively on what makes us laugh and why (which would be classified as receiveroriented research), and sociologists and anthropologists have contributed to an understanding of stand-up comedy as a cultural mediation (Mintz), rhetoricians will be able to apply a new layer of language analysis as well as an emphasis on situation in comedic performances.

Mary Douglas observes, "the joke form rarely lies in the utterance alone, but... can be identified in the total social situation" and describes joking as "public affirmation of shared cultural beliefs and... reexamination of these beliefs.” Stand-up is an excellent illustration of how the "total social situation" contributes to the joke form; a stand-up comedian relies on word construction but also gesture, inflection, volume, facial expressions, and even the room itself to complete the joke form. Victor Turner's work too highlights the "experience of public joking, shared laughter, and celebration of agreement on what deserves ridicule and affirmation [which] fosters community and furthers a sense of mutual support for common belief and behavior” (Mintz 73). In “Standup Comedy as Social and Cultural Mediation,” Mintz declares standup comedy to be arguably the oldest, most universal, basic, and deeply significant form of humorous expression, and calls for "thorough studies of joke texts and comedy routines... as well as more careful analyses of forms and techniques"-which was one of cues for this research.

When I began this research, an interdisciplinary literature review was at least partly necessary because of the lack of attention to stand-up comedy in rhetoric and 
composition journals and books. Very recently, however, in 2016, Matthew R. Meier and Casey R. Schmitt edited a book entitled Standing Up, Speaking Out: Stand-Up Comedy and the Rhetoric of Social Change, in which they assembled various professors of Rhetoric, English, Communication, and Sociology to reflect on and write about the relationship between stand-up comedy and the rhetoric of social change. It was inspired, they write in their preface, by "a handful of rhetoricians" who "started a serious conversation about stand-up comedy.”

Meier and Schmitt are essentially my kindred spirits, urging colleagues to recognize that "modern stand-up comedy deserves close critical attention as a rhetoric that tells the truth, but tells it slant," a nod to Emily Dickinson's advice to "tell the truth but tell it slant.” They mark the middle of the twentieth century as a point where standup comedy represented a divergence from other comedic actors like joke tellers, vaudevillians and radio performers, who had operated mainly on rote gags and canned jokes, toward a "uniquely oratorical form of entertainment that was both captivating and provocative.” As part of this shift, more attention was paid to invention rather than delivery, and the stand-up comedians doing the work of that invention became a new class of public intellectuals, whose work was "rhetoric more than a performance, and as such, their comedy was not only entertaining, it was also persuasive” (Meier and Schmitt).

To be transparent, it has been surprising, invigorating and challenging to witness a surge in scholarship on the topic of stand-up comedians as public intellectuals at the time of writing this dissertation. On the one hand, it strengthens a sense of justification in studying this topic, and it provides a richer basis for demonstrating its relevance. On 
the other hand, it produces a certain anxiety that others are "going public" with these ideas faster, and that it may be "old news" by the time I read what they've written on the topic and catch up to include that in my own analysis. On either hand, though, the fresh cropping up of similar arguments around stand-up comedians as rhetors and change agents does suggest that Graban may be correct in her observation that a growing number of rhetoric and composition scholars have been enticed to consider humor's bearing on cultural production and inquiry.

While some scholars reverently maintain that "the power and authority with which some comedians hold their audiences' attention and gain agreement seem almost shamanistic" (Olson), others clearly feel that the decision to focus on comedy must be defended. Even the titles of books dedicated to the study of comedy can come off as defensive: Why Stand-up Matters, Laughing Matters, Beyond a Joke, All Joking Aside... they seem to scream, “I’m not kidding, you guys, I really do think this is important!” Perhaps this is because "the paradox of writing seriously about humor is that humor makes a mockery of seriousness" (Lockyer and Pickering), and some scholars don’t wish to make a mockery of seriousness. Well then, now is as good a time as any to introduce the idea that in addition to considering and adding to work that has been done by scholars, we must necessarily look to non-scholarly sources as well. Part of the argument that rhetoric and composition scholars should take up the study of stand-up comedy is acknowledging those non-scholars who have thought and written seriously about stand-up comedy. Therefore, we must be willing to examine words by Aristotle in one paragraph and excerpts from a documentary mini-series hosted by Billy Crystal in 
the next. We must expand our thinking to include College English but also The Atlantic and NPR.

For example, my assertion that stand-up comedians consciously employ rhetorical agency to articulate opinions and criticisms is strengthened by statements by comedians themselves, often shared in not-so-scholarly outlets. To wit, comedian Erin Judge, writing for Boston Globe, declares:

The whole goal for any comedian is to raise awareness about social issues when people are disarmed by laughter. Because you can have these awkward encounters in contrived social settings, where people of color and white people are trying to explain themselves to one another. But when you have something like stand-up as the framework, it’s incredibly disarming. Which makes it incredibly powerful. (Judge)

Her stance on comedians’ goals should be acknowledged as relevant to the conversation about how stand-up comedy functions rhetorically, since she is a comedian and therefore able to speak to her own goals and experiences. Likewise, Sol Saks may not be part of the academic community, but he was an American screenwriter and published several books about comedy writing that offer thoughtful insights into comedy production, including, "Like a heat-seeking missile, humor finds and attacks hypocrisy." And comedian Paul Provenza is quoted in a scholarly article as proclaiming, "Anyone who makes you laugh is always doing more than just that” (Waisanen).

In Make 'Em Laugh: The Funny Business of America, multiple producer-oriented takes are offered, including, "Our comedians are mercenaries. We pay them to do the outrageous things that we can't do," and "We should treasure our comedians much more 
than we do; they contribute much more to our society than we're aware of." Another documentary, Just Like Us, presents stand-up as having the "powerful ability to provide relief, encourage a younger generation, break down barriers and serve as a platform for cross cultural dialogue" and concludes, "The role of the comedian is to speak truth to power and point out things that maybe people aren’t talking about.” Similarly, various stories on NPR champion the rhetorical advantages of comedy, including a description of how Amy Schumer drops social commentary once we're paying attention (Deggans) and an assertion that "If you can make someone laugh, you can secretly make them learn something" (“Drunk History”).

To address a dissenting point of view, let’s consider Ralph Rosen’s “Efficacy and Meaning in Ancient and Modern Political Satire: Aristophanes, Lenny Bruce, and Jon Stewart,” in which Rosen comes across as dubious that humor, or satire, specifically, can contribute to social change. He says, "satirists claim to have something urgent to say and insist that what they have to say is actually true," but "there remains deep suspicion about comedy, the effects of laughter, and the gamesmanship of satire: Where is there a space for truth-telling and moral seriousness when a satirist always has an eye on making the audience laugh?” (Rosen 3). The deep suspicion about comedy he describes is evident in the rest of his work, where he questions whether the satirist actually accomplishes anything other than making an audience laugh, and sprinkles in a healthy dose of condescension, including throwaway comments like "or perhaps we should say schtick” to “correct” himself for calling material by Lenny Bruce a "passage.” Concluding that no, the satirist does not succeed in actually instigating change or enlightening anyone, Rosen essentially crosses his arms and ends with a defiant, "So 
there!" in the form of: "Satirical efficacy ends with laughter rather than persuasion or education, even if satirists craft their work as if the opposite is the case.”

In response to Rosen's grumpy defiance of satire contributing to social change in any way, I would first point out that the category of satire is too broad, just as the category of stand-up comedy is too broad, to make any clear cut definitive statements about. Rosen would need to clarify which types of satire he finds unsuccessful at instigating social change, just as I provide qualifications for the specific stand-up comedians I'm referring to when I argue that they are successful at shifting mindsets. Secondly, he is thinking too narrowly if he is only willing to concede that satire contributes to social change when there is visible, visceral evidence of a mind having been changed or an an action having been taken. On the contrary, a stand-up comedian's influence on listeners can be counted in many other ways, including reinforcing existing values, pushing against a previously held belief, and helping to knock down the untouchable prestige of a topic or group by toppling it with mockery.

Rosen would do well to read Oliver Double's response to the criticism that stand-up comedians are "preaching to the converted" because the fans who choose to watch them often already hold the same beliefs. Double argues that the criticism relies on the assumption that preaching to the converted is a useless activity, but in truth, part of the purpose of a sermon is to share and celebrate common beliefs and "send the flock out into the wicked world with a strengthened faith” (290), so an evening spent listening to someone you already agree with isn’t automatically disqualified from being purposeful or impactful. Similarly, Rosen could see what Sophie Quirk has to say on the matter, as she also argues, "the way that stand-up functions as an expression of in- 
group unity may be seen as one of its most effective political features” (180). Finally, satire can have some overlap with stand-up comedy on a venn diagram, but since we are specifically studying stand-up comedy here, we need to take Rosen’s harrumphing about satire with a grain of salt, knowing that there are important distinctions that make standup stand apart from satire, including the key quality of one person standing on a stage addressing a crowd through words, inflection, pace, and gesture.

I promised I'd include a juggler in this literature review, and now I want to make good on that covenant. I should probably add though that Chris Bliss isn’t just a juggler, but a stand-up comedian as well. One of the foundational purposes for comparing standup comedians with Sophists, jesters, public intellectuals and social activists has been the notion that comedians are able to employ a particular form of persuasion through their humor. Bliss’s 2011 TED Talk “Comedy Is Translation” was so much a part of the bedrock of my thinking on this topic when it was in its nascent stages that I actually think it deserves one of those longer quotes that goes past four lines and therefore gets tighter margin:

A great piece of comedy is a verbal magic trick, where you think it's going over here and then all of a sudden you're transported over here. And there's this mental delight that's followed by the physical response of laughter, which, not coincidentally, releases endorphins in the brain. And just like that, you've been seduced into a different way of looking at something because the endorphins have brought down your defenses. This is the exact opposite of the way that anger and fear and panic, all of the flight-or-fight responses, operate. Flight-or-fight releases adrenalin, 
which throws our walls up sky-high. And then comedy comes along, dealing with a lot of the same areas where our defenses are the strongest— race, religion, politics, sexuality— only by approaching them through humor instead of adrenalin, we get endorphins, and the alchemy of laughter turns our walls into windows, revealing a fresh and unexpected point of view. (Bliss)

It is interesting that Bliss would label a great piece of comedy "a verbal magic trick," as it calls to mind a similar statement made by Sharon Crowley in "A Plea for the Revival of Sophistry” about rhetoric: "Today, the efficacy of public discourse is so well hidden that America has a nearly silent citizenry. The discipline of rhetoric, as well as the techniques that inform its practice, remain invisible to all but a few eccentric academics and a phalanx of highly skilled practitioners who work their verbal wizardry in the public media” (322). Stand-up comedians, I contend, should be counted among that phalanx of highly skilled practitioners, for they are working their verbal wizardry in the form of those verbal magic tricks described by Bliss, and what's magical about their work is the way they can leverage humor as a less combative form of persuasion than other, more traditional forms of rhetoric. It "provides a mechanism by which incongruous viewpoints, and information which contradicts the hearer's pre-existing attitudes, may be presented in a non-threatening manner” (Quirk 164).

Having focused primarily in the literature review thus far on texts that advance an assessment of the aims and purposes of comedy, we should also acknowledge the three major theories of humor that have received the most attention, out of over one hundred documented theories: (1) the relief theory, which posits that the purpose of 
humor is to relieve tension and anxiety, (2) the incongruity theory, which suggests that we laugh when we recognize a shift in perspective from what we expected, and (3) the superiority theory, which maintains that the misfortunes of others are humorous because they cause us to feel superior. As American satirist and social critic H.L. Mencken reportedly said in 1918, "A professor must have a theory as a dog must have fleas” (DiCioccio 4). To add a flea, I will now introduce the evolutionary and computational theory of humor, presented by Matthew M. Hurley, Daniel C. Dennett and Reginald B. Adams, Jr. in Inside Jokes: Using Humor to Reverse-Engineer the Mind.

\section{The Evolutionary and Computational Theory of Humor}

A professor who specializes in the study of stand-up comedy is a rare bird, but one such bird is the aforementioned Sophie Quirk, a lecturer in drama and theater at the University of Kent in the UK, who asserts, "humour is useful in interpreting the incongruity in such a way as to provide pleasure rather than discomfort... [and] gives the persuasive speaker an advantage in that his message may be received warmly when it could otherwise have triggered negative feelings or reactance” (164). A recent computational theory of humor by Hurley, Dennet and Adams uses an evolutionary approach to help us understand why we may experience that pleasure rather than discomfort, explaining that humans have developed a sense of humor as a reward for recognizing errors in our systematic thinking. They locate humor in the moments when an active committed belief clashes with a latent committed belief brought into the same active mental space. For Hurley and company, the pleasure we feel is a reward that has evolved to motivate us to constantly spend energy in updating our belief systems, keeping them flexible and sharp, which can give a competitive advantage in survival and 
reproduction. In other words, humor is an evolutionary way to reward ourselves for shifting our thinking. While humor can serve to unify, divide, persuade or disparage, let us learn more about how it can serve as an error correction mechanism to reward reframing and revising beliefs with pleasure.

Going back to 1964, Arthur Koestler questioned what the evolutionary purpose of humor and laughter might be in The Act of Creation: A Study of the Conscious and Unconscious in Science and Art:

What is the survival value of the involuntary, simultaneous contraction of fifteen facial muscles associated with certain noises that are irrepressible? Laughter is a reflex, but unique in that it serves no apparent biological purpose; one might call it a luxury reflex. Its only utilitarian function, as far as one can see, is to provide temporary relief from utilitarian pressures. On the evolutionary level where laughter arises, an element of frivolity seems to creep into a humorless universe governed by the laws of thermodynamics and the survival of the fittest.

Hurley, Dennett and Adams do not accept the premise that humor and laughter serve no biological purpose or utilitarian function beyond temporary relief, and they argue that understanding the ultimate purpose of humor is a worthwhile endeavor—one that has been largely ignored as humor researchers instead focus on determining what makes something funny. This mirrors the call for more research on humor production, in addition to the abundance of attention to humor consumption and appreciation, in Nathan Miczo’s earlier mentioned "Humor and Message Production.” 
To set up how other survival traits evolved in humans as adaptive solutions, Hurley, et al. provide several examples. First, they consider traits that once served a purpose but are no longer required, like goose bumps, which were effective for our hairier hominid ancestors as a way to trap an insulating layer of air, but have stuck around when we get the chills today, even though they don't serve the same purpose on our less hairy bodies. Second, they consider traits that are not actually designed by evolution at all, but are rather "nondebilitating by-product[s] of another trait that has enhanced the fitness of the bearer's progenitors," like music appreciation. Third, they consider traits that got hijacked from their original evolutionary purpose, like the sneezing reflex, which has been exploited by cold viruses to infect new hosts. Fourth, they consider traits that were designed "to solve a computational problem faced by our brains that has not heretofore been identified," and it is in these last two examples that they locate humor (10-12).

In light of the third example, of traits being hijacked or exploited so as to spread themselves, humor is considered as a "plausible candidate for fecund cultural replicators that... fuel their own replication by providing us with a bounty of pleasure” (Hurley, Dennett and Adams 11). The authors point to Richard Dawkins' concept of a meme, or "an idea, behavior, or style that spreads from person to person within a culture," providing an immediately apparent connection to humor, which is often transmitted via memes. The notion of jokes as seeds to spread ideas was also put forth by Sophie Quirk, who said that "jokes have the advantage of being eminently repeatable and thus able to spread ideas to a much wider audience.” Another Sophie, Sophie Scott, has made mention of the evolutionary quality of humor as well: "When you laugh with people, 
you access an ancient, evolutionary system to make and maintain social bonds and regulate emotion."

Adding to the possibility that humor could potentially fit into this third type of trait, by virtue of its viral-like quality, Hurley et al. point out that humor may have been appropriated as an evolutionary marker for fitness-enhancing and mating purposes, citing an observation that people who have a large store of humor are more popular and more likely to influence others, as evidence. Here they introduce Geoffrey Miller’s proposition that “[f]emales use sense of humor (in males) as a hard-to-fake advertisement of intelligence and power” (Hurley, Dennett and Adams 11). Putting aside, for a moment, the glaringly heteronormative nature of this hypothesis, we will look back on Miller's statements. He first identifies that “[s]ome theories of humor have proposed that laughter evolved to promote group bonding, discharge nervous tension, or keep us healthy,” but dismisses these theories as failing to take into account the quality of jokes or people's ability to discern which jokes are genuinely funny to them, as indicated by the fact that people may not feel compelled to laugh at any joke, or at a joke they may have already heard before (Miller 241). Instead, Miller posits that “[a] good sense of humor means a discriminating sense of humor" and "[s]uch discrimination is easy to understand if our sense of humor evolved in the service of sexual choice, to assess the joke-telling ability of others” (241).

Hurley, Dennett and Adams entertain this evolutionary approach to humor as a revealer of personality traits by expanding on it beyond the purposes of mating: "Since humor is hard to fake, both in the creating and in (the suppression of) appreciation, it is particularly valuable as a litmus test not just for intelligence but for enduring personality 
traits, hidden loyalties, and socially crucial attitudes and beliefs” (12). To illustrate their point, they offer the following examples:

A young man who cannot abstain from snickering when presented with a juvenile scatological remark wears his immaturity on his sleeve; people who cannot chuckle at satire when it is deftly on target may betray their political loyalties, just as someone who casually makes a racist quip betrays a cast of mind that might otherwise be concealed. Detecting these signs, and other such practical uses of humor, may well have become established in societies without the (full) appreciation of the individuals who adopt them... For instance, people may not have the slightest idea why they distrust various others who laugh or don't laugh at various moments; these folks just 'strike them the wrong way,' while others, whose laughter is felt to be genuine and which synchronizes with their own, are sought out and categorized as friends. (Hurley, Dennett and Adams 12)

Before committing themselves fully to this third type of evolutionary trait, the authors pull back and add the caveat that cultural evolution must first have a genetically evolved basis on which to hang its hat, "a proclivity that can be harnessed by these social ends, wittingly or unwittingly” (Hurley, Dennett and Adams 12). It is there, in the fourth type of evolutionary trait, that they finally establish their theory.

In a nutshell, they posit that humor indirectly emerges from a design feature in our genetic endowment that exists to solve a computational problem faced by our brains. Beliefs and presumptions enter into our mental space at breakneck speed, and the feeling 
of humor or mirth acts as a powerful reward system to identify which of those beliefs and presumptions should stick around and which should be tossed. This means that humor can be a gatekeeper, helping us to check content for truth and identify ideas that have value. If our brains' unsupervised generation process is left unexamined, "the inevitable errors in these vestibules of consciousness would ultimately continue on to contaminate our world knowledge store," so we are in need of humor to weed out the wrong ideas that could contaminate our world knowledge store (13). Cue the comedians. Hurley, Dennett and Adams’ theory of humor as an evolutionary tool for error correction is a game changer. It represents a massive elevation to how comedy can be viewed. If we are wired to find pleasure in the learning or unlearning of ideals and beliefs, as befits a greater benefit to group co-existence, then wow, stand-up comedy is a weapon of mass construction. With it, comedians can build societal norms, reveal to us the error of our thinking, and redirect our values, all to the soundtrack of ringing peals of laughter as we reward ourselves for discovering and/or affirming which ways of being and thinking would best benefit humans as a group. With great power comes great responsibility, and not all stand-up comedians answer that call. As comedian Sam Kinison once said, “Anyone can go out on stage and start beating people over the head with rubber chickens. That'll get people's attention. Real comedy doesn't just make people laugh and think, but makes them laugh and change.”

As with any profession, we cannot paint in broad strokes and proclaim that all standup comedians wield their ability to captivate audiences with words as a tool with which to reshape group thought. Some just enjoy getting laughs out of strangers, and will gladly play into popular he-man woman-hating themes to get those laughs (ahem, we're 
talking about you, Andrew Dice Clay and Anthony Jeselnik). Others relish in their wheelhouse of holding up common experiences for our scrutiny, pulling laughs out of our recognition of ourselves in their fresh but relatable observations (and thank you for that, Jerry Seinfeld and Demitri Martin). But some stand-up comedians take the stage to make us laugh and, whether they know it or not, shape our cultural views and beliefs. They tap into what we will now acknowledge as our evolutionary instinct to know better, be better and do better.

\section{Preview of the Argument}

This research highlights how stand-up comedians are linked to the ancient rhetorical tradition, and draws on previous work chronicling stand-up comedians (Nacman, Zoglin, Provenza). In chapter one, I have provided an interdisciplinary literature review of works that lay the groundwork for our understandings about the performative, persuasive nature of the work that stand-up comedians do. In chapter two, I align stand-up comedians with Sophists and jesters. To answer the question of how the work of a stand-up comedian is similar to that of a Sophist, I first provide an overview of who the Sophists were and how they were reread and recovered by rhetoric and composition scholars. Once the background has been provided, I enumerate the ways in which stand-up comedians function similarly to Sophists and argue for rereading the stand-up comedians as well. Moving on to jesters, I show how stand-up comedians are able to speak truth to power in a non-combative way due to their standing as entertainers, and how this can be traced back to court jesters, as archived by Beatrice K. Otto in Fools Are Everywhere: The Court Jester Around the World. Using multiple examples from 
comedians who consistently demonstrate a strategic intention to address social issues, I address the subversive, disruptive power of stand-up comedy as a rhetorical motive.

In chapter three, I align stand-up comedians first with public intellectuals, drawing on definitions by Nathan Crick Edward Said, and then with social activists, providing multiple examples of performances by stand-up comedians along the way. Chapter four provides a necessary and important perspective on comedy production: the comedians'. I include my methodology for interviewing comedians about how they see themselves as having rhetorical agency, and how they intentional wield that agency, and look for answers to those questions in already existing interviews with comedians as well. With chapter five, I reflect on my own identity as a writer, researcher, and comedy consumer, and conclude by offering major takeaways and implications that have come out of this work.

\section{A Note on Tone}

One last thing before we embark on this journey laid out for you in these chapter previews: Part of the argument being made here is that the way stand-up comedians deliver their messages makes those messages more palatable, and therefore draws more people to listen to them over other, more traditional forms of rhetoric. They take, if you will, a sort of "you catch more flies with honey than vinegar" approach to sharing their thoughts and arguments with others. In that spirit, you may discover that in writing this dissertation, I occasionally part ways with what we might expect from traditional, formal documents like one intended to secure someone some extra letters at the end of their signature. The intention behind this parting of ways with consistently formal writing mechanics is to play with the idea that the way something is presented impacts the 
reader's engagement with the message. As a social experiment, let's explore together whether moving between heavy rhetorical lifting, like quoting and citing and lining up points, and slightly more whimsically tinted bursts, like... this one... could result in a more engaged interaction with a text—or, instead, if it might simply result in a reminder that academic writing and point making are intended to be accomplished in one specific, agreed upon formal tone, using specific, approved language choices.

Allowing for just one more paragraph's worth of thought to the tone of delivery here, I will add, transparently, that even the use of first person in an academic document can feel like a major misstep or trespass, but a good rhetorician is constantly reflecting on important things like arrangement and audience, and a really good rhetorician might even be inspired by scholars like Gloria Anzaldúa, on whom, as I once proclaimed in a response for our WRT 524 Histories and Theories of Writing Instruction course, I have an academic crush (Belanger). Anzaldúa writes of her mestiza identity: "Identity can never be reduced to a 'bunch of little cubbyholes'... Identity flows between, over aspects of a person” (252-3). Likewise, my own writing identity is not exclusively rooted in academic jargon, but is influenced by a decade of teaching creative, freespirited, urban high school students, a lifetime of reading books with the indiscriminate palette of someone who holds Sweet Valley Twins in the same high regard as Jane Eyre, and the hundreds of hours of stand-up comedy I've watched for fun and for research, and it is from those multiple perspectives and more that this writing will flow, simulating, at times, the decidedly non-academic tone of stand-up comedians' own work. Speaking of the comedians themselves, another thing with which to preface the remainder of your reading is the disclaimer that because stand-up comedians often 
utilize informal language, dialect, and cursing in their stand-up shows, and because some of their material is transcribed here for the purposes of analysis, you will need to prepare yourself to see words like ain't, gon' and motherfucka. And that's just a single excerpt from comedian D.L. Hughley. 


\section{CHAPTER 2}

\section{WHAT DO SOPHISTS, JESTERS, AND STAND-UP COMEDIANS HAVE IN COMMON?}

To whom can we anchor stand-up comedians in history? In the ancient rhetorical tradition, orators used speech to persuade and inform. Michael Gagarin reviews recorded purposes of rhetoric at the start of his 2001 article, "Did the Sophists Aim to Persuade?”, from Aristotle’s “ability, in each [particular] case, to see the available means of persuasion” to Gorgias’ “power to persuade by speech” in every gathering, to Socrates' description of producing persuasion in the minds of the audience (275-6). Certainly, stand-up comedians perform these actions in their acts, delivered to live audiences in much the same way that Greek rhetors would deliver their speeches, but more than that, stand-up comedians can specifically be compared with Sophists, traveling orators who went city to city, selling speech as their product.

This chapter aims to demonstrate how stand-up comedians do parallel work, in surface-level ways as well as in deeper ways, to Sophists and jesters. We will start with an overview of who the Sophists were, then explore the ways in which they have been re-read by rhetoric and composition scholars, and then we will examine the parallels between stand-up comedians and the Sophists. I will make the argument that stand-up comedians too need to be re-read by rhetoric and composition scholars. Moving on to jesters, I explore the ways in which stand-up comedy is an extension of the work that court jesters did to inform leaders and audiences in a non-threatening, palatable way that presents as entertainment. 


\section{Who Were the Sophists?}

In Greek, Sophos means “wise,” and in the mid-fifth century, traveling teachers called Sophists flocked to Athens as the first instructors of rhetoric (Conley 4). According to Patricia Bizzell and Bruce Herzberg in The Rhetorical Tradition: Readings from Classical Times to the Present, the Sophists were "a diverse group of early philosophers who were interested in exploring all branches of knowledge” and who "wandered from city to city, expounding their views to those who could pay for the privilege of listening, and also committing their ideas to writing” (22). Speaking well during this period in Greece was becoming increasingly important once tyranny was overthrown in Syracuse and law courts and other democratic institutions called for people to be able to speak for themselves in ways they hadn't before. Sophists benefited from this new need by becoming traveling speech makers and demonstrating to the sons of wealthy families able to pay for their services that they could teach them how to speak and make arguments as they did.

Traveling from place to place afforded Sophists a unique opportunity to gain insights into multiple perspectives. Moreover, their "ability to see many sides of an issue encouraged cultural tolerance, which would be a stabilizing factor in a diverse society, as Athens increasingly was because of the influx of foreigners seeking to enjoy Athenian cultural and political advantages or to avoid the ravages of war elsewhere” (Bizzell and Herzberg 25). In the Sophists' view, opposing views have to be conducted through language, which they recognized as fraught with emotional and cultural baggage and therefore never "objective"; they "sought to call attention to the function of language in inducing belief, rather than encouraging audiences to give themselves up 
uncritically to its power to move and persuade” (Bizzell and Herzberg 23). In other words, they advocated for critical thinking and spurred their students toward rhetorical greatness, and what can be said against that?

Historian of rhetoric John Poulakos claims that the "playfulness” of Sophists” techniques undermined one of the main tenets of Sophists' verbal competitions- the idea that the stronger and better would prevail (Bizzell and Herzberg 24). According to him, the Sophists did not take the work of persuasion and critical thinking seriously enough because they were playful while doing it. The criticism does not stop there, though. Isocrates did his part in contributing to the negative perceptions of Sophists by penning “Against the Sophists,” in which he accuses sophists of lacking scruple, charging too little for their services and having no interest in truth. Of course, it must be remembered that Isocrates was actually himself educated by Sophists, and sought to separate himself from that group at least in part for the purposes of luring students to his own, stationary school, which he saw as superior to the traveling camps of speechmaking and -teaching performed by the Sophists.

One method for understanding who the Sophists were would be to examine what they produced. Given the less-than-lasting recordkeeping capabilities of mid-fifth century Greek scholars, we don't have as full a library of Sophistic literature as we might like, but one emblematic, anonymously authored text was Dissoi Logoi, a compilation of lecture notes scholars believe were influenced by Protagoras, Hippias, Gorgias and Socrates. In it, questions are presented of what can rightly be considered good or bad, seemly or shameful, just or unjust, and true or false. Since Sophists traveled from city to city and saw multiple cultural approaches to behavior, dress, and 
other customs, they became aware of and comfortable with differences in various areas and had unique opportunities to see that what may be considered shameful in one place is actually seemly in another. As a result, Sophists took a nuanced, rather than binary, approach to whether something ought to be considered just or unjust. One example offered in Dissoi Logoi is a predicament in which one’s parent must take medicine, but is unwilling to consume it; the author argues that hiding the medicine in the parent's food is a just action to take, and therefore deceiving one's parent is, in that situation, the better choice. It is precisely this type of nuanced deliberation that Sophists touted and taught, and it represented a change from a more authoritarian, religiously based system that represented truth as being wholly good and deceit as being wholly bad.

On a broader level, Thomas M. Conley divides sophistic teaching into “Protagorean,” or debate-oriented, and “Gorgianic,” or persuasion-oriented, and summarizes that Protagoras was "accused of teaching his students how to 'make the worse case appear the better’ and Gorgias of providing his students with a power equivalent to 'putting a knife in the hands of a madman in the crowd'” (6). Having just now gone over the text Dissoi Logoi, we have a fresh understanding of where the criticism of Protagoras teaching students how to make the worse case appear the better came from. Among the accusers were Aristotle and Plato, both of whom sought to set themselves apart from Sophists by widely sharing their own philosophies about rhetoric. Perhaps Aristotle shared the opinion that the Sophists’ playfulness undermined the seriousness required of persuasion, since we know from the previous chapter that he considered jests to be ungentlemanly buffoonery. 
Criticism aside, eloquence in public speaking was a skill that was becoming increasingly required of citizens; Sophists saw that need and filled it. Bizzell and Herzberg described the role of Sophists as follows:

[T]he Sophists taught young people that they could improve themselves via Sophistic teaching. They did not need to defer to the wisdom of their elders or social betters—-self-improvement was open to anyone who could pay for it, and anyone, no matter what his or her natural endowments, could make some progress under Sophistic teaching. Hence the traditional privileges of the aristocracy were undermined. (22)

And of course we know that any time privileges of an aristocracy are undermined and “elders and social betters” are no longer deferred to, some feathers will be ruffled, and some haters will kick up dust in an effort to preserve the status quo from which they benefit. The dust kicked up by Isocrates, Plato, Aristotle and others covered the legacy of Sophists in a dirty film of discredit and disdain until certain scholars, centuries later, sought to pick up the Sophists and... dust them off.

\section{Sophists Reread}

Sophists were considered less than because their speech and their instruction were for sale. In the history of rhetoric, they were looked down upon by many until they were recovered and reread by Eric Havelock, Harold Barrett, Sharon Crowley, Susan C. Jarratt, Michael Gagarin, Nathan Crick, and others in the field of rhetoric and composition. This interest occurred at a time when mass communication was obliging scholars to rethink relationships between audiences and authors, messages and meanings, and representation and reality. Picking up Havelock’s 1957 thread of thought about 
Sophists, Barrett wrote The Sophists: Rhetoric, Democracy, and Plato's Idea of Sophistry in 1987, actively challenging and correcting the "historical untruth" perpetrated by Plato and others who sought (successfully, it had seemed) to discredit the work of the Sophists. In Barrett's retelling of the sophistic movement, Sophists did not "put the knife in the hands of the madman in the crowd," as the people in power at the time had somewhat hysterically proclaimed, but rather "directed the power of their writing and teaching toward raising people's consciousness of their attributes as social creatures and of their identity as individuals” (36). By teaching citizens to view themselves as social creatures and infusing in them (for a fee) the ability to advocate for themselves through persuasion, the Sophists threatened the authority of those in control and were therefore punished by reputation defamation.

For Crowley, the Sophists offer a model for helping students to understand that discourse helps us to consider "the existence of competing viewpoints and the availability of choices among these," and she posits that "Sophists saw that education was intimately tied to politics; they thought of language as an instrument of political and social change, and most importantly, they thought that teachers should be active participants in bringing change in these arenas” (329). Arguing that the Sophists' rhetoric amounted to a theory of social change, Crowley asks readers to reconsider the discursive practice of Sophistic pedagogy, which had earned them Plato’s scorn, as a positive engagement in political and social issues.

Also arguing that the Sophists' texts represented an entry into the issues of social difference and discursive strategies, Jarratt points to writings by Sophists Gorgias and Protagoras as inviting thought about gender difference and status as a foreigner, 
respectively. Whereas those who came immediately after the Sophists took great pains to discredit their work, announcing that Sophists had done something dangerous by teaching students how to argue either side, and that citizens should instead come study in their own schools (ahem, Isocrates and Aristotle), Jarratt looks back in time and sees Sophists as critical in the transition from "instruction in aristocratic behavior and skill in arms, central to the status of the warrior/aristocrat" to "the new arête essential for democracy: the ability to create accounts of communal possibilities through persuasive speech” (98).

Not only did Sophists inspire a significant shift in what was considered valuable in the instruction of citizens, but they also redefined who had access to that instruction, introducing what Jarratt calls "the very first education for empowerment” through their model of teaching for fees, which allowed anyone (read: any men) with money the opportunity to engage in the training necessary to speak well and therefore participate in the assembly, council and courts. Considering the fact that the only previous option was to get lucky enough to be born into a noble family with connections to intellectuals who would teach their sons, Jarratt is correct in reading the Sophists' traveling teaching-forfees as a step toward democracy and empowerment. In hindsight, it seems natural and predictable that those seismic shifts prompted by Sophists would be bucked by members of the nobility seeking to discredit their efforts; what's more surprising is that it took so long for scholars to recover the intent behind the sophistic movement and hold it up for what it was: a time in history when a group of people traveled around, using words to investigate injustice and help others unlock how they could do the same. Of Aristotle’s scornful assessment of the Sophists' teaching as a deceitful way to "make the worse case 
better,” Jarratt responds that “a reading informed by a democratic political agenda understands the process of discovering contradictory statements to be grounded in the sophistic belief that phenomena are characterized by constant change” (104). So there, Aristotle.

If my notes from WRT 512: Studies in Rhetorical Theory are to be trusted, a look at the rehabilitation of Sophists in the field of rhetoric and composition would be incomplete without the inclusion of Nathan Crick's take on the scene, since I seem to have recorded him as "the hottest, most current voice on Sophists.” (I’m assuming I do not need to parenthetically cite my own class notes, but that is a verbatim quote from them.) In The Sophistical Attitude and the Invention of Rhetoric, Crick adds his hot, current voice to the growing number of scholars teaming up to knock down arguments against Sophists and elevate them to their rightful place. In addition to modeling for us what clear, structured, well arranged writing looks like ("In this essay, I argue that..."), Crick countered Johnstone's statement that Sophists were anti-foundationalists first, productive artists and pedagogues second. According to Crick, Sophists are much more than just that. Kicking off with a nod to John Dewey’s reading of Sophists as "the first practitioners of experimental method in art and in science,” Crick doubles down on Dewey's notion that Sophists marked a distinct change from a time when divination and pious sacrifice were the "only resources to address crises of instability and change" (25$6)$.

Crick's central claim is that "the core of sophistical methods of invention grew out of [an] experimental attitude toward knowledge in which theory was a means for generating novel perspectives and guiding situated practices within kairotic moments” 
(31). In his hot, current take, Sophists did not necessarily start the Greek Enlightenment, but they were an indisputably indispensable part of it, and their experimentalism was as much cause to celebrate as their contributions to pedagogy and the shift in audience they represented. By reinserting the notion of temporal continuity into the cynical stance that Sophists taught now to turn the weaker argument into the stronger, Crick repositions the aforementioned dissoi logoi to be "a doctrine of reasoned judgment that occurs through the dialectical engagement of multiple views that are constantly being tested, rejected, modified, and embraced through experimental action in a changing environment” (36). This far more favorable interpretation of Sophists' intentions behind instructing students to argue from multiple perspectives provides a much different lens than the traditional derision with which Sophists had previously been considered. In conclusion, the successful rereading of Sophists moved them from a place of disgrace—where they had been previously positioned by Plato, Aristotle, Isocrates and others in Athens who were threatened by the more equal democracy Sophists invited—to a place of honor, being credited by scholars like Barrett and Havelock as essentially inventing the idea of education as an identifiable, conscious process.

\section{Similarities Between Sophists and Stand-up Comedians}

Sophists aim "to make people see that what has always been so does not necessarily have to continue,” and that is just the first of several ways in which stand-up comedians can be compared to them (Bizzell and Herzberg 24). An argument can be made (and is being made, right now, actually!) that stand-up comedians fill much the same role as Sophists, have been maligned in similar ways, and should be reread. The first and most obvious similarities to point out between Sophists and stand-up comedians 
are the surface level traits: Both jobs require traveling from city to city to sell speech as a product. Certainly we could point to many jobs that require these two elementstraveling and speech making — as components of work, but there are few jobs in today's society that are comprised primarily, almost exclusively, of touring around making speeches to live audiences. To test this claim, let's examine whose work does include traveling speechmaking. "Priests!” one audience member shouts. "Motivational speakers!” another adds. Someone else calls out, "What about politicians, professors, and people who talk at graduations?” Great examples, imaginary audience members. Let's go through them and examine the motives for sharing speeches, the audiences with which speeches are shared, and the extent to which the speech sharing is central to the position.

Priests and other faith based leaders do indeed prepare speeches to share with congregations on a regular basis. However, the content of their talks is necessarily restricted to religiously related topics, and the moral or outcome of their messages are tied to already established norms and conditions, whereas the world is a stand-up comedian's oyster. Comedians in general are not beholden to any set of beliefs or expectations by default, and therefore the speech performances that they invent and deliver can cover a limitless range of topics, tones, opinions and messages. Furthermore, religious leaders typically deliver their speeches to audiences that are pre-determined by the location of the church and the membership of the religion. Though there are times that some religious leaders will travel to preach to a different congregation, it cannot be argued that they do this on as regular a basis as stand-up comedians do, and it also cannot be positioned as the feature most central to their work as religious leaders, 
whereas the work of a stand-up comedian is centrally to share prepared speeches with multiple, varied audiences.

Motivational speakers, if they are motivational speakers by trade and not as a side endeavor, do make their bread and butter by traveling around sharing prepared speeches, but those speeches are again singular in nature, intended mostly for the result of motivating an audience to take a particular action or adopt a certain belief. A motivational speaker may be driven by the desire to convince teenagers everywhere not to drink and drive, which is a worthy endeavor, but this target audience will most likely be placed in front of the speaker by order of a principal or a guidance counselor or some other well intentioned adult hiring the speaker with the express goal of driving this message home to listeners through powerful and engaging persuasion. Comedians, on the other hand, have access to listeners who choose to attend their performances of their own volition, unless, of course, a principal happens to have hired the comedian to speak to a group of students on whatever topic the comedian so chooses, which probably doesn't happen with incredible frequency.

If many people were to try to think about a prepared speech they've listened to voluntarily in recent memory, a speech made by a politician might come to mind. Politicians surely do travel around making speeches, and target audiences for any given speech by a politician may vary more widely than the audience of, say, a religious leader or a motivational speaker. Putting aside the caveat that, in fact, many politicians enlist speech writers to actually prepare these speeches, which leaves them only with the delivery portion and can't be compared to comedians' work of preparing and delivering speeches, we will focus instead on the centrality of speech making to the work of a 
politician. Hopefully, politicians are not primarily concerned with preparing and delivering speeches.

Though the tradition of sharing messages with the public through the time honored practice of speaking to live groups of people seems to be sticking around in politics, despite the now readily available alternatives of pre-recording a talk or simply writing updates and sharing them electronically with mass audiences, the speeches made by politicians are intended as touch points to relay their work or positions, and do not in and of themselves represent the work of the politicians. Conversely, comedians are not sharing speeches with live audiences in order to relay the other work they're doing; the speeches themselves, and the live performance of them, are the work. Along those same lines, professors may be traveling and sharing prepared speeches or lectures with audiences in multiple locations in order to promote a book or a cause, but again, they are sharing those speeches to explain or publicize the larger body of work they are responsible for; the speeches themselves do not constitute the core of the work, whereas speech sharing lies at the center of the comedian's work.

Finally, though commencement speeches are shining examples of the classic tradition of speech preparation and delivery, the people who deliver them are not career commencement speakers, so the performances cannot be considered central to a specific position or career. The content of commencement speeches may cover a wide range of topics and beliefs, but ultimately they are meant to convey some message or advice about transitions or rites of passages. Additionally, listeners are, in some ways, held captive by the context of the situation; whereas audiences for stand-up comedians are, again, generally present for the occasion by choice, and for the express purpose of 
hearing the comedians, audiences for commencement speeches are primarily there to celebrate a graduation, when we get right down to it. As with the prevailing practice of politicians' speeches, it may be comforting for rhetoric and composition enthusiasts to know that there is still a time and place reserved for a well designed and powerfully delivered speech, but we cannot conclude that commencement speeches exceed or supersede the performances of stand-up comedians in terms of the practice of making speeches and and traveling around to deliver them.

"Wait!" one member of the imaginary audience shrieks, remembering suddenly that their task is to name jobs that include traveling and speechmaking. "I forgot about people giving TED Talks! Do they count?” I'm so glad you've brought them up for us to consider, imaginary audience member, even if you are a little late to the proverbial game; it makes for a more interesting introduction to TED Talks than the phrases I usually see in They Say/I Say: The Moves That Matter in Academic Writing, in my opinion. TED Talks are, of course, examples of speeches and they do tend to attract audiences in large masses, both in person and online. They also occasionally make use of humor as a technique for sharing important messages, but another technique more consistently employed should be examined as a significant departure from the work done by Sophists and stand-up comedians: the use of images and presentations, preloaded and ready to go, behind the speaker to emphasize the points being made. Here, a TED Talk presenter has a marked rhetorical advantage over a stand-up comedian, who must rely exclusively on him- or herself on stage when speaking. Additionally, a TED Talk presenter is not a TED Talk presenter by trade, but rather is delivering a TED Talk as an overview or summary of a topic or finding crucial to his or her actual work. 
Having gone over the ways in which stand-up comedians' work primarily consists of traveling to deliver speeches to a greater extent than the examples that the imaginary audience members shouted out, we can confirm the statement presented in American: The Bill Hicks Story: "Who do you ever pay to talk? Maybe a preacher, maybe a lecturer, possibly a politician. Even those, rarely. Comedians are the only ones that you pay to hear 'em talk. 'Talk to me. Make me listen.”' We should also acknowledge that the job of a comedian extends beyond traveling speech making. Especially in the social media saturated $21^{\text {st }}$ century environment, many comedians promote their work in online forums and share some of their material in places like Twitter and YouTube, which requires neither speech making nor traveling, but nevertheless, these two features remain the main points of stand-up comedy. So we can concretely confirm that Sophists and stand-up comedians are similar on the surface level. Let's go deeper.

Both Sophists and stand-up comedians represent a shift in audiences and access. As Susan C. Jarratt pointed out in Rereading the Sophists, "In centuries prior to the fifth, a young man from the aristocratic class would have been 'adopted' in an informal way and trained in performance of fitting 'words and deeds' by an older male friend of the family... But in the middle of the fifth century, a small number of exceptionally qualified traveling intellectuals began to gather young men able to pay a fee into small 'colloquia' or seminar groups for 3 or 4 years of political education.” The importance of the shift from nobility to wealth cannot be overstated in terms of moving toward a more democratic, equitable distribution of power. If the only way to gain access to learning environments was to be born into a family with the connections to someone who could 
train you in education, then the arrival of the Sophists on the scene, accepting money from anyone able to offer it, was a big deal. Access to learning was still limited to people with the means to pay for it, of course, and "the aim of the education movement led by the sophists was not to educate the people, but to educate the leaders of the people" (Jaeger, 290).

Stand-up comedians too represent a shift in access to ideas, messages and learning. Who reads scholarly articles? Scholars. Who gets to listen to lectures by people who have studied a topic and prepared something to say about it? Students. Who generally commits leisure time to catching up on think pieces in print and online publications? Mostly people with some degree of formal education. Ahh, but who consumes standup comedy? Everyone. Ok, I take it back; that may be a bit too farreaching an answer for readers to accept. But if not everyone, certainly more people than are typically represented by the first three groups referenced-scholars, students and formally educated people. Formal education isn’t a prerequisite for access to messages delivered by standup comedians, and moreover, those messages don't need to be tied to course credit or some other scholarly carrot in order to motivate people to consume them; audiences seek out standup comedy of their own volition. Therefore, the messages shared by a standup comedian are accessible to a bigger, broader population than the ideas put forth in the hallowed halls of universities and in the prestigious pages of publications — and there's no tuition or subscription required either.

Having established that standup comedians are similar to Sophists in that they travel, deliver speech as a product, and represent a shift in audience and access, let us turn now to the content of their work. With the aforementioned caveat that we are not 
considering the work of standup comedians as a whole to be the subject of this comparison, but rather the work of comedians that place an emphasis on social and political topics and prioritize the goal of enlightening audiences and/or instigating change, we can move to the concept of these comedians as public intellectuals, another way in which they echo Sophists. As Jarratt pointed out in Rereading the Sophists, "the sophists' 'practice,' not confined to the classroom, made them into the pre-eminent public intellectuals of their era” (95). The same can be said for stand-up comedians, who are certainly not confined to a classroom, but rather, peddle their words and ideas around to, as previously mentioned, wide audiences of listeners, from all levels of education and backgrounds.

The idea of standup comedians as public intellectuals will be further fleshed out soon, so stay tuned for more on this topic, but for the time being, and for the purposes of establishing a clear comparison between Sophists and stand-up comedians, suffice it to say that if Jarratt can claim that Sophists "could be termed the first public intellectuals in a democracy" because they "engaged in a range of public discourse activities including teaching, both shaping and advancing a political agenda through their talk” (98), then we can also use that logic to apply to standup comedians, who might not be the first public intellectuals in a democratic society, but definitely shape and advance a political agenda. Similarly, the ways in which Sophists anticipated writing-across-the-curriculum programs, which, according to Jarratt, "have the potential to provide critical perspective from outside disciplinary frames of reference” (97), align with the ways in which standup comedians can provide critical perspective, also from outside disciplinary frames of reference. 
For Jarratt, the association of Sophists' legacy with democracy is more compelling than any arguments that hold up rational education of individual consciousness or Sophists as technicians as reasons they should be reconsidered and restored as positive contributors to a history of speaking and teaching. She considers the "rhetorical turn" described by Patricia Bizzell to be one in which rhetoric and composition scholars return to democracy, ethics and the idea that the course of language usage extends beyond pure functionality of technique to the wider outcome of transmitting permanent human values. Jarratt sees this "rhetorical turn" as the "current version of the sophistic counter-response to the Platonic critique” and there is an emphasis on the type of pedagogy for which Bizzell advocates—one that "takes seriously its mandate from the democracy enfranchising it—-to provide equal opportunity for all its members and investigate injustice and inequity wherever they currently operate” (Jarratt 97). Here again we see a bold, straight line between the motivation for Sophists and the motivation for the type of stand-up comedians we've pinpointed here — the ones for whom "investigating injustice and inequity wherever they currently operate" is a goal that is accomplished show by show, audience by audience. As for providing an equal opportunity for members of a democracy to participate in and bear witness to these investigations of injustice encompassed in comedic material, well, we've already examined how stand-up represents a shift in access to these types of observations, away from the prerequisite of a formal education and toward the general public, which has been lured into listening by the dangling carrot of being made to laugh. Moving over to Crowley's contributions in the recovery of Sophists that can be lifted up and transferred to a recovery of stand-up comedians, we will remember how 
Crowley pointed out that teachers, whom she was aligning with Sophists, could not escape the public aspect of their work, and consider how stand-up comedians, whom I align with Sophists, are not only not escaping, but embracing the public aspect of their work. In fact, Crowley alludes to the two ways that Sophists knew to teach the mastery of any practice — by example or by theorizing — and then shares that "the Greek word from which theory is derived originally designated a spectator who sat in the furthermost rows of the theater, literally 'observing from afar'” (330). Clearly, stand-up comedians would be working within the first way, by example, since they are far from a spectator in the furthermost rows of the theater. In Crowley's interpretation of the two options, teaching has a "locatedness" that makes example the superior method over theory, and she even goes so far as to conclude: From a Sophistic point of view, teachers who refuse to make judgments about which issues are more important than others, which issues deserve to be studied, and which issues should be ignored abdicate their responsibilities to the students, and to their communities” (332-3). Applying this condemning distinction to stand-up comedians, we can surmise that comedians who leverage their "verbal wizardry" to make judgments about issues they see as needing to be addressed are fulfilling their responsibilities to their audiences and their communities.

Continuing in the comparison of the content of Sophists' and stand-up comedians' work, and with the idea of both being public intellectuals of sorts, we are ready to confront the idea of "unsettling pupils" that Crowley introduces in "A Plea for the Revival of Sophistry": "Just as doctors use drugs to change unsatisfactory physical conditions into more comfortable ones, teachers unsettle their pupils in such a way as to move them away from unsatisfactory positions toward more useful ones. In this way, 
social and political change come about.” This practice in which teachers engage students, whereby the former "unsettle” the latter, was a key component to Sophists' work. Likewise, standup comedians for whom social and political change are central goals "unsettle" their audiences away from unsatisfactory opinions or beliefs toward positions the comedians find to be more useful.

For example, in Ellen Degeneres’ 2000 comedy special The Beginning, she dismantles the argument against same sex marriage—or, as Liz Feldman calls it, marriage, because she doesn’t "gay park” or "go out to gay lunch” (Harper)— by addressing a commonly made point that marriage has always been between a man and a woman, and if it's changed to two people of the same sex, "what is next? Someone could marry an animal?” Degeneres goes on to imagine what it would be like to live together in an apartment with a goat "to see if you're compatible," with pictures of "you and the goat on the beach running, holding hands," and trying to read the newspaper on a Sunday morning while the goat is trying to eat it.... She may not be "unsettling" her listeners away from an unsatisfactory position, but rather, leading them to see the ridiculousness of it by indulging the idea of marrying an animal and turning it into a comical situation. This comes after Degeneres' material about directions on conditioner bottles, ants carrying around other dead ants, and looking at one's butt in the mirror, so she has also made some rhetorical decisions around warming her audience up by making them laugh about less controversial topics, and then addressing same sex marriage, once she has established herself as someone with whom they can agree and laugh.

In the example above, Degeneres is using humor to lead listeners toward a position she holds. In other instances, comedians with the rhetorical adeptness and 
access to audiences necessary to change minds may be using humor to reinforce misogyny or hegemony. This ability to sway listeners in either direction is another parallel to Sophists, some of whom subscribed to the notion of dissoi logoi, a rhetorical exercise based on the premise that at least two contrary sides must be taken into account (Poulakos). As Plato writes in Apology of Protagoras, "Wise and good orators make what is beneficial rather than what is harmful appear just to the cities.” Judging which comedians are "wise and good" is a challenging task, since these are necessarily subjective determinations, but it can at least be said that a comedian like Degeneres is attempting to make what she considers to be wise and good appear just to listeners.

With a litany of ways in which Sophists and comedians are similar already under our belts, what other similarities can we list? Ah yes, what about the in-personness of gathering people together in the same space? "You had to be there," someone will often offer, shaking his or her head, laughing at the memory of something that you had to be there to find funny. The kairos of comedy, examined in chapter one, involves the need to be present in a common space and time in order to participate in a stand-up performance. Not only did Sophists travel around teaching about kairos, among other things, but the act of traveling teaching itself depends on opportune time and conditions. Several scholars have addressed the clear tie to physical presence inherent in rhetoric (Porter, Turner), and some have even extended this thinking to stand-up comedians (Rutter, Quirk), but there are more opportunities to connect the you-had-to-be-there-ness of stand-up to conversations around public culture discourse communities.

Just as Jarratt demonstrates that Gorgias, Protagoras and other Sophists forced a recognition of social differences with their work, using rhetoric and discursive strategies 
to "identify and negotiate differences among social groups," stand-up comedians also fill this role, inviting audiences to consider social differences and recognize biases (92). As part of a two-man duo called Fear of a Brown Planet, Aamer Rahman performed a bit in 2013 about "reverse racism" that will serve to demonstrate how stand-up comedians can force recognition of social differences. In it, he muses about how "if you ask some black and brown people, they'll tell you flat out there's no such thing as 'reverse racism.'” Rahman counters that there is such a thing as "reverse racism," but it would require a time machine. In his description of how he could be a reverse racist if he had a time machine, Rahman declares, in his deadpan delivery:

I'd go back in time to before Europe colonized the world, right? And I'd convince the leaders of Africa, Asia, the Middle East, Central and South America to invade and colonize Europe, right? Just occupy them, steal their land and resources, set up some kind of, like, I don't know, transAsian slave trade where we exported white people to work on giant rice plantations in China—just ruin Europe over the course of a couple centuries so all their descendants would want to migrate out and live in places where black and brown people come from. But of course, in that time, I'd make sure I'd set up systems that privilege black and brown people at every conceivable social, political and economic opportunity and white people would never have any hope of real self-determination. Just every couple of decades make up some fake war as an excuse to go and bomb them back to the Stone Age and say it's for their own good because their culture's inferior. And just for kicks, subject white people 
to colored standards of beauty so they end up hating the color of their own skin, eyes and hair. And if, after hundreds and hundreds and hundreds of years of that, I got on stage and said, “Hey, what's the deal with white people? Why can’t they dance?” That would be reverse racism. (Rahman)

Surely, if Jarratt can credit Plato's Protagoras with forcing recognition of ethnic or national difference by referring to his vulnerable status as a metic, or foreigner in Athens, we can credit Rahman with forcing recognition in his astute, on-stage imagining of what it would take to constitute "reverse racism.” His matter-of-fact catalog of all the social constructs and privileges that would need to be retroactively put in place in order to make a joke about a white person's dancing "racist" in an equivalent kind of way to a joke about a person of color represents a brilliant piece of logic, and also serves as an excellent explanation of why "punching down” isn’t as purely funny as "punching up.”

Finally, let’s consider the parallel “bad rap” Sophists and standup comedians alike have been assigned. Just as "rhetoric" in general is used in a negative, pejorative way ("political rhetoric" is usually a slight), the definition of "sophistry" is "a subtle, tricky, superficially plausible, but generally fallacious method of reasoning,” and Sophists are often criticized for not having ethics attached to their teaching of how to argue. Similarly, how often are comedians written off as substance-less mirth makers who have little more to contribute to communities than the guy (or girl) who got Class Clown in your senior yearbook? Pretty often. Why is this, when we consider that, as Sophie Scott noted in her 2015 talk at URI, "When you laugh with people, you access an ancient, evolutionary system to make and maintain social bonds and regulate emotion"? 
It's possible that the pleasure that comes with laughter and humor make it easier to imagine that the messages carried with that laughter are unimportant. Sophists, as previously mentioned, were thought to have undermined their rhetoric with the playfulness of their techniques, demonstrating that even centuries ago, playfulness was seen as a weakening of an argument's perceived clout. Moreover, the wide range of material covered by stand-up comedy means that some comedians are largely making fart jokes and complaining about women in their sets, which makes it even easier to write off the whole lot of them. Plenty of comedians might embrace this light treatment, maintaining that they are there to tell jokes and make people laugh, and "it's not that serious.” However, there is a danger in letting the bad rap earned by some comedians cloud our judgment about the medium as a whole, or writing off an entire group of rhetors and performers because a portion of them make unsavory jokes that educated people might consider uncivilized and unworthy or further discussion or analysis. Instead, we should consider how Crick, in borrowed Deweyan terms, reimagined Sophists as having “discovered a method of bridging the instrumental (or 'logical') and consummatory (or 'aesthetic') qualities of language within a single discursive form capable of generating common action in response to a shared exigence" (41). We should then ask ourselves: What might be gained by reimagining stand-up comedians as operating within a single discursive form (stand-up comedy) capable of generating common action in that unexpected way described earlier by Chris Bliss as an endorphininducing transformation of walls into windows?

\section{Argument to Reread the Stand-ups}


While Sophists were relegated to the wings of the history of rhetoric until such time as scholars like Havelock, Barrett, Jaeger, Crowley, Crick and Jarratt saw fit to pull them onto the main stage and reconsider their contributions, stand-up comedians continue to be largely written off, and deserve to be pulled onto the main stage and reconsidered for their contributions to the field of rhetoric, and to the formation of the public's thoughts and opinions. Stand-up comedy is often enjoyed and appreciated as performance, but seldom analyzed or respected as persuasion. Just as Gagarin reframes the purpose of Sophists beyond simple persuasion and Crick works to recover the professionalism and experimentalism of Sophists, I seek to reframe the purpose of standup comedy beyond entertainment, and to recover the professionalism and experimentalism of stand-up comedians.

Scholars have applied thoughtful analysis to humor in multiple ways in the past few decades, including a number of studies on political comedy by David Letterman, Stephen Colbert and Jon Stewart (Holcomb, Compton and Miller, Waisanen, Hariman, Goodnow, et. al.), but one main difference between the work of comedians like Letterman, Colbert and Stewart on television shows supported by writing staff members and the work of comedians in the stand-up genre is that stand-up comedians independently produce and deliver their own material. Some comedians may have writing assistance, but the majority of comedians write their own material, travel alone, and sell this material as their product, much like the Sophists did, yet comedians are seldom, if ever, considered rhetors in their own right.

There is a lot to be gained by considering comedians rhetors in their own right, and if we, as rhetoric and composition scholars, are successful in seeing them for the 
thoughtful composers and deliverers of important messages that they are, we will be on our way to rereading comedians in a similar grand-scale fashion to the rereading of the Sophists. Rereading the Sophists opened up a whole new historical and theoretical direction for our field, and rereading stand-up comedians will afford a similar opening. For starters, imagine the freshness and excitement that would come from consuming stand-up comedy sets critically, appreciating them professionally, and bringing them into our classrooms as texts to hold up to the light for reading, understanding and discussing.

If we did agree, as a field, that stand-up comedy sets and the rhetors who create and perform them are worth continued attention, what might our research look like, and our findings from that research? What might our classrooms look like? What would our students gain from the natural enjoyment of encountering humor during learning, and from the strong messages of power and human behavior and social constructs described by comedians? Well, our research might look more like what Anne Ruggles Gere describes as how how "writing development occurs regularly and successfully outside classroom walls" in "Kitchen Tables and Rented Rooms: The Extracurriculum of Composition.” Currently, bringing a speech by the first lady at a convention into a composition classroom for analysis and discussion would not be likely to raise any eyebrows, but showing a ten-minute excerpt from a Sarah Silverman stand-up special might. If we agree to reread stand-up comedians and make space for their work in our classrooms, perhaps neither the speech nor the stand-up set would seem out of place in a composition classroom, and who is to say that both types of texts wouldn't be important to expose students to and ask them to interact with? 
By acknowledging that comedians might not deserve that bad rap they’ve earned, and that their identities can be reconstructed as powerful contributors to public thought, we will be able to see them as public intellectuals in the same way that Jarratt argued Sophists to be public intellectuals. One interpretation of a public intellectual is “primarily a philosopher who possesses a secondary talent for attracting public interest in their ideas” (Crick 26), which is useful in viewing comedians first as people who philosophize, whereas they are typically defined by that secondary talent, which is attracting public interest in their ideas. Many other characteristics attributed to Sophists by Crick can also be applied to comedians: that they are "antifoundationalist[s] first,... productive artist[s] and pedagogue[s] second" (27), that they "use all the resources of reflective thought to bring forth productive transformations in a complex and changing environment” (28), and, perhaps most importantly, that they concern themselves with “the act of 'bringing-forth' (poiessis) that makes present things previously concealed or inchoate” (29). Again, not all comedians will warm to this assessment of their work as making present things that were previously concealed, just as no Sophist would lay claim to the goal of shaping of the soul (Jarratt 87), whether they were actually doing that or not. Jaeger sees the central educational task of the sophistic movement as developing “consciousness” though, and whether or not comedians lay claim to that goal, their words do in fact develop consciousness.

Comparing the reasons scholars successfully cited for rereading Sophists to the reasons we should reread stand-up comedians could go on all day, but alas, we have other connections to draw—namely, to jesters, public intellectuals, and social activists— 
so let us conclude this particular connection by reaching way back to 1957, when Eric Havelock wrote this about Sophists:

If we intend to use the term sophist of these people, in its modern derogatory sense, the title is a misnomer, and that, even if we rearrange our values sufficiently to grant that they grappled seriously with problems of language, discourse, and communication, we still have not made a sufficient historical adjustment.... Of course they taught rhetoric as a technique for the effective formulation of political ideas, but as ancillary to a bigger thing, a larger view of life and man altogether. If there is one quality which identifies them, and yet which is wholly incompatible with their traditional reputation, it is a sense of social and political responsibility. Beginning with the sociology attributed to Protagoras with its rationality, its humanity, its historical depth, continuing with the pragmatism which seeks to understand the common man's virtues and failings and to guide his decisions by a flexible calculus of what is good and useful, and ending with a theory of group discourse as negotiation of opinion leading to agreed decisions, we are steadily invited to keep our eye not upon the authoritarian leader, but on the average man. (Havelock 229-30)

Working from this assessment of Sophists, let us look for places where we can easily substitute "stand-up comedians.” Grappling seriously with problems of language, discourse and communication? Check. Leveraging rhetoric as a technique for the 
effective formulation of political ideas? Check. Offering us a larger view of life and man altogether? Check. A sense of social and political responsibility that is wholly incompatible with their traditional reputation? Check. (Think: fart jokes as "traditional reputation.”) Seeking to understand the common man's virtues and failings, and to guide his decisions by a flexible calculus of what is good and useful? Check.

Demonstrating a theory of group discourse as negotiation of opinion leading to agreed decisions? Check. Directing our eye on the average man? Check.

In order to make a sufficient historical adjustment in our treatment of stand-up comedians, we will need to follow in the footsteps of those who created a path for rereading the Sophists in our efforts to reread the type of stand-up comedians we are concerned with here as the next iteration of Sophists. Advancing a reinterpretation of stand-up comedians should get added to the to-do list of the rhet/comp community, so who out there will be the Crowley to my Havelock? To close with some Jarratt-esque motivation, I invoke the final line from Rereading the Sophists: "For those composition teachers who wish to participate in the revitalization of our own democracy, the voice of sophistic rhetoric speaks out in playful, persuasive, and promising tones” (117). When we again replace "sophistic" with "stand-up comedians," we see how their "playful, persuasive, and promising tones” do indeed speak out as inspiration for the revitalization of our democracy.

\section{Jesters Speak Truth to Power}

If you were sufficiently- or even somewhat- convinced of the comparable nature of stand-up comedians' work to Sophists', dear readers, I think you will find this next 
parallel, between stand-up comedians and jesters, an even easier leap to make with me. Just as with Sophists, there are multiple surface-level ways in which jesters and stand-up comedians are similar, but more importantly, there are deeper, more significant ways in which their roles and functions align. Jesters told jokes—sure, let’s start there. Certainly there is a clear overlap between jesters, whose purpose was to entertain, and stand-up comedians, whose purpose is the same. When we tried to think of who, besides stand-up comedians, made a living off of traveling around, selling speech for profit, we had a hard time coming up with a better match, right? Now try the same with the profession of singlehandedly making crowds laugh through wit, wordplay and wisecracks. It's the comedians all day again.

Thinking back to the computational theory of humor may help us to understand why jesters spanned across time and space, cropping up on multiple continents in an age where one king wasn’t exactly calling another up on the phone to say, "I have this great system where I let a goofy, unattractive person give me advice and it doesn't hurt my delicate feelings because he’s just so funny.” Perhaps the necessity of that error correction function of humor is what drew all those leaders in all those places to come to the same conclusion. Quirk alluded to this same concept when she told us, "Comedy serves an important prosocial function by testing those ideas that we take for granted.”

Oscar Wilde and George Bernard Shaw are both credited with the adage, "If you want to tell people the truth, make them laugh, otherwise they'll kill you." Whoever said it, it accurately and succinctly characterizes how jesters got away with leading leaders by the elbow toward better, fairer decisions by jovially pointing out the error of their ways. To better understand jesters in general, and court jesters in particular, we will turn 
to Beatrice K. Otto’s thorough, comprehensive overview of their functionality and universality in Fools Are Everywhere: The Court Jester Around the World. Tasked with the entertainment of leaders, jesters have "existed across the globe and across history, in most of the major civilizations of the world and many of the minor ones” (Otto xvii). The fact that jesters appear to have arisen spontaneously and independently in so many different areas of the world suggests that they "fulfill a deep and widespread social need" (Otto xvii).

The words fool, clown, trickster, and buffoon are sometimes used interchangeably with jester, but for consistency's sake, we'll stick with jester for this chapter. For centuries, jesters have advised and instructed kings and other leaders by sneaking uncomfortable truths into their entertainment diets. Despite their widespread presence, jesters have been largely ignored by historians who write at great length about kings without acknowledging their "omnipresent pal[s] and adviser[s]," the jesters (Otto xx). A jester could use humor to mock and advise a king without causing offense because of his identity as a harmless simpleton, but was also regarded as a potential mouthpiece for God or a prophet (Otto 33). The amnesty afforded by adopting the status of a jester meant that men "with their wits about them" could "speak through the mouths of their stage fools" and thereby earn the "license to speak truth with impunity" (Otto 37).

Otto's examination of jesters is extensively researched, with examples spanning the whole globe. While most histories of jesters that do exist concentrate almost exclusively on European courts, Otto jumps around the world, providing detailed accounts of jesters like: Birbal, jester to Akbar the Indian Mogul emperor (xxi, 16); 
Tenali Rama, an Indian “superjester” (xxi); Andrelini, French court poet who inherited the post of jester from Seigni Johan (13); Babriel la Mena, jester to Don Fadrique Enríque, admiral of Castille in Spain (17); and multiple jesters from China with telling names like Upright Fellow Wish (Zhu Hanzhen) (17), Moving Bucket (Shi Dongtong), jester of Emperor Gaozu (18), Newly Polished Mirror (Jing Xinmo) (18), Full Streamer, Tang dynasty magician-jester (19), Liu Wenshu, a Mandarin jester renowned for his rhetoric (19), Subtle Reformer King (Wang Ganhua) (20), and Immortal Revelation (22).

The Hopi Indian tradition of clowns is shown to be in direct correlation with the jesters in all of the places just listed with a quotation from an unnamed Hopi Indian describing their clowns:

The clowns represent us in our misdeeds... the clowns show life as it should not be... the clowns show, mimic the "hidden immoralities" and bring them into the open so we can see where we have gone wrong.... This is a small village and people gossip.... Only the clowns can get away with it. They can get away with anything.... When we came here to live with the Great Spirit, someone hollered and we looked back and there were the clowns... the clowns show the essence of morality... clowning is a public confession for humanity. (Otto 42)

Otto holds this up as evidence of the "age-old, deep-rooted human need for clowns" and follows up with other tribes that reserve places for clowns to do the work described by the Hopi Indian above, including the Bougouni tribe of Sudan, the Mayo and Yaqui Indians, and the New Mexico Pueblo Indians (42-43). The consistency with which different groups across time and space have assigned someone to do this same work of 
serving as the "release valve" and moral guide for a group of people is borderline baffling, but it may become less mystifying when we consider the theory of humor suggesting its evolutionary purpose.

Desiderius Erasmus contemplates jesters with In Praise of Folly, maintaining, "We have all seen how an appropriate and well-timed joke can sometimes influence even grim tyrants... The most violent tyrants put up with their clowns and fools, though these often made them the butt of open insults.” Mikhail Bakhtin too defines a clown as “a rogue who dons the mask of a fool in order to motivate distortions and shufflings of languages and labels, thus unmasking them by not understanding them” (404-5), and describes how, in his role as "herald of the truth," the medieval joker articulated truths and social commentaries using laughter and jokes that mocked and degraded those in power. In one of the oldest texts I'll be referencing in this document, The Ass Race: Or

the Secret History of Archy Armstrong, Fool to King Charles I, by Archibald Armstrong in 1740, a jester himself remarks that jesters are perceived as being on the side of the people, "the little man fighting oppression by the powerful... By fooling wisely ('en folastrant sagement'), the jester often won favor among the people ('gaigna de grace parmy le people’).”

\section{Stand-up Comedians as Jesters}

Stephanie Koziski Olson claims, "Stand-up comedians perform an important role by providing an arena where tension-provoking subjects can be publicly scrutinized [and can] catalyze new awareness... when humor illuminates new possibilities or puts old prejudices in a new light." If that sounds familiar, it's because it's what those jesters we just read about did. More profound than the obvious alignment of bringing mirth to 
crowds, the deep-seated purpose of that mirth is what we ought to be looking at. Jesters, as Bruce Dessau tells us in The Bluffer's Guide to Stand-up Comedy, were “society’s safety valve, a controlled way of expressing discontent” (8). A comedian’s unique position to speak truth to power comes in part from the "foolishness" often ascribed to them, as to jesters:

Jesters are also generally of inferior social and political status and are rarely in a position (and rarely inclined) to pose a power threat. They have little to gain by caution and little to lose by candor-apart from liberty, livelihood, and occasionally even life, which hardly seems to have been a deterrent. They are peripheral to the game of politics, and this can reassure a king that their words are unlikely to be geared to their own advancement. (Otto)

It is from this vantage point that comedians perform their rhetorical moves through humor, and this research seeks to transcribe, describe and analyze those rhetorical moves.

There actually aren’t too many published articles drawing lines between jesters and stand-up comedians already out there, possibly because the surface-level similarities appear too obvious to require them. It is the deeper-rooted alignments that we are interested in for our comparison of the two, however. Lawrence Mintz takes a moment to note that stand-up comedy follows in the tradition of fools, jesters and clowns in that aforementioned seminal text that made me declare myself a Mintzian scholar, "Standup Comedy as Social and Cultural Mediation,” but only in passing (72). Barbara Plester and Mark Orams provide a nice setup detailing all the ways in which jesters were important to democracies, some of which are included earlier, but then where do they go 
directly from there? Jokers in the workplace. Specifically, they examine how employees identified by colleagues as jokers were able to express alternative possibilities and question authority in the workplace at three New Zealand IT companies. It's an interesting study, but makes for sort of an unexpected pivot toward such a narrow comparison, when a much clearer connection can be drawn between jesters and stand-up comedians.

Moving again to the reflections of non-academics, Bill Hicks is described in American: The Bill Hicks Story, as “a patriot [who] questioned the government because that's what a true patriot does.” If we assume that jesters were patriots of sorts because they supported and defended their countries through their own brand of loyalty—poking fun in service of improving - then the above characterization of Hicks could be considered an endorsement as a jester. Similarly, Joan Rivers struck up the notion of exposing truths through comedy when she spoke about fellow comedian Lenny Bruce, calling him a warrior who fought hypocrisy, and comparing him to "the one who ripped the clothes off the emperor and said, 'Look, he's naked'" (Make 'Em Laugh). In the cautionary tale of which Rivers speaks, many of us are familiar with the small child who announces that the emperor isn't wearing any clothes, while the rest of the townsfolk and the emperor himself are too afraid to say they don't see the suit of clothes two sly weavers have "made" for the emperor, telling him that it's woven from a fabric that can only be seen by the eyes of those of high enough class and intelligence to see it.

Otto demonstrated how a physical deformity or abnormality in a jester operated as a basis for enabling him to jokingly point out imperfections in others, with a lead-in like, “I know I'm not perfect, but have you looked at yourself recently?” (31). Picture, if 
you will for a moment, Gaston from Beauty and the Beast delivering harsh jabs to a king. It's likely that the king would not take too fondly to hearing a strong, strapping, ablebodied specimen jeering at him, because kings can develop pretty thin skins from being told how great they are all the time. Now consider Joan Rivers' observation about Phyllis Diller, who "was the last of the women that had to look like clowns to be heard" (Make 'Em Laugh). The reason why Diller, dressed like a bird with wild hair and a feather boa, was allowed to be funny was that she essentially disguised herself as a clown, and "for a female to develop into a clown, joke-teller or story teller, she must violate the cultural expectation that females should not aggressively dominate mixed-sex social interaction" (McGhee).

Already belonging to a marginalized group may make it easier to abandon socially acceptable behavior and become a jester, who was "certainly part of the counterculture that existed beneath the surface of officialdom” (Birnbaum). Comedians too have often been considered to be part of a counterculture tradition, defying or simply ignoring conventions, just as Dessau says clowns have always had the tacit permission to do in the Middle Ages, when "jesters were able to speak their mind in the monarch's court” (Dessau 8).

\section{Dissecting a Frog: Killing Comedy by Analyzing It}

Now would be a great time to present some examples of ways in which stand-up comedians operate under similar circumstances to jesters, but there's that awful quote by E.B. White to contend with when undertaking the task of analyzing a comedian's material: "Analyzing humor is like dissecting a frog. Few people are interested and the frog dies of it.” The thing is, though, the argument that analyzing humor is not a 
worthwhile endeavor suggests that we should stick to analyzing unfunny material, when, in fact, there's a lot to be gained by analyzing humor. On the flip side, the very notion that humor is not something to be analyzed may have been what's allowed jesters and comedians the freedom to wax philosophical under the guise of harmless, un-analyzeable humor all this time. In fact, the very phrase "jester’s privilege” invokes the protection of something "only being a joke,” and therefore essentially harmless.

Jon Stewart, who started out as a stand-up comedian, and then spent sixteen years as the host of Comedy Central's The Daily Show, would often hold up his network as a shield against being taken seriously: "My show is on Comedy Central," he would point out. In a 2011 interview with Fox News anchor Chris Wallace, Stewart even went so far as to explicitly state, “I'm not an activist. I'm a comedian.” Refusing to accept the authority that would come with the title social activist, he could effectively crouch behind the humor defense wall in order to continue throwing truth snowballs from behind it. In the same interview, Stewart later tells Wallace that he does push "an anticorruption, anti-lack of authenticity, anti-contrivance” agenda. John Oliver often goes hand in hand with Jon Stewart in people's minds, so we may as well reference a moment when Oliver too denied having the power or authority to change minds. Responding to the question of whether political comedy changes people’s minds with co-author Andy Zaltzman in a 2005 article for New Statesman, he says there are two answers- “a short one, and a slightly longer one. The short one is: no, it doesn't. The slightly longer one is: no, of course it doesn't, don't be ridiculous.”

At the risk of blowing up the spot of comedians everywhere who enjoy the protection of the humor defense shield, we will move now to dissect some frogs in order 
to explore the many ways in which stand-up comedians align with jesters. We won't be the first to embark on analyzing humor, of course, and useful frameworks are provided by scholars like Don Waisanen, whose "Standing-Up to the Politics of Comedy" provides clear, careful analysis and a thorough explanation of his methodology. Waisanen focuses on top-earning comedians, transcribes their material, and examines their "political-communicative visions" through "methodological language analysis," effectively serving as a model for dissecting a frog without killing it.

Neither is Writing and Rhetoric scholar Joshua Compton afraid of dissecting a few frogs. In "Image Repair in Late Night Comedy: Letterman and the Palin Joke Controversy,” Compton and establishes a different framework by applying Benoit's image repair theory to several case studies of comedians being made to apologize for jokes they made about people in positions of power. Perhaps our best scholarly model for dissecting stand-up comedy is Sophie Quirk, who demonstrates a masterful treatment of comedian after comedian's material, managing to succinctly capture the humor of the bit she's referring to in a no-nonsense way and then skillfully sketch out a descriptive diagram of what the humor accomplishes. For a taste of how she does this, we'll examine an analysis she offers of British comedian Mark Thomas' attack on the Serious Organised Crime and Police Act (SOCPA) in his 2007 show Serious Organised Criminal. (You may have noticed earlier that humour was spelled with a U when I used a quote from Quirk and mentioned that she taught at the University of Kent, in which case you are not surprised by the spelling of organised with an S.) Part of SOCPA made it illegal to hold a demonstration in the area around Parliament Square without obtaining police permission first. In Thomas’s bit, he describes a picnic his friend Sian had on 
Parliament Square that got busted up by the police because she had a Victoria sponge cake that had "peace" written in icing on it, which made "the police deem her cake to be a political cake” (Quirk 120).

After transcribing the segment of Thomas's performance, including pauses and audience laughter, Quirk sets to work breaking down the delivery and the appeal to logic. First, she makes note of Thomas's emphasis of the words picnic and cake, noting that he is "popping their satisfyingly short and punch syllables out so that the bouncing hardness of the sounds is juxtaposed with each word's homely, innocent connotations" (Quirk 120). Then she comments on the volume and tone of his delivery, portraying it as increasingly frustrated, reaching a fever pitch when Thomas declares, "And I thought any law (.) that means we can be arrested (.) for a cake...” but concluding with a drawing back into "a cheeky expression and wry smile” as he concludes, "we can play with [laugh]” (Quirk 120). And play with the law he does, once he has “elicit[ed] consensus by appeal to logic,” which is Quirk’s final assessment of Thomas’s rhetorical success with that joke.

Social scientists have also found ways to dissect political comedy. At The Center for Media and Public Affairs at George Mason University, Professor Robert Lichter and his team have spent over twenty years cataloging and coding late night TV jokes. Their brand of comedy analysis differs greatly from the type of analysis we've looked at so far. While Waisanen, Quirk and Pearson take a more qualitative, narrative approach, describing a part of a comedian's act and then explaining its impact on listeners, Lichter and his team are more interested in quantitatively representing the topics and targets of jokes by comedians like Jay Leno, Jon Stewart, and Stephen Colbert. Both approaches 
are useful and important, and comedy research would benefit from many more examples of qualitative and quantitative data like that which is put forth by the scholars listed so far.

Drawing strength from the leadership of Waisanen, Compton, Quirk, and Lichter, we will put aside E.B. White's callow claim that humor can't be analyzed because no one cares and the joke won't be funny anymore and turn a critical eye to some specific examples of stand-up comedians operating as public intellectuals and social activists. In the United States, our presidents don't typically keep jesters around the White House to entertain them with good natured ribbing over domestic and foreign policy decisions, although comedian John Fugelsang has mused that President Obama would have had even higher approval ratings if he'd hired Chris Rock to be the staff jester. We do, however, have an annual tradition of the White House Correspondents' Dinner, at which a comedian typically serves as an entertainer and performs some of those same functions we saw jesters fulfilling all over the world in Otto’s overview. While Don Waisanen has published some scholarly analyses of White House Correspondents' Dinners, he’s actually been focused on the presidents' jokes, and not the professional comedian present. Waisanen examines the risks inherent in presidents adopting humor as a rhetorical strategy in "Comedian-in-Chief: Presidential Jokes as Enthymematic Crisis Rhetoric" and discusses how jokes made by the president at the White House Correspondents’ Dinner can provide a strategic distraction from political content in "Laughing or Learning with the Chief Executive? The Impact of Exposure to Presidents' Jokes on Message Elaboration.” 
What we want to look at is the comedians at these events, because their presence and performance feels awfully familiar after reviewing all that stuff about jesters just now. They typically take aim at the political leaders in the room, like the president, vice president, and members of senate and congress, and at representatives from the news outlets present at the dinner as well. If we were to apply the motives of a jester to these speeches, we would assume that criticisms launched by the comedians are intended to redirect and correct the behaviors of their targets. Past performers have included comedians Richard Pryor, Bob Hope, Jay Leno, Sinbad, Paula Poundstone, Al Franken, Bill Maher, John Stewart, Ray Romano, Cedric the Entertainer, Stephen Colbert, Wanda Sykes, Seth Meyers, Cecily Strong, and, most recently, Larry Wilmore. What a list! In order to do some comparisons across the board, we'll look at speeches by Seth Meyers, Cecily Strong, and Larry Wilmore, all of which included jokes about C-SPAN, MSNBC, President Obama’s hair, and Donald Trump, among other things.

Starting with the most recent, we saw Wilmore start his 2016 speech by referring to the event as "Negro night” and end it by "keeping it 100” and telling President Obama, "Yo Barry, you did it, my nigga." In between those two statements, Wilmore took aim at Fox News, saying that they would report the evening as "Two Thugs Disrupt Elegant Dinner in DC”; at MSNBC for now standing for “Missing a Significant Number of Black Correspondents”; and at C-SPAN for being the number one TV station senior citizens die while watching. Wilmore also derided Obama for not closing Guantanamo Bay and golfing every day, and Trump for saying he’s going to be more presidential, which Wilmore said for him meant that when he boasts about his genitalia in future debates, he'll only refer to it as his President Johnson. In what had become a tradition at 
that point, Wilmore included a couple "Obama’s hair so white” jokes: "Your hair is so white it tried to punch me at a Trump rally. The president's hair is so white it keeps saying, 'all lives matter.'” Like most of the comedians who furnish the speeches at the White House Correspondents’ Dinner, Wilmore becomes more serious toward the end, offering a sincere, humble acknowledgement of the historical significance of having a black president and pointing out that when he was growing up, a black man was thought to be not good enough to lead a football team, and now a black man can lead a whole country. The fact that so many of the comics drop the comedy to deliver their praise reinforces the "jester’s privilege" of needing that humor defense wall to hide behind when throwing those truth snowballs that really sting.

Working backward, Cecily Strong delivered the 2015 White House Correspondents' Dinner speech, and she kicked it off by asking, "It feels right to have a woman follow President Obama, doesn’t it?”, a reference to Hillary Clinton’s bid for presidency in 2016. She plays down her authority from the start, telling the audience that she's “only a comedian," so she wouldn't tell politicians how to do their jobs; that would be like them telling her what to do with her body. Early on, she brings up the lack of accountability for police brutality against people of color by following up a joke against the secret service with the remark, "I don't want to be too hard on those guys, because they're the only law agency in the country that will get in trouble if a black man gets shot." Those in the audience made their customary collective "boo" that comes after a joke hits a little too hard or gets a little too real, and Strong pretended not to understand, asking if they were saying "boooo" or "truuuue," a refrain she returned to for other jokes that elicited a boo as well. She addressed the networks present, saying C- 
SPAN's viewers are mostly cats, MSNBC lacks diversity of programming, and Fox News is a channel full of "hot blondes and old dudes."

Toward the end of her set, Strong rebuked the practice of holding female politicians up for scrutiny over their looks by making all the journalists raise their right hands and repeat, "I solemnly swear not to report on Hillary Clinton’s appearance, because that is not journalism." Her contribution to the "Obama's hair so white" tradition was, "Your hair so white now it can talk back to the police," again turning the spotlight onto unequal patterns of behavior by the police. She may have started out by claiming to be “only a comedian” who wouldn’t tell politicians how to do their jobs, but in her twenty-three-minute set, she tackled health care, police brutality, gender double standards - just in the span of jokes we were able to review in the space of two paragraphs. Just like the jesters directing their rulers by poking fun at their failures, Strong is wielding humor as a way to highlight the transgressions of her leaders.

Jumping back to Seth Meyers' speech at the 2011 White House Correspondents' Dinner, we start to see a pattern in the targets for jokes. He offers the obligatory wisecracks about the news outlets present, mocking C-SPAN for being boring and having few viewers, just as we saw Wilmore and Strong doing; after greeting the crowd before him, he alluded to the "handful of people watching at home on C-SPAN," calling it the official network for wide shots of empty chairs and saying that people think Osama Bin Laden is in hiding but he actually hosts a show on C-SPAN from 4-5 every day. For the rest of the networks, Meyers pretended to give previews of what their afterparties would look like: At MSNBC’s party, President Obama makes the kool-aid and everyone there drinks it; the Breitbart party will be crazy—it won't be good, but it’ll be 
crazy; and Huffington Post is having a party but they're asking everyone to go to another party first to steal food and drink and bring it there. They're antics, of course, but they contain criticisms of the stereotypes each is accused of being. Furthermore, they represent Meyers' direct critique of the people present in the room, in the grand tradition of jesters delivering criticism to leaders in the court.

Meyers riffed on Donald Trump for a little under three minutes, who was present at the dinner; the cameras zoomed in on his face multiple times throughout the barrage of jokes and he smiled zero times. Among the one-liners was one that people would later point to as the reason Trump did decide to run for president, although Trump refutes that: "Donald Trump has been saying that he will run for president as a Republican, which is surprising because I just assumed he was running as a joke.” He turned his ridicule on the Congress as well, telling members that we are not impressed that they're spending an evening sitting next to people they disagree with, because the rest of us call that Thanksgiving. Continuing on the theme of not being impressed with Congress, Meyers cuts a little deeper with the second reference, telling members that we are not impressed then they complain that bills are too long to read, and in fact, he thinks they don't read them at all, but instead "vote on bills the same way the rest of us agree to updated terms and conditions on iTunes.”

Meyers' rhetorical motive here could be characterized as an attempt at getting a laugh, but more accurately, he is taking the representatives of congress present at that dinner that the American people are disappointed in their failure to take their jobs seriously. By calling into question whether or not they actually read the bills they are tasked with considering, Meyers calls them on the carpet with a smile. The comparison 
to the impatient, inattentive way in which many people agree to updated terms and conditions on iTunes is a rhetorical strategy that highlights the irresponsibility of agreeing without full understanding. As for his “Obama’s hair so white” joke, Meyers tells Obama that if it gets any whiter, the Tea Party is going to endorse it.

The Radio and Television Correspondents’ Dinner is another annual tradition, although less widely viewed than the White House Correspondents’ Dinner, which is why Hasan Minhaj kicked off his 2016 speech there by calling it “the Correspondents’ Dinner that nobody cares about it,” adding, “tonight is definitive proof that we all definitely haven’t made it.” Similar to how Wilmore began his speech by calling the event "Negro night,” because the comedian and the president were both black, Minhaj notes that last year's speaker was Aasif Mandvi, telling the audience, “Thank you so much, RCTA, for going back to back with your browns. You guys are killin’ it.” Diving right into the de rigueur C-SPAN jabs we saw in the White House Correspondents' Dinner speeches, Minhaj announces that the channel is now available in HD (High Definition), "which is great, so now you can see all that legislation not getting passed in 1080p—all the wrinkles and inefficiencies just, ugh, so crisp.” The other networks get the comedic treatment too, of course, with Minhaj saying CNN is basically Bravo with plane crashes, Vice will send your local barista to talk to the head of ISIS, MSNBC is everybody’s annoying vegan friend- “we get it you're right, I just don’t want to hear it right now”- and Huffington Post and BuzzFeed have more journalistic integrity than the lot of them.

The really brave part of Minhaj's speech comes at the end, after some jokes about Donald Trump being similar to Biff's character in Back to the Future II and 
Hillary Clinton dressing like someone who works at PF Chang's—-I guess he didn't take Cecily Strong's oath the year before. Minhaj had taken some shots at the members of Congress in the room already by responding to accusations by the media that they're a do-nothing Congress: “The media's hard on you guys; they say you're a do nothing congress, but you guys do a lot. You go to fundraisers. You host fundraisers. You have your staff set up fundraisers for you to host. That's three things right there!” But he really went after them in the last five minutes of his speech, when he delivers an earnestly scathing condemnation of the Congress:

We look to you guys as our leaders. You make almost $\$ 200,000$ a year to write rules to make our society better, not tweet, not tell us about your thoughts and prayers, to write rules to make our society better... Right now, since 1998, the NRA has given $\$ 3.7$ million to Congress. There are 294 sitting members of Congress that have accepted contributions from the NRA, and that doesn't even include the millions of dollars from outside lobbying. Before I get up here in my liberal bubble and I ask for gun control and universal background checks and banning assault rifles, we've got to be able to have the conversation. Right now, specifically, Congress has blocked legislation for the CDC to study gun-related violence. We can't even talk about the issue with real statistics and facts. I don't know if this is like a Kickstarter thing, but if $\$ 3.7$ million can buy political influence to take lives, if we raise $\$ 4$ million, would you guys take that to save lives? (Minhaj). 
In considering the complex relationship between subversive critique and political advocacy, we can recognize Minhaj’s rebuke of Congress' failure to respond appropriately to growing threats posed by gun violence as both a critique and an act of advocacy, since his platform and position as a comedian make his comments widely available to the public for consumption and consideration.

Now, thinking back to Meyers' accusation that the Congress complains about how long the bills are to read, we can view these comments in the same light as when jesters ribbed their kings about their actions or inactions. In both cases, the jesters and the comedians are making moves that enable critical ideas to be accepted by people when they are rhetorically structured as comedy. We should attribute the same courage for doing so, too; the comedians addressing Congress today may not be in danger of having their heads lopped off and placed on sticks the way some jesters did, but they are still standing in a room full of people and lobbing critiques at them, and that is an activity not many would sign up for. And they're comedians! They're supposedly joke tellers, but they're up there advising members of Congress, pointing out flaws they see in the President and his staff's work, and making everyone laugh while they're doing it. Plester and Orms posit, "the jester was the one person likely to brave telling the truth, usually to prevent excessive pride and arrogance in his leader and possibly prevent foolish behavior. His use of humor prevented unpleasant repercussions, but his position could be described as ambiguous, although the jester may have been 'high born' and highly educated, he was never appointed to serious court positions” (Plester and Orams 256). I posit that the same can be said of the rhetorical power and bravery our 
comedians show by speaking truth to power, as we've seen Minhaj and others do in their Correspondents’ Dinner speeches to Congress.

Correspondents’ Dinner speeches correlate with court jesters’ performances because they provide criticisms of leaders enacted before the leaders themselves, thereby speaking truth to power. While the speeches we've examined are delivered by stand-up comedians, the context and setting differ from stand-up comedy as a genre. If we're looking for examples of stand-up comedians speaking truth to power within the context and setting of traditional stand-up, we'll need to talk about Richard Pryor, who is often held up as a Jackie Robinson-type figure who paved the way for public criticism of whiteness (Stone, Zoglin, Mintz). In the earlier stages of his career, Pryor played it pretty safe, performing for mainly white audiences with what he later referred to as “Mickey Mouse material that [he] couldn’t stomach anymore” (Zoglin 48). Initially resisting efforts to link his comedy to a black political movement, Pryor was influenced by his wife Shelley Bonus, “a white Jewish hippie from a Brooklyn show business family who had marched with Dr. King and who encouraged Pryor to do more radical material” (Zoglin 49). Improv comic Paul Mooney also reports having intentionally pushed Pryor toward embracing a more socially conscious, politically charged presence, stating, “Richard was in awe of me because I wasn’t afraid of white people. I added kerosene to the fire” (Zoglin 49).

Pryor went on to add his own kerosene to the proverbial fire, in the form of raw retellings of experiences he’d had. In his 1971 special Craps (After Hours), Pryor describes being hauled into police lineups because “all the ugly white girls that couldn’t get any said niggers raped 'em” and rooting for black fighters in boxing matches: 
“please, whip the white folks, I don't want white folks to win nothin”” (Zoglin 50). In his 1974 special That Nigger's Crazy, he acts out how he behaves when confronted by white cops, opening his eyes wide and saying, slowly, loudly and dramatically, “I AM REACHING INTO MY POCK-ET FOR MY LI-CENSE.” Zoglin calls his vivid character vignettes “little masterpieces of autobiographical comedy” and labels Pryor’s comedy "harsh, but healing” $(51,63)$. According to Zoglin, the black comics who came before Pryor had "reached out to white audiences... to foster racial understanding by stressing how much alike we are” whereas Pryor "rubbed our noses in the differencesand yet made us feel their universality” (63).

With his blunt, no-holds-barred observations on race relations, Pryor used the platform of stand-up comedy to force recognition of unequal treatment between races and became a rock star in the field of stand-up comedy. This trajectory mirrors that of jesters who gained notoriety and enjoyed favor for their razor-sharp wit, and were therefore able to publicly raise awareness of inequality and injustices. Other comedians applauded and imitated Pryor's style, which Zoglin identifies as having some drawbacks: "Plenty of comedians, white and black, emulated his rough language and in-your-face style but missed the empathy and vulnerability that informed it” (63). In Make 'Em Laugh: The Funny Business of America, Cheech Marin highlights Pryor's as a "black voice not only filled with rage, but with insight,” and it was precisely that combination of rage and insight, paired with the country's socio-political climate, that kept Pryor in the center of the public eye. Fellow comedians weren't the only ones who could identify Pryor’s performances as socially significant; multiple academics have written about his career, making observations like, "Pryor’s humor became a resource for challenging 
dominant cultural assumptions and managing the risk of speaking truth to power" (Rossing).

The subversive nature of comedy makes it a suitable weapon for launching criticism; mocking or deriding an established system of power can be a powerful form of dissent, and stand-up comedians like Pryor are able to lure listeners into accompanying them on a journey to uncover immoral discriminations and biases. As we saw with the overview of jesters, renegade comedians can agitate from behind a veil of "all in good fun,” making them dynamic revolutionaries who can sneakily subvert systems and institutions of power. Plenty of scholars have addressed the subversive nature of comedy writ large (Sanders, Radulescu, Stone, Shugart), but to isolate the specific brand of comedy generated by a stand-up comic in an in-person performance is to take the power of subversion a step further. Comedy in general buzzes with the potential to subvert, yes, but stand-up comedians in particular have quite an awe-inspiring task to tackle alone on stage, under a spotlight, as audience members are ostensibly drinking beer, holding side conversations, and occasionally heckling them, so the fact that they are able to contribute to a greater sense of social commentary on top of all that is pretty impressive.

\section{Stand-up Comedy as Resistance}

Having saved the best for last (to use another transition phrase that likely won't be found in They Say/I Say: Academic Moves That Matter), let us focus our attention on the use of stand-up comedy to resist, just as the jesters resisted by cleverly framing their criticisms of and to the leaders. Resistance implies a struggle, or an attempt to prevent by action or argument. When stand-up comedians engage in subversive criticism of 
those in power, they are not only personally engaging in resistance as individuals, but they are making available an example of resistance to others. Audience members who observe their acts of resistance may experience a sense of resolved strength to engage in resistance themselves. And what makes their brand of resistance special is that it sneaks in through the back door of our consciousness, as Bliss suggested. To examine how stand-up comedians can promote a subversive, less combative sort of resistance, let's consider two similar arguments—one made in the more traditional method of persuasion and one made through comedy.

The recent U.S. Presidential election generated fresh forms of political communication as public policy advocates expressed their concern about the rise of Donald Trump during the fall of 2016. Steven Goldstein, Executive Director of the Anne Frank Center for Mutual Respect, said in a statement on Wednesday, January $25^{\text {th }}, 2016$ : Donald Trump is retracting the promise of American freedom to an extent we have not seen from a President since Franklin Roosevelt forced Japanese Americans into internment camps during World War II. Today the Statue of Liberty weeps over President Trump’s discrimination.... His slamming America's doors on the starving, the wounded and the abused is a grotesque blot on our nation's history of freedom. The President's actions are an embarrassment to the timeless vision of America as inscribed by Emma Lazarus to 'give us your tired, your poor, your huddled masses yearning to breathe free.’ Demonizing refugees and immigrants, and spending billions of taxpayer dollars to keep them out of our nation, will go down in American history as one of 
the most tragic deviations from our national conscience. (AbbeyLambertz)

Goldstein's statement clearly represents a graver, more somber communication style than stand-up comedy generally embodies. In contrast, let's look at a similar argument made by D.L. Hughley in his 2007 stand-up special Unapologetic, in which he, like Goldstein in the statement above, addresses immigration and the idea of building a wall along the Mexican border. He sets it up thusly: "Of course the immigration debate is raging. They wanna build a wall to keep the Mexicans out. I'm like, 'Who the fuck gon' build it?' I know we ain't, and I cannot imagine white people working in the sun that long—oh lawd." Hughley leans back here, exaggerating these last words while the audience applauds. He continues, imitating a white person building the wall: "How many more bricks do we have to go? Jesus. José, help me with the wall. As long as you're on the other side when we finish, no one will know. Please José.” After leaning over and holding his forehead for a short pause to demonstrate the imagined wall builder's fatigue, Hughley straightens back up to add some history to his narrative: “Arizona, California, Texas, New Mexico and Nevada was all Mexico until the 1900s. Them motherfuckas ain’t crossing the border; we moved it.”

The audience laughs, and then Hughley takes a turn for the more serious: "These are the people who build our homes, watch our children, and grow our food, and we gonna insult them by building a fucking wall? If we gon' build a wall, at least put they names on it and tell them it's a monument or something." With that, he brings it back into the absurd, allowing the audience to laugh as he turns and pretends to point to something: “This is for you, Lupe. Here’s your name, right here.” Turning again to face 
the audience, he allows the laughter trail off a little before making another serious statement, "This nation was founded by immigrants," and punctuating that with another punchline, "Everybody in this motherfucka took a boat.” People applaud. Hughley adds, “Some of us willingly..." as a reference to slavery before describing a law that says that if Cubans arrive, they can stay, and saying that if he were Mexican, he would go to Cuba and "ride back with them motherfuckas." He elaborates on this scenario for about a minute, essentially giving the audience a moment to enjoy some continuous laughter before returning once again to his main point: “The Statue of Liberty, you go to New York, it has an inscription at the bottom by Emma Lazarus, that is a tribute-an invitation to immigrants: 'Give me your tired, your poor, your huddled masses, yearning to breathe free, the wretched refuse of your teeming shore. Send these, the homeless, tempest-tossed, to me, and I lift my lamp by the golden door.'

“That shit is beautiful," he finishes, as the audience again applauds, "but if we don't mean it, let's scratch that shit off. Or at least put, 'P.S. except for Mexicans. We reserve the right to refuse service to anybody. She's holding a lamp, not a leaf blower.' I don't understand it, man.” For this last part, he again turns and pretends to be writing, adding the line to the Statue of Liberty and, with the mention of the leaf blower, returning to the sentiment he alluded to at the beginning of the bit about Mexicans working as laborers. Hughley is not an overly physical comedian, like Steve Martin or Kevin Hart, who regularly use exaggerated gesture, facial expression and movement throughout their shows, but the parts where he does turn and point or lean over rubbing his forehead are worth mentioning because they add to the overall experience of watching stand-up. 
It's an almost perfect every-other-line formula of serious statements and funny gags. If we were to remove the more overtly humorous parts, of pretending to be a white person out in the sun, struggling to build a wall and imitating a Mexican pretending to be Cuban, we would be left with a string of sentences in a tone not unlike that of Goldstein's statement about paying billions of taxpayer dollars to keep refugees and immigrants out of the country. Rhetorically, Hughley is masterful at building his argument: he begins by setting the scene and introducing the topic of immigration; alludes to the race and class divisions that often separate the type of work done by white, black and Mexican Americans; provides a little historical and geographical context; argues against disrespecting a group of people whom he identifies as frequently doing the important, thankless work of "build[ing] our homes, watch[ing] our children, and grow[ing] our food”; points out that America is built on immigrants, adding that enslaved people were not willing immigrants; cites the poetry on the Statue of Liberty; and condemns discrimination and the idea of going against the spirit of this nation's foundational values. He does all this in under three minutes. He does it on stage in front of hundreds of people. He does it without notes and he does it to great laughter and applause. It is a bona fide example of invention, arrangement, style, memory and delivery, and of active resistance to boot.

When we compare Goldstein's written statement with Hughley's three minutes of material, we can agree that they have parallel messages. We can see that they both address the same topic and cite the same inscription on the Statue of Liberty, but that they are delivered very differently. Without needing to prioritize one over the other, hopefully we can also agree that both avenues are important forms of resistance against 
what they characterize as an unjust discrimination against immigrants. Goldstein's words are strong, moving and especially significant coming from the Executive Director of the Anne Frank Center for Mutual Respect. Hughley’s words too, from nine years earlier, are strong and moving, and potentially significant to a different demographic. His position as stand-up comedian means he has wide access to public audiences, and his use of casual, conversational language, punctuated with swears, impersonations and punchlines, make him an authority in a different way than Goldstein is—in the way, say, that the jester's absurdity operated. 


\section{CHAPTER 3}

\section{A STAND-UP COMEDIAN, A SOCIAL ACTIVIST, AND A PUBLIC INTELLECTUAL WALKED INTO A BAR... IT WAS W. KAMAU BELL!}

Having explored the ways in which stand-up comedians are similar to Sophists and jesters, we will now be entering a more consistently contemporary arena as we examine how stand-up comedians are also aligned with public intellectuals and social activists. In order to fully appreciate how stand-up comedians function as both public intellectuals and social activists, and why that should be important to rhetoric and composition scholars, it is useful to first zoom out and firm up a broader understanding of how and why humor in general can be utilized to shape opinions and shift mindsets.

\section{Comedians as Public Intellectuals}

To first shore up what is meant by the term "public intellectual," we will return briefly to Nathan Crick, of sophistical rehabilitation fame from earlier in chapter two. In his efforts to expand on Jarratt's claim that "the sophists could be termed the first public intellectuals in a democracy," Crick offers several customary understandings of what we take a "public intellectual” to be. In one interpretation, for instance, "a public intellectual is primarily a philosopher who possesses a secondary talent for attracting public interest in their ideas” (26). If we were to sit with that definition for a moment and ponder how stand-up comedians might fit it, we would ask ourselves if stand-up comedians are primarily philosophers who happen to be adept at attracting public interest in their ideas via making them funny. Hmmm, we might think, I suppose some 
stand-up comedians are philosophers who package the meat of their thinking inside a flaky, pastry shell of humor and serve them up hot and delicious to audiences. But then we realize we are making ourselves hungry with the beef wellington metaphors, and we shake our heads to return our thoughts once more to what a "public intellectual" is.

Crick asks us to revise our "dualistic understanding of a public intellectual to mean something more than an intellectual skeptic with a knack for public speaking” and instead calls for "a pragmatic approach that defines public intellectuals as those who use all the resources of reflective thought to bring forth productive transformations in a complex and changing environment” (27-8). In this understanding of public intellectual, we see an even clearer alignment with stand-up comedians, who call on an especially compelling resource of reflective thought—humor-to bring forth productive transformations in a complex and changing environment.

Alan Lightman, along with his contemporaries Stephen Pinker and Neil deGrasse Tyson, serves as a public intellectual by sharing science information with the public in accessible ways. Lightman and Pinker teamed up to deliver remarks at a 1999 MIT Communications Forum, in which they both shared what being a public intellectual means to them and why it's important. According to Lightman, a public intellectual is someone who decides to write and speak to a larger audience than his or her professional colleagues. For whatever reason, Lightman decided to restrict this description to those who are "on the faculty of a college or university," which would severely limit the pool of people eligible to be considered public intellectuals, according to his definition. This is interesting, considering he references Ralph Waldo Emerson's description of an intellectual as the "world's eye," communicating ideas to the world, not just to fellow 
intellectuals. If the only people qualified to serve as the "world's eye" are those employed by a college or university, we might have a problem on our hands, since quite a good deal of formal education is required to achieve those positions, thereby necessarily restricting who could be counted in this category.

Edward Said's take on the public intellectual went in the other direction. Instead of making the status of a public intellectual dependent on belonging to the academic community, Said advocated for amateurism as a way of maintaining relative intellectual independence. In a section called "Speaking Truth to Power" in his 1993 Reith Lectures, "Representations of the Intellectual," Said elaborates on the amateur status he sees as beneficial for public intellectuals to preserve. One way in which intellectuals could accomplish this is by "choosing the risks and uncertain results of the public sphere - a lecture or a book or an article in wide and unrestricted circulation - over the insider space controlled by experts and professionals” (87). Another way is to refuse to be bound by professional training; Said did not rule himself out from matters of public policy just because he was only certified to teach modern European and American literature, but spoke and wrote on broader matters because he considered himself to be spurred on by commitments that went well beyond his narrow professional career (88).

According to Said, an intellectual's job is to question authority and advance human freedom and knowledge to as wide a public as possible. This often means standing outside of society and its institutions to actively disturb the status quo "with an alternative and more principled stand that enables them in effect to speak the truth to power” (97). The goal of speaking the truth, he emphasizes, is to project a better state of affairs and and "try to induce a change in the moral climate" (100-1). By speaking truth 
to power, Said concludes, public intellectuals intelligently represent ideas where they can do the most good and cause the right change, even if the intellectual's voice is lonely along the way. Stand-up comedians can certainly lead lonely existences, traveling alone from city to city—comedian Will Ferrell famously described stand-up as "hard, lonely, and vicious” (Sher 16). They also question authority and speak truth to power, although, again, not all comedians across the board do this.

To be clear, I am not saying I'm the first person to draw parallels between standup comedians and public intellectuals. Some of the most coherent, evocative writing on the topic of comedians as public intellectuals has been done by non-scholars, in fact. Just as we have examined the ways in which a comedian's access to wide, willing audiences represents a shift from the pre-requisite of formal education in order to be exposed to ideas and messages, we should also consider the benefits of publishing an article about stand-up comedians as public intellectuals in a highly visible space like The Atlantic. Megan Garber did just that with her May 2015 article in The Atlantic, "How Comedians Became Public Intellectuals.” In it, Garber offers a qualitative analysis, focusing first on a specific example of Amy Schumer’s material about Bill Cosby and then zooming out to characterize Schumer's work as “in line with the work being done by her fellow performers: jokes that tend to treat humor not just as an end in itself, but as a vehicle for making a point.”

One caveat to including Garber's article in this argument is that some of the material she is referencing, including Schumer's Bill Cosby bit, is actually in the form of sketch comedy. For the most part, in an effort to remain focused on stand-up comedy, sources that address other forms of comedy— such as sitcoms, improv, late-night talk 
shows, and sketch comedy—have been eschewed. However, some of the material Garber references, (and at a rapid-fire rate, hyperlinking to videos on YouTube and Comedy Central left and right) is from stand-up comedians’ acts, and her overall argument is very much in line with the parallel we are currently concerned with, of stand-up comedians to public intellectuals.

Garber does identify both stand-up and sketch comedy as targets for her analysis; she writes that although the comedy of late-night TV used to consist mainly of quippy monologues and vapid celebrity interviews, and still does, to some extent, "the stuff that is firmly rooted in traditions of sketch and standup... is taking on subjects like racism and sexism and inequality and issues including police brutality and trigger warnings and intersectional feminism and helicopter parenting and the end of men.” She concludes this train of thought by remarking that jokes double as arguments, and consequently, the phrase "comedy with a message" is increasingly redundant, since she views the genre of comedy as becoming more like cultural criticism.

\section{Lubricating Conversations}

In an effort to explain what may be encouraging this shift toward comedians doing the work of cultural criticism, Garber qualifies that predecessors to contemporary comedians also "used laughter as a lubricant for cultural conversations- to help us to talk about the things that needed to be talked about,” listing Richard Pryor, Joan Rivers and George Carlin as examples, and hyperlinking, somewhat haphazardly, to a YouTube video, a broken page of the Detroit Free Press, and a Wikipedia page, respectively, to demonstrate how each comedian lubricated with laughter. What she sees as new and different then is not just a trend toward moral messaging in comedy, but direct, mass 
access made possible by increased uses of YouTube, Facebook, and other social media platforms. She remarks that the immediate attention offered by the Internet means that a comedian's work is no longer confined to time-bound performances in "sweaty clubs," a point that I made myself in an article published in Comedy Studies, "Comedy Meets Media: How Three New Media Features Have Influenced Changes in the Production of Stand-up Comedy.”

In addition to moral messaging and mass attention, Garber suggests that the beginning of a more inclusive field of comedians has contributed to an elevation of comedians to the status of public intellectuals. Reflecting back on popular sources of comedy in the 1990s, Garber describes how, "[g]radually and then suddenly, the smug nihilism of Larry David and Adam Sandler and Carrot Top and that guy who smashed watermelons with comically oversized mallets came to seem not just out of place, but regressive.” In its place, she sees the popularity of Amy Schumer, Tina Fey, Trevor Noah, and Key and Peele as meeting a new need for comedy to represent a more important place in public:

Comedy ceased to be the province of angsty and possibly drug-addled white guys making jokes about their needy girlfriends and airplane food. It became (slightly) less exclusionary to women and minorities. It began to ask, and answer, the questions that newfound diversity will tend to bring up—questions about power dynamics and privilege and cultural authority. As comedy began to do a better job of reflecting the world, it began, as well, to take on the responsibilities associated with that reflection. (Garber) 
Just as the telling of truths was highlighted as an important task associated with jesters, Garber identifies truth telling as a responsibility that lifts comedians into the public intellectual category: "These are bits intended not just to help us escape from the realities of the world, but also, and more so, to help us understand them. Comedians are fashioning themselves not just as joke-tellers, but as truth-tellers—as intellectual and moral guides through the cultural debates of the moment.”

Before moving on from Garber's overview of how comedians became public intellectuals, we will take one more look at a piece of evidence she leverages as proof that this transformation is taking place. Noting that Amartya Sen, Noam Chomsky, and Mario Vargas Llosa were among those named in a 2009 Foreign Policy list of the world's top twenty public intellectuals, Garber explains that "when the magazine gave the public the opportunity to suggest a write-in addition to the official list, readers didn't select an economist or a novelist or a philosopher for the honor. They selected Stephen Colbert.” Hopping over to Foreign Policy to see how this write-in winner was reported, we see that his appeal to young people is highlighted by the author: "Colbert so deftly and hilariously skewers the politically powerful that he has become one of young America’s go-to sources for genuine news and analysis” (Amburn).

While that particular evidence by itself might not hold up to the research standards of a peer reviewed journal, we cannot deny that it is a meaningful piece of the puzzle when seeking to understand how and why stand-up comedians can increasingly be considered public intellectuals. Erratic hyperlinking aside, Garber's work here should be recognized as contributing to an important conversation about the role of stand-up comedians, and, in a metacognitive sense, it should also be recognized as 
confirmation that, just as stand-up comedians can deliver serious messages to the public, non-academics can report on it in publications outside the scholarly realm, and in fact, comedy research benefits greatly from the thinking and sharing by non-scholars as well. Garber was writing for The Atlantic. Many writers who publish think pieces in high traffic places have the benefit of many more eyes on their words, but the drawback of getting far less prestige for the work. Scholars may scoff at the thought of academic journals inviting prestige, but the truth is, something published in a peer reviewed journal has to be officially cited by the author's name whenever it's referenced, while someone in the break room can ask, "Did you see that piece in The Atlantic?” without anyone reminding her to mention the author by name.

Occasionally, scholars writing on the topic of comedy will refer to a nonacademic source, but more often than not, any nods to other thinking on the topic will be in the direction of scholarly articles and books. Rosen actually acknowledges that "there has been a flurry of scholarly activity—not to mention countless nonacademic discussions in blogs and newspapers—-trying to assess exactly what, if any, influence Jon Stewart's Daily Show has on audiences” (Rosen 2). However, it's significant that he uses the phrase not to mention to preface the category, since he does not, in fact, mention what any of them say. I am intentionally pulling in ideas and analyses put forth by a variety of sources, including the "countless nonacademic discussions in blogs and newspapers” (and documentaries, and magazines, and stand-up performances themselves), so I'll continue to mention them.

\section{Comedic Use of Social Media}


Other non-scholars have made connections between stand-up comedians and public intellectuals without necessarily calling the connection out as clearly as Garber has. Marisa Kabas wrote about comedian Michael Ian Black as “an unexpected voice of reason in the debate over gun control" in her 2016 article "Michael Ian Black and the Golden Age of Idiocy” for The Daily Dot. In his interview with her, Black addresses the common criticism that comedians should stick to the job of making people laugh and not engage in political conversations. He asks who, then, should be allowed to talk about political issues? Only politicians? That notion is offensive to Black, who recalls taking to Twitter to share his opinions about gun control with his two million followers after the shooting happened at the Sandy Hook Elementary School, ten minutes from where he and his family live. The intentional use of his status as a stand-up comedian to project his position on gun control marks Black a candidate for the category "public intellectual," as long as we're not going by Lightman's limiting restriction to those on the faculty of a college or university.

As we saw with Black's use of Twitter, social media platforms have created new ways for comedians to serve the public interest as public intellectuals by using innovative stunts, hoaxes, and other dangling carrots of entertainment. Twitter and other social media platforms like it are only about ten years old, so there's lots of innovation but little documentation of these practices in the scholarly literature, but we do, once again, have some non-scholarly texts to look to for this analysis. Lindy West of Jezebel covered LA comedian Solomon Georgio's use of Twitter and his comedian status to pull a uniquely fresh public intellectual stunt in her article, "Comedian Celebrates MLK Day by Tweeting 'I Love You' at Racists.” For less than two hours, Georgio sought out racist 
tweets about Martin Luther King, Jr. Day and responded with something patient and kind, always ending by telling the person he loved him or her, before announcing that he needed to break for ice cream.

Georgio’s act undoubtedly looks different than other acts we may feel comfortable identifying as public intellectualism. However, his public act of non-violence and consequent raising of awareness that people were tweeting the things they did (messages under 140 characters that manage to be so sharply cruel that I cannot include any of them here, even after the early warning that foul language would be coming), and the evidence that he could reply with a patient, loving statement created a juxtaposition that begs the question, "Why wouldn't this be public intellectualism or social activism?” Because it is from a comedian? Because it is on Twitter? Georgio himself humbly deflected any such analogy, telling his followers, "Thank you all for the kind regards, but sitting in my pajamas typing ‘I love you’ isn’t MLK comparable. Let’s all do more!” (West). Though he may not give himself credit for MLK-level activism, through his open communication with his fans and followers, Georgio has effectively capitalized on his identity as a comedian and called on his relationship to audiences to encourage action against hate speech and racism.

The rise of the Internet has also helped to create a market for accessible approaches to the critical analysis of stand-up comedy. Websites like Pop Matters pioneered the serious examination of popular culture to a mass audience back in 1999 and since then there has been an explosion of popular culture commentaries. Francie Latour is another critical analyst of humor who isn't writing from the perch of an academic journal. In “Wise Guy: Wrapped in Louis C.K.'s Stand-up Material Are 
Powerful Insights on Race,” Latour summarizes a bit by Louis C.K. in which he points out that as a white man, he would be able to get in a time machine and be safe anywhere. “And there you have it,” Latour concludes, “one of the most clear-eyed analyses of white privilege ever to reach mainstream America, wrapped in a three-minute comedy routine with a Showtime premiere and 7 million-plus hits on YouTube.” While the article may be hosted on Boston.com, a source likely to make some academic readers cringe and question credibility, Latour is engaging in the work of identifying a part of a stand-up act that makes an important social point, summarizing that part and explaining how and why it does the work of social commentary. She even goes on to compare C.K.’s work with Peggy McIntosh’s watershed 1988 essay, “White Privilege: Unpacking the Invisible Knapsack.”

To be fair and to avoid misrepresenting Latour as an author, it is important to note that she does have academic associations, having worked as an adjunct journalism professor for three years and as coordinator of the Broad Diversity Initiative at MIT and Harvard, so we can hardly say she’s a layperson. The fact remains, though, that the critical analysis being presented in "Wise Guy" does not fit within the traditional borders of academic research and publishing, and the reason it's worth noting, at the risk of steering too far off the path of examining how stand-up comedians function as public intellectuals and social activists, is that people feel compelled, not only to think about comedy and what it accomplishes, but to write about it as well. If the humor attached to important critical points about white privilege is the spoonful of sugar that helps the medicine of a difficult-to-grapple-with concept go down, then perhaps it is worth 
considering what may happen when composition students are asked to apply critical analysis to self-selected stand-up material and write about their conclusions.

\section{Working Within the Language of the People}

Inside the scholarly realm, we see another contribution to the conversation about the role of stand-up comedians as public intellectuals in David Jenkins' dissertation, "Was It Something They Said?: Stand-up Comedy and Progressive Social Change,” which positions stand-up comedy as a vital part of intellectual, social life and a vehicle for progressive social change. In a section called "Stand-up Comics as Modern Public Intellectuals,” Jenkins admirably and concisely asserts that comics function as public intellectuals by publicly mocking, educating, shaming and praising. As examples of stand-up comedians who move past their role as entertainers to offer critical insights to the public, Jenkins offers Sarah Silverman, Louis C.K., and Chris Rock. Stating that our current culture does not value critical thought at large, Jenkins explains how stand-up comedians are nevertheless able to instigate us to think critically: "Stand-up comics have an access to both the public space and the rhetorical tools (not only in their ability to craft messages, but their ability to do so in the language of the people) that can make us think critically without the same resistance” (46). This notion of working within "the language of the people” brings us back to that important shift we looked at when aligning stand-up comedians with Sophists, whereby the prerequisite of formal education is removed as a barrier to accessing information and ideas.

Jenkins alludes to both the use of humor to introduce a differing opinion in a surprise attack/backdoor way_ - "those moments when comic wit cracks through what someone thought they knew”- as well as to solidify group agreement, which he adds to 
by pointing out that the listener may have previously lacked the ability to articulate the idea, again reinforcing the idea that comedians can substantially impact listeners from a broad range of formal education backgrounds (42). Both scenarios are identified as "potentially generative of a reckoning or epiphany... hold[ing] us up to a kind of ethical standard” (42). Furthermore, the thinking and ways of expressing introduced by standup comedians are not limited to the time and space of the performance itself; Jenkins explains that "witnesses can take it back into daily life and use it as weapon or shield" (43). To better understand what he mans by this, let's review an example Jenkins offers of Eddie Izzard's response to a popular National Rifle Association (NRA) argument that “guns don’t kill people; people do.”

“I think the gun helps, you know? I think it helps,” Izzard tells his audience in the 1998 special Dress to Kill. Calmly, he elaborates: "I just think just standing there going (sticks finger out miming a gun), 'BANG!' That's not going to kill too many people, is it?” (Jenkins 41). Now, audience members may or may not have already agreed with the position that the NRA's argument is fallible and misleading, so the experience in Izzard's show may have been a reckoning for some and an epiphany for others, but either way, they would now be equipped with a short, clear, pithy, humorous weapon for any future arguments about gun control in their daily lives. In other words, Izzard acts as a public intellectual by engaging audiences on a topic, generating their thinking, and equipping them with ideas to sit with, take home, and maybe use again in conversations with others, thus planting and spreading the seeds of ideas.

Providing people with methods for navigating and negotiating major social issues is just one of the functions of a public intellectual. Referring to Lightman's 
remarks at the 1999 MIT Communications Forum, Jenkins draws particular attention to the three levels of public intellectualism outlined by Lightman:

Level I: Speaking and writing for the public exclusively about your discipline.

Level II: Speaking and writing about your discipline and how it relates to the social, cultural, and political world around it.

Level III: By invitation only. The intellectual has become elevated to a symbol, a person that stands for something far larger than the discipline from which he or she originated. A Level III intellectual is asked to write and speak about a large range of public issues, not necessarily directly connected to their original field of expertise at all. (Lightman) Jenkins establishes that a stand-up comedian's discipline is entertaining, and that most comedians venture into Level II by virtue of connecting their entertainment to the social, political, and cultural world. For comics that fit into Level III, he offers Jackie "Moms" Mabley, Lenny Bruce, and George Carlin. To illustrate ways in which stand-up comedians serve at the third level of Lightman's public intellectual ladder, Jenkins explains that in addition to taking up important issues on stage in their acts, comedians are asked their opinions on world events in interviews. Additionally, "[n]ow they access Twitter, Facebook, podcasts, and YouTube in ways that not only cut out institutional structures but also provide an immediacy and ease of access unavailable in the past” (Jenkins 46). In all of these ways—on stage, in interviews, and on social media, Jenkins shows that we use comedians as authority figures, and as such, they are our modern public intellectuals. 


\section{Comedians as Social Activists}

Most dictionary definitions of social activism center around direct, intentional, vigorous action to support or oppose a cause in an effort to bring about social change. Based on everything we've determined so far about the similarities between stand-up comedians, Sophists, jesters and public intellectuals, it may seem like an easy leap to look next to social activism. If it does, that means I've done a sufficient job of leading us down the path so far. If it doesn't, well then I'd really better nail this next comparison, hey? Returning briefly to Lightman's three levels of public intellectuals, a Level III candidate who is asked to write and speak about a large range of public issues is a good jumping off point to begin considering at what point stand-up comedians can be seen as social activists. Oratorical performance in general is, as Meier and Schmitt say, "uniquely conducive to social engagement and disruption of widely shared social opinions.” Stand-up comedy in particular, as we've noted already, is a form of oratorical performance that offers the added benefit of joy and release. It is a perfect concoction of alluring entertainment and far-reaching platform, and, if Hurley, Dennett and Adams are correct about the evolutionary role of laughter as a mechanism for error correction, it has enormous potential to bring about social change by revealing truths and untruths and identifying ideas that have value.

Social change is often naturally driven by oppressed, underrepresented groups, because therein are the people for whom social change would be a good thing. Those in power would rarely offer freely to have less power, and therefore social change wouldn’t be headlining their priority lists. Speaking out with the goal of generating social change signifies a relative silence or status quo being broken, "as 
underrepresented perspectives are given voice and attention, as topics that went unspoken due to taboo or hegemonic agenda-setting are loosed for public and social discussion” (Meier and Schmitt). If there's one thing a stand-up comedian is good at (and there are, actually, many things a stand-up comedian is good at), it's loosing a topic for public discussion. To those who are comfortable with the balance of power exactly as it is, a comedian loosing a topic for public discussion is likely to be seen as an “irritating gadfly,” as Rosen refers to Jon Stewart in his previously mentioned essay.

We already know that stand-up comedian Hasan Minhaj recognizes the opportunity for social activism in stand-up comedy from reviewing his Radio and Television Correspondents' Association Dinner performance in chapter three. We now return to Minhaj to examine a transmedia series and documentary called Stand Up Planet he hosted to find the best comedians from the developing world and "harness the universal power of comedy to change the conversation about global poverty.” In Mumbai, India, Minhaj tells viewers in the documentary that $40 \%$ of people live in slums, and a new generation of stand-up comics there are making their voices heard. He follows comedians Aditi Mittal and Tanmay Bhat as they perform material on stage about condoms, toilets and sanitary pads, and then talks with them about the underlying issues that have motivated them to prepare and share material on these topics. For instance, Bhat jokes about the absurdity of bleeping the word "condom" out in television programming when overpopulation is such a serious issue.

In another bit, Bhat explains that $54 \%$ of people in India do not have regular access to plumbing: “This number’s been going up since 1947... Basically the British left and we started shitting ourselves a lot more, right? I think this is the best defense 
strategy any country can adopt-like, make the country smell so shitty that no one will want to invade us again.” Minhaj asks him later if, when Bhat was writing the joke, he really wanted audience members to think about this issue, and Bhat confirms that his intention is to draw attention to this social issue. Minhaj proceeds to elaborate on the need for toilets in India, noting that you don't have to be an observational comic to notice that there was a problem. He tours public bathroom facilities and talks with city leaders about the need to install more toilets in order to address health and sanitation dangers posed by widespread lack of indoor plumbing. Returning to Bhat's original joke meant to raise awareness about this issue, Minhaj concludes, “All in all, not bad for a poop joke.”

In Aditi Mittal’s set, she jokes about a brand of sanitary pads called “Don’t Worry”: “I like that they’ve stopped attempting to name themselves and just tell you how to feel.” Minhaj explains to viewers that “it’s not easy for women comedians anywhere, but until recently, women in India weren’t supposed to say much of anything, let alone jokes.” In her explanation of why she's chosen to include material on sanitary pads in her set, Mittal tells Minhaj that women in India are stigmatized as "untouchables" during their menstrual cycles and are not supposed to cook or enter temples during that time. Minhaj asks her how far she’s willing to push on this issue and Mittal immediately replies, “If it’s truth, then I will defend it until the day I die.” Cut to Mittal onstage again, discussing the vaginal beautification industry: “They want our vaginas to be fairer. They want our vaginas to be tighter. I'm like, 'how 'bout we do that for our women’s laws?'” The crowd laughs, Mittal smiles, and Minhaj, in the audience, raises 
his eyebrows and says, “Wow.” Yes, wow. Ladies and gentlemen, there’s your social activism right there.

Wrapping up his time in Mumbai, Minhaj reflects on the absence of local female role models for Mittal and narrates, “My trip to India proved one thing for sure: nothing is funnier than the truth, and the young comics I met were making sure people knew it.” In a video chat with American comedian James Adomian, he describes the up and coming comedy scene he’d witnessed and Adomian agrees: "Part of the magic of comedy is that you can force people who disagree with you or even hate you... to listen.” This segment of the documentary emphasizes again two recurring themes we've visited thus far: Stand-up comedy is both a vehicle for truth and a mechanism for fresh, noncombative persuasion.

\section{Poverty and Racism Are (Not) Funny}

Moving on to Soweto, South Africa, Minhaj participates in a Freedom Day celebration and recalls the country’s joy when Nelson Mandela became the first president after apartheid. Stating that poverty, violence, and a deadly AIDS epidemic have since gripped South Africa, dampening the dreams inspired by Mandela, Minhaj asks, “So where’s the comedy in all this?” He finds it in open mic nights, Africa’s first full-time comedy club, and a satirical news show hosted by Loyiso Gola, all of which Minhaj identifies as "signs of a comic uprising.” Meeting Gola at a barbershop, Minhaj asks him how much race shapes his act, and Gola replies, “A lot.... I mean, wherever I go I talk about race.” Providing background information about how there had been white comics, but they weren't talking to black people, Gola says that he does feel a responsibility as one of the first major black comics in South Africa. An example of 
Gola talking about race in his act comes when he addresses the drastic difference in likelihood that a white man or black man will be imprisoned: "White people don’t think of going to jail. Jail is so far away. As a black man, you think of jail at least once a day. At least once. You wake up, breakfast, jail. Ok sure, sure.”

Kagiso Lediga, Gola’s partner in a comedy sketch show called Pure Monate Show, describes the general sense in the country in 2003, when the show first aired, as one in which “people weren’t talking about things - there were many elephants in many rooms.” Their show, Lediga tells Minhaj, was the first time someone made fun of apartheid on TV, offering the release of laughter. “By joking about race,” Minhaj narrates, "Kagiso and Loyiso are helping heal old wounds through the power of laughter.” Pivoting to the AIDS epidemic, Minhaj wonders if comedy can help solve a problem that big and asks Lediga if he feels the need to address global poverty issues beyond race. The segment that follows squarely positions Lediga in the category of a Level III public intellectual. In it, Lediga has been asked by Shout It Now to do a public service announcement about male circumcision, and does so by dressing up as a penis and sharing statistics about HIV prevention. If that is not some Level III public service right there, I'd be hard pressed to find something that is.

The third comic Minhaj introduces us to in South Africa is Mpho Popps, whom he describes as having grown up after apartheid. The first material we get to see from Popps is not a stand-up set, but a rap he recorded about student loans to teach kids how to save and invest money. Popps explains that because it's a rap, kids would be singing the song without realizing they were being educated, which mirrors our concept of comedy as a spoonful of sugar to help the medicine go down. Like Lediga, Popps is 
also engaged in the movement to educate young people about HIV prevention through circumcision and safe sex. He does this through his onstage material but also as part of his offstage persona, visiting schools and playing soccer with students, then huddling up to have a serious conversation, punctuated with a joyous, impromptu rap session.

As Minhaj points out, South Africa is lucky to have young, sharp comedians like the three he's introduced in the film turning problems into punchlines: "Young gifted and funny are good natural resources to have.” Back home after his trips Mumbai and Soweto to sniff out stand-up comedians there promoting social change through their performances and personas, Minhaj pitches the comedians he wants to bring to the United States to fellow comedians James Adomian and Michelle Buteau. When he describes how Mittal is one of the first women in Mumbai to be doing comedy, Buteau calls her "the Harriet Tubman for other females in Mumbai—she’s paving that path.” Surely we would not find too many people who wouldn't agree that Harriet Tubman was a social activist, so hopefully the comparison between the two women will be a clear indication that what Mittal and others like her are doing with their stand-up comedy work is also social activism.

Mittal and Popps are invited to the United States to perform with Minhaj, and the documentary shows them touring Los Angeles and meeting two of the film's project advisors, Norman Lear (All in the Family, Sanford and Son, etc.) and Carl Reiner (The Dick Van Dyke Show, The Jerk, etc.). In this way, Minhaj and the rest of the film's team pay homage to the history and legacy of comedy as a means to move audience's opinions. When asked about how to walk the line between going for a laugh and making an important point, Reiner advises the group, "You can say anything you want, 
but make sure you're making somebody laugh.” Minhaj tells the two comedy legends about the work he's seen the two up and coming comedians do, saying that the best comedy is comedy that says something, and when he saw the comedians in Mumbai and South Africa perform, they had a purpose. I argue that that purpose is social activism, and these comedians as well as others who engage in that type of social change work should be recognized and analyzed as such.

In the closing of Stand Up Planet, footage of impoverished places in India and South Africa is shown, featuring the hopeful, smiling faces of young people, as Minhaj's voice delivers the following final message:

The last thing a comic wants is to be taken seriously. But I can tell you this: You hear people say, 'Oh, there’s so much suffering in the world; jokes are inappropriate.' But I say hunger is inappropriate. Poverty is inappropriate. Lies and hypocrisy from governments, that's inappropriate.... All over the world, people are taking up microphones. It's a comic spring—an uprising of punchlines. And I'm telling you, man, the revolution will be hilarious.

Reiner chimes in to assert, "Politics is not going to save this world that requires a lot of saving. What will save the world is the comics.” Phrases like uprising, revolution, and save the world may seem boldly dramatic when we're talking about stand-up comedians, but when we consider that other individual speech makers in history have been attributed with those same phrases, and that comedians are traveling from place to place and leveraging social media and other forms of engagement to share messages 
directly with broad audiences, those terms make perfect sense and contribute to an overall understanding of stand-up comedians as social activists.

Researchers and public policy analysts have explored the power of comedy to influence public opinion and concluded that entertainment may be the best way to deliver messages to audiences who are less likely to be critically analyzing messages when they are laughing. One interpretation of this finding could be that comedians are manipulating audiences by disguising persuasion as entertainment and taking advantage of viewers' guards being down when they approach comedic material without the critical lenses they might use with information or advocacy. However, when we consider Hurley, Dennett and Adams’ theory about how humor essentially functions as the gatekeeper that helps us to identify which ideas should make it past our guard, we are able to see comedy as a tool to help uncover and field test authenticity rather than disguise and muddle it.

Caty Borum Chattoo, executive producer of Stand Up Planet, conducted and reported an impact evaluation that helps us to see how the film's comedy operates more as the gatekeeper than as the guard being let down. Comparing Stand Up Planet to another hour-long documentary addressing global poverty, The End Game, Borum Chattoo seeks to answer questions like "Can audiences learn about a tough social issue through comedy?” and “How does a comedy and entertainment storytelling style compare with a somber journalistic style in terms of viewers' knowledge, attitudes and behaviors related to global poverty after watching?” (7). The term entertainment storytelling is a broad one meant to encompass multiple forms of media, like radio 
dramas, TV soap operas, and films, but since we are specifically concerned with standup comedy, we will zoom in on that for the purposes of this analysis.

With this focus in mind, it is especially significant that Borum Chattoo determines that the comedy format of Stand Up Planet made younger viewers, aged 18 to 24 , more likely to find the information presented compelling and to share it with others. In all 1,258 viewers polled, aged 18 to 49, Stand Up Planet scored higher for awareness, concern, and intended action around global poverty, even though The End Game scored higher for educational value (34). Concluding that "content that is accessible and engaging is the key to motivating action" and "entertainment storytelling may offer a unique opportunity to shift attitudes and change behaviors around social issues," Borum Chattoo's findings add to our growing understanding of comedy as a means of persuasion (35). More importantly, they center stand-up comedy, specifically, as leading to the outcome of attitude shifting and behavior changing.

Other scholars have come to similar conclusions about the persuasive power of presenting information in more entertaining ways. Sheila Murphy, a professor in the Annenberg School for Communication and Journalism, is an excellent example of an academic who publishes in both scholarly and non-scholarly places to share her work in the Communications field. In "Stories Are Better Than Lectures at Teaching Us About Health,” published in online academic website The Conversation, she provides a clear, reader-friendly account of a study she and her team at the University of Southern California conducted to determine if information presented narratively could convince more women to learn about and get tested for cervical cancer. Using a randomly selected pool of 900 women in Los Angeles as a starting point, Murphy and her team 
divided them in half and showed one half a narrative film and the other half a nonnarrative film about cervical cancer prevention, detection, and treatment. Both films were eleven minutes long and contained the same ten facts.

The narrative film "led to more supportive attitudes toward Pap tests for all three ethnic groups" (African-American, Mexican-American and non-Hispanic white women) and motivated a higher percentage of viewers to actually take action and seek out a Pap test (Murphy). Notably, Murphy determines that "the narrative film proved particularly useful for those with lower levels of education,” which brings us back to our point from chapter two about stand-up comedians representing a shift in access away from a prerequisite of formal education. In her conclusion, Murphy addresses the caveat that "writing or creating narratives that immerse or transport viewers may require the help of professional screenwriters, filmmakers and other entertainment industry professionals,” and to that last, general bucket of "other entertainment industry professionals," I would heartily add, "Like stand-up comedians, for instance!” in the style of the imaginary audience members who helpfully called out suggestions back in chapter two. Thought leaders in Soweto had clearly identified comedians Lediga and Popps as having the star power and the audience engagement tools necessary to help lead the movement for circumcision and safe sex in Stand Up Planet. If we continue to blow open the potential for stand-up comedians to contribute to the task of transporting viewers in service of changing the minds and actions of people, we will find endless opportunities to pursue social activism in new, invigorating ways, and to have fun doing it.

\section{Funny Formulas for Entertainment Education}


Comedy is an effective way to introduce the public to new ideas and values. Borum Chattoo is currently involved with another project and report series, “The Laughter Effect,” funded by the Bill and Melinda Gates Foundation, which examines the serious role of comedy in social change. She has developed a typology of comedy to address four major comedy formats that deal with social issues in some way: political satire, like Last Week Tonight with John Oliver; scripted entertainment, like Modern Family; marketing and advertising; and stand-up and sketch comedy. In a talk intended to preview the project, Borum Chattoo hits on several of the key points we've been working through in this examination of stand-up comedy, including the intense, lasting ripple effect of messages relayed comically and the wide potential for viewership that social media and the internet offer. Stating that one in five Americans report trusting public officials and one in thirty people report trusting corporate leaders, she says we seem to be turning to comedians, and she summarizes three major influence highlights from the project's attention to how comedy can impact awareness, attitudes and actions.

First, Borum Chattoo addresses comedy’s persuasive muscle, which may have a “sleeper effect,” causing messages delivered humorously to sit with us a little longer, even if we had discounted the message as a joke. Secondly, Borum Chattoo warns that we may be engaging in reductive reasoning when we look to comedy to "make us do something right away,” but that over time, comedy is actually more useful than many other genres in encouraging us to learn, feel, share information, and normalize our feelings about other people and ideas. Referencing two characters in a same sex marriage from the sitcom Modern Family, Cam and Mitchell, she suggests that a Gallup poll recording public opinion from 2009, when the show first aired, until 2014 showing 
a historic decline in opposition to same sex marriage can at least partially be attributed to the show's representation of these two men and the family they've created. Acknowledging that many other things were going on during this time, Borum Chattoo maintains that normalizing the two characters through entertainment offered "a safe way in” and over time fostered tolerance and acceptance.

Finally, she shares that the barrier of entry to complex issues is reduced when we are first introduced to them through comedy. This finding suggests that serious journalism and comedy do not need to compete but can instead work together, because if people are first introduced to an idea through comedy and that lowers their barrier of entry, they will be more likely to engage in information presented seriously on the same topic in the future. Again, the spotlight is on comedy in the broader sense, encompassing the four major comedy formats Borum Chattoo lists at the start of her talk, whereas we are more interested in recognizing the singular accomplishments of stand-up comedians, who deliver these lasting messages by themselves, in traditional rhetor fashion, alone on a stage with a microphone and without the assistance of a team of writers, a screen of images to point to, or commercial breaks.

Couching all of these conclusions in the warning that comedy is only the way forward when actual comedians are involved, because contrived humor by noncomedians can miss the mark, Borum Chattoo leaves us with what she calls a soapbox moment: "We need to marshal our creativity and our innovation and our courage to try this, because we are up against some pretty dang high odds on social issues that we care about.” The comedians themselves are already marshaling those very things, so it appears as though Borum Chattoo is calling on scholars, researchers, and laypeople to 
recognize what they are doing through comedic work and perhaps be more intentionally strategic about how to leverage and highlight it.

\section{Pulling Back the Curtain on Comedy}

In fact, the comedians themselves are occasionally also stepping into the role of explaining to us how their work operates as social activism. Aparna Nancherla takes that on in the article she penned for The Village Voice in December of 2016, “Comedians in the Age of Trump: Forget Your Stupid Toupee Jokes.” In it, she mentions a "quasi-contractual obligation as comedians to roast the powerful” alluding to the "punching up” quality of comedy described earlier. Then President-Elect Trump is described by Nancherla as "a millionaire who answers to no one — the very definition of a punch-up comedy target.” However, she qualifies this by noting that Trump’s rhetoric, "grounded in hate,” positions himself as the victim, painting any insults aimed at him as punching down.

If you would agree that a definition of social activism could include “overturn[ing] and shak[ing] and deconstruct[ing] and weigh[ing] every system that governs life,” then you'll be able to recognize stand-up comedy as social activism, since that's just what Nancherla identifies as the job of a stand-up comedian. The only catch in the scenario she's laid out is that to focus on Trump's hair or tan or habit of

reflexively, brashly sharing his opinions on Twitter would be to normalize him-just as Borum Chattoo argues Cam and Mitchell normalized same sex marriage through jovial treatment. Whatever your political leanings, Nancherla's view of the work that she and others do is useful in constructing an identity of a stand-up comedian as a social activist: 
"Comedians make sense of the world through sharing, and often skewering, common perceptions of it. We're certainly not going to topple the power dynamics in this country, but every voice has power.... It's an idealistic notion, but I am a comedian, and I can project my voice more widely than many.”

She's not the only one elaborating on the general idea of comedy as social activism and projecting a message of a specific type of comedic attack. The Economist ran a similar piece just the month before, identifying comedy as an important medium for political resistance, and reminding readers that there's a reason satire is heavily suppressed in authoritarian countries like Russia, North Korea and China. Heather LaMarre of Temple University, like Nancherla, warns that because "satirists' power to undermine the system depends on their position as outsiders," many political comedians are now part of the liberal urban elite, not the pool of little guys picking on the big guy. Mainly citing shows like Saturday Night Live, The Tonight Show with Jimmy Fallon, Late Night with Seth Meyers, and Last Week Tonight with John Oliver-which inarguably do feature stars squarely in celebrity status — the argument again misses the distinctly unique task of a single rhetor taking on a person or group in power. Here is where rhetoric and composition scholars could swoop in and rescue those single rhetors in the manner that Sophists were rescued. We could pull the limelight a little closer to the stand-up comedian alone, and break off from the larger conversation about how comedy or satire accomplishes social activism, toward a rhetor-centered exploration of how stand-up comedians, very specifically, accomplish this work.

\section{Windows and Mirrors}


Ok. Maybe you're not quite feeling convinced about stand-up comedians as social activists. Maybe you were kind of along for the ride as we aligned them with Sophists, jesters, and even public intellectuals, but I lost you at the "social activists" juncture. I hear you. Maybe you've watched one too many bug-eyed Rodney Dangerfield performances to be ready to associate stand-up comedians with social activists. Maybe you've seen footage of social activists being physically assaulted during a march, like Representative John Lewis, who was beaten by police officers on multiple occasions, and it's difficult to use the same term to describe someone who can sleep until the afternoon and then spend a couple hours onstage telling jokes. Let's downgrade it one notch then. Do you remember the \#weneeddiversebooks movement, where Dr. Rudine Sims Bishop stated that we need mirrors and windows in our books? Mirrors reflect our experiences back to us, and windows offer insights into experiences that are different from our own. Comedians can do that for us too.

When Louis C.K. impersonates parents at a school event watching the action from behind a sea of recording phones rather than being in the moment, listeners might see their foibles reflected back and laugh at the recognition of it. But stand-up comedians can also offer windows. Take Cristela Alonzo. In her 2016 special Lower Classy, Alonzo describes what it's like to be a first generation American. Her mother was an undocumented immigrant and feared anyone in a uniform, which Alonzo works into a joke about her mother not wanting to answer the door for Girl Scouts selling cookies. For those in the crowd who have had the experience of living with an undocumented family member, the joke operates as a mirror, but those who haven't, it offers a window into what that was like for her. Similarly, in the aforementioned Stand 
Up Planet, Hasan Minhaj performs a bit on stage about how when he returns to the village his parents were from, he feels like the rapper who made it and is treated like a king because he brings Capri Suns, Fruit Roll-ups, Gushers and Oreos. Members of the audience can be seen doubled over in laughter as Minhaj describes telling villagers, “I’m not even gonna give you a Samoa. You can't handle this, son. This green box, it changes everything. Strap in.” Borum Chattoo argues that entertainment storytelling may be a superior way to bring social issues into focus than what she says is sometimes called "poverty porn," and with this bit, Minhaj introduces audiences to a firsthand account of a place where food is so scarce that someone arriving to say, "When Hasan's here, everybody eats!” can be hailed as a royally celebrated announcement.

If you can concede that a stand-up comedian may provide a window in this way, even if you can't quite bring yourself to call it social activism, consider what President Obama said about Ellen Degeneres when awarding her the Presidential Medal of Freedom. He cited how important it was "for all us to see somebody so full of kindness and light—somebody we liked so much, somebody who could be our neighbor or our colleague or our sister-challenge our own assumptions, remind us that we have more in common than we realize, push our country in the direction of justice” (Zayra). In this way, DeGeneres served as a window that allowed people to see and be charmed by her as a person and therefore correct a potential error of assigning negative characteristics to her based on her sexual orientation. And since that earned her the country's highest civilian honor, we can see how it might count as social activism.

To wrap up by harkening back to Hurley, Dennett and Adams' theory of humor as a means of supervising input and identifying errors in the ideas introduced to us, let's 
review a comparison they laid out for us: "we have Chevrolet brains running Maserati software, and this strain on our cerebral resources led to the evolution of a brilliant stopgap, a very specific error-elimination capacity that harnessed preexisting 'emotional' reward mechanisms and put them to new uses” (12). Is it not an act of public service to steer that stopgap, shifting listeners' brains to recognize and correct errors in the content being introduced to us at breakneck speed? Whether it’s Aamer Rahman craftily outlining the circumstances under which "reverse racism” could be considered "a thing” or Louis C.K. providing "one of the most clear-eyed analyses of white privilege ever to reach mainstream America” (Latour) or Ellen Degeneres demonstrating the flaws in comparing same sex marriage to bestiality by playing out Sunday mornings with a goat partner, comedians have the power to introduce the public —in the general sense of "the public," without formal education as a prerequisite — to socially sound concepts, and to steer us away from harmful beliefs, and to make us want to hear what they have to say, because it's funny and it makes us laugh. 


\section{CHAPTER 4}

HOW MANY COMEDIANS DOES IT TAKE TO UNDERSTAND THEIR

RHETORICAL MOTIVE?

\section{The Importance of Including Comedians’ Voices in a Study of Stand-Up Comedy as Rhetoric}

No study on stand-up comedians should be considered complete without the inclusion of stand-up comedians' perspectives, regardless of how many scholarly or non-scholarly sources have been cited. This chapter will provide those voices, in the form of interviews I've studied as well as those I've conducted myself. Comedian Colin Quinn wrote, in his foreword to The Complete Idiot's Guide to Comedy Writing, "Listen to other comedians. We are all we've got." It’s appropriate advice, given the premise of the book, which is intended to teach aspiring comedy writers how to not be complete idiots anymore. Who better to elevate hopeful writers out of idiot status than someone who has "optioned more film scripts than you can shake a stick at," as author James Mendrinos says of himself in his bio? Just as Quinn makes a great case for following the guidance of comedy writers themselves, Mendrinos establishes his own credibility as an author of the book by listing popular comedy clubs he has performed in, establishing associations to other esteemed comedians he's shared the stage with, such as Sam Kinison and Chris Rock, and mentioning, last, that he is “a teacher for Gotham Writer's Workshops,” where he has taught comedy writing. 
As a rhetorician, Mendrinos’ author bio makes for a fascinating case study in ethos, since he lists his connection to an academic institution last, whereas scholars typically lead with that. In case there can be any question that the Gotham Writer's Workshop “counts” as an academic institution, because those unfamiliar with it may assume it has something to do with Batman or the comic book world in general, I should add that it is the "United States's largest adult-education writing school” and was “founded in New York City in 1993 by writers Jeff Fligelman and David Grae”, according to the internet. Just kidding, I know I'm not allowed to cite the internet in a dissertation, but it's actually from Wikipedia and that seems frowned upon too- that could lead us to enter into a discussion about how we access information and whether or not it's appropriate to get a quick read on a topic from search results online and then check it against other sources to confirm, which I did.

At any rate, what interests me about a teacher from the Gotham Writer's Workshop authoring a book called The Complete Idiot's Guide to Comedy Writing is that it's a beautiful example of respecting the practitioner's perspective. Gotham Writer's Workshop’s website describes its faculty as expert teachers and working writers who have "been in the trenches, working daily at the craft of writing," "know the lay of the land," and "are equally adept at the fine art of teaching” (Gotham Writers). Moreover, it boasts “wonderfully diverse students_-doctors, lawyers, diplomats, taxi drivers, actors, homemakers, experienced writers, newbies, anyone with a story to tell” (Gotham Writers). In other words, it is a place that offers writing instruction outside of the traditional structure of higher education, to students who can sign up to learn about 
something that interests them without encountering the barriers that can come with formal schooling.

If the lifting or side-skirting of formal education barriers sounds familiar, it may be because that's one of the defining characteristics of stand-up comedians we examined in chapter two, where we compared comedians' engagement with the general public, sans formal education barriers, with the Sophists' turn from nobility to wealth in mid-fifth century BC Athens. Just as stand-up comedians have the ability to bring important ideas and opinions to the forefront of the public's minds and compel them to focus their attention on listening to arguments about those ideas for extended periods of time, Gotham Writer's Workshop could be seen as bringing writing instruction to the people. And James Mendrinos, as a teacher there and an experienced stand-up comedian himself, is bringing comedy writing instruction to the people in The Complete Idiot's Guide to Comedy Writing. The Complete Idiot's Guide series in general has become popular by offering guidance in an unintimidating how-to guidebook format, bringing an entry onramp into a variety of topics to the people.

This whole "bringing it to the people" sequence brings us, the people, back to Colin Quinn's statement in the foreword to Mendrinos' book, which is so short it really bears repeating just to return us to our original sentiment: "Listen to other comedians. We are all we've got.” It succinctly captures the concept that if you want to deeply know and understand something, you should ask the people closest to it. By listening to what comedians themselves have to say about the art, rhetoric and intention of their work, I hope to avoid making assumptions based on observations alone. Hearing straight from the source about how comedians see their work is a strategy intended to add authenticity 
to an effort to recover the rhetorical, persuasive, and informative nature of stand-up comedians' work. To that end, we will now turn our attention to some stand-up comedians to learn more from them about the themes we've explored so far.

Of course, we have already analyzed plenty of work by stand-up comedians: Ellen Degeneres’ goat-marrying analogy; D.L. Hughley’s commentary about the wall; Correspondents’ Dinner speeches by Seth Meyers, Cecily Strong, Larry Wilmore, and Hasan Minhaj; Aamer Rahman’s reverse racism bit; Eddie Izzard’s gun logic; Cristina Alonzo’s window into poverty; excerpts from Richard Pryor's performances; and material from Aditi Mittal, Tanmay Bhat, Loyiso Gola, Kagiso Lediga, and others in Stand-up Planet. Those were all important primary sources to help provide a broad understanding about stand-up from the comedians themselves. However, our task now will be to learn more directly from comedians about comedians' work, and for that, interviews with practicing comedians are used to contribute to a whole picture of how stand-up comedians view their own rhetorical agency.

Since I am specifically interested in how stand-up comedians may or may not see their work as being aligned with the work of sophists, jesters, public intellectuals and social activists, I found myself having to actually ask them personally; you may have already noticed or guessed that there aren't a ton of resources readily available in which anyone has already recorded what stand-up comedians think about rhetors from ancient Greece, or about the five canons of rhetoric, and so on and so forth. There are, however, plenty of firsthand accounts by comedians about their work in general, in the form of interviews with others, articles in both scholarly and non-scholarly publications, documentaries, TV shows, and social media. 
As we saw from the literature review in chapter one, there is an established and expanding interest in the study of comedy in general, but much of the research is receiver-oriented. In order to respond to Miczo’s call for more producer-oriented approaches to studying comedy, let's shift our attention from how consuming comedy about a specific topic can be therapeutic in that it gives a person power to be able to laugh down an idea toward what producing that comedy might elicit. For example, we know that Richard Pryor took the stage at a time when black men weren’t generally in the business of making public mockeries of white people, so from a receiver-oriented approach, we can imagine that the experience of hearing Pryor exert power over oppressors by casually but confidently belittling them onstage was therapeutic to many listeners.

Let's imagine, then, from a producer-oriented approach to humor, what it may have offered Pryor himself, or how he viewed that power dynamic. If audiences are empowered by hearing him say onstage that he’s always rooting for black people because he doesn't "want white folks to win nothin'," then we should think about what the motivation and payoff for Pryor would have been (Zoglin 50). Thanks to authors like Richard Zoglin, who dedicates some of his book Comedy at the Edge: How Standup in the 1970s Changed America to chronicling Pryor's performances and commentary, we know that Pryor was aware of the need to establish a reputation for himself first and then introduce his sharp, biting racial commentary into his act.

Zoglin describes Pryor’s early career in this way: "Sometimes he would sneak a few firecrackers into the box of sweets... But mostly, Pryor, with his lithe body, rubbery face, and big, worried eyebrows, was cute and eager to please” (45-6). This is a valid, 
interesting analysis of Pryor's approach, to be sure, but let’s look at how Pryor himself described his transformation toward a more personal, race-conscious ethos:

It was Mickey Mouse material that I couldn’t stomach anymore. In Vegas, my audience was mostly white and I had to cater to their tastes. I did a lot of that in those days. I wanted to do more black material, but I had people around me telling me I had to wait until I had really made it and then I could talk to the colored. I knew I had to get away from people who thought like that and the environment that made them think like that. (Zoglin 48)

There's no substitute for Pryor's own self reflection if we're looking for insight, substance and honesty. I wish Pryor were around so we could learn more from him about how he made decisions about what to include and how to develop his own identity.

I wish we could ask Bill Hicks how it felt to tell audiences that life is just a ride, and "here's what we can do to change the world right now to a better ride: take all that money we spend on weapons and defense each year and instead, spend it feeding, clothing, and educating the poor of the world, which it would many times over, not one human being excluded, and we can explore space together, both inner and outer, in peace,” and then close his show to thunderous applause (American). Even though Whoopi Goldberg directed that beautiful documentary Moms Mabley: I Got Somethin' To Tell You, I wish we could ask Moms Mabley herself to tell us about joining the vaudeville circuit as a teenager and going on to become the first woman to headline Apollo Theater, adopting a stage persona as a housedress-wearing, younger-man-lusting older woman in a floppy hat and injecting commentary about racial bigotry into her 
otherwise benign material, all the while living as an out lesbian woman with a chic style sense offstage (Watkins). George Carlin’s famous 1972 “seven words you can’t say on TV" bit seems strangely similar to Michel Foucault's thinking about taboo topics in The History of Sex, which came out in 1975, and I wish I could ask Carlin for his reflections about how his message reached a different, wider audience than Foucault, though they both made similar points at around the same point in time.

Those comedians, as you may already know or have guessed, are no longer alive. Fortunately for this project and for all of us at large, there are plenty of comedians who are walking around now, getting on stages and saying things to people. Even more fortunately for this project, I was able to talk with some of them. In my opinion, a producer-oriented approach to stand-up comedy and its uses and effects cannot be complete without the inclusion of the voices of those that produce the stand-up comedy. Are there some comedians who would not wish to adopt the identity of power that I am assigning them by outlining the many ways in which they have access to audience's ears and minds by sneaking in the back door of endorphins, as Bliss said in his TED Talk? Well sure, comedians aren't a monolithic group that can easily be captured by a single set of values-what group is? Either way, we won't know unless we ask them, and the absence of comedians' voices would put this project in peril of being one noncomedian's scholar's unsubstantiated projections onto comedians. In an effort to include those voices, I watched and read interviews with comedians to learn more about how they see their role of rhetorical agency, and conducted three of my own interviews, based on availability, willingness, and proximity of comedians.

\section{Interview Sample}


My methodology for this work began with identifying a sample of comedians I wanted to talk to. Meier and Schmitt notably address this question of qualification many comedy researchers are tasked with addressing: How did they choose which comedians to include and which material to analyze? Acknowledging that the subjects of stand-up comedy run the gamut between issues of grave importance and the utterly mundane, and that they would be unable to "consider every theme used to wrest laughs from and change the minds of audiences," they simply conclude that they "believe that all of the comics treated by the authors of this collection are worthy of scholarly consideration,” later adding that the comedians examined mainly reflect the social challenges of post-World War II American culture (Meier and Schmitt).

Don Waisanen offers a more useful, thorough explanation of his methodology for selecting specific comedians to include in his article, "Standing-Up to the Politics of Comedy," describing his decision to focus on top-earning comedians, transcribe their material, and examine their political-communicative visions through methodological language analysis. Setting the criteria for whom I wanted to interview was a little more complicated because I did not want to focus on something as vague as being "worthy or scholarly consideration" or as measurable as earnings. Ultimately, due to the nature of my interests in learning more about how comedians may or may may not see their own rhetorical motives and their alignments with sophists, jesters, public intellectuals and social activists, I selected to study contemporary comedians from the past four decades who have demonstrated a strategic, intentional commitment to addressing social issues through their material in an effort to enlighten audiences and/or instigate change. 
This means that comedians who mainly address banal situations or use humor to reproduce misogyny or hate speech were not considered. In other words, if your material consists mainly of fart jokes, observations about the airport, or variations on the “Aren’t women so dumb” theme, you didn’t miss my email; I never sent it. Based on a review of material by many currently practicing comedians, I found the following comedians to embody the history of ancient rhetoric, the tradition of court jesters or fools, and the spirit of social activists and public intellectuals: Hari Kondabolu, W. Kamau Bell, Patton Oswalt, Chris Rock, Bill Maher, Lewis Black, Sarah Silverman, Amy Schumer, Louis C.K., Dave Chappelle, Aamer Rahman, Aparna Nancherla, D.L. Hughley, Carmen Esposito and Wanda Sykes.

Once I had identified which comedians I wanted to interview, I reviewed their touring schedules to see when they would be in the Rhode Island area, and contacted them using social media to ask if I could schedule an interview for a time when they were in the area. Because of the traveling nature of their careers, the comedians I had listed were likely to perform in a nearby location over the course of the years that I worked on the project. The first major comedian I successfully landed with my tweet requests was W. Kamau Bell, who was performing at Fete in Providence on December 6, 2014. On October 21, 2014, I tweeted at Bell: “Q for @wkamaubell: What are you doing before your Providence show? Hopeful A: Talking to Jillian for her book on standup as social activism.” About a half hour later, Bell replied to my tweet, “@PaperWithPencil Sounds good to me. Contact @WhitesmithEnt \& @ksemamajama.” The talent management company he was referring to, Whitesmith Entertainment Inc., was co-founded by Keri Smith and Emily White, two women with whom I exchanged 
many emails in the process of setting up my interview with Bell. Smith and White asked me to email one week before the show, when they had a better idea of Bell's schedule, which I did, but they were ultimately unable to commit to making time for an interview until one day before Bell's show. Less than twenty-four hours before the scheduled show, Smith wrote to let me know that they would leave a backstage wristband for me at the door, and that I could speak with Bell for fifteen minutes before his show.

Timing is everything, in comedy and in life, and the timing for interviewing John Fugelsang was pretty ideal. He was coming to URI campus as an invited speaker at the university’s honors colloquium, The Power of Humor, on October 13, 2015, so on October 10, I tweeted at him, “@JohnFugelsang Any chance you'll have time to be interviewed by me while you're at URI for my dissertation on stand-up as social activism?!” Again, in less than a half hour, I had a response: “@PaperWithPencil Yes, but I won't be held responsible for what this does to your final grade.” Since he was scheduled to speak to an honors class during the day before giving his talk in the evening called “Humor in Politics,” I was able to interview him between these two engagements, so the pump was primed, so to speak, to talk about comedy with him. At the talk that followed, I took notes while Fugelsang spoke, trying to mark ideas to come back to and expand on in my own work. Luckily, the event was taped, so I had not only my own audio and notes to work from, but a full recording as well.

The third interview came on July 24, 2016, when Aparna Nancherla was scheduled to perform at Comedy Connection in East Providence, RI. I tweeted at her that afternoon to say, “@aparnapkin Welcome to our itty bitty city! I'm writing my dissertation about comedians as social activists... any time for an interview?” and I 
quickly followed it up with “@aparnapkin I interviewed @wkamaubell + @JohnFugelsang when they were in town and I'd love the chance to talk with you too before your show!” in an effort to demonstrate that I was credible because I had already interviewed Bell and Fugelsang. One minute later, Nancherla replied, “@PaperWithPencil o sure! would after or before the show work? send an email to link in my bio \& we can coordinate :)" After a brief email exchange, we decided on a time before her show, and I met her at Comedy Connection for the interview.

The lightning fast responses seem like Cinderella stories when I see them all collected here, but keep in mind these are the successes from my Twitter-hunting for comedians. I also contacted Hari Kondabolu, Amy Schumer, Sarah Silverman, Wanda Sykes, Patton Oswalt, Lewis Black, and Aamer Rahman requesting interviews when they had performances in the area, to no avail. Actually, Rahman is an Australia-based comedian and did agree to do an interview via email or Skype, but in the end, he was unable to find the time. One of the challenges of interviewing popular comedians is that they are accustomed to being paid for their time spent talking. Another is that they are very mobile and transient, and are often within a given geographical zone for only a short time before moving on to the next stop on their tour, although of course that feature of their work also doubles as a benefit, since it provides the opportunity to request interviews them when they are nearby.

Even more practically, an obstacle to conducting interviews with relevant practitioners for a project like this is the inaccessibility of popular comedians; often, establishing connections with comedians necessitates going through booking agents and public relations representatives who are protective of the comedian as a commodity and 
are looking mostly (and sometimes exclusively) to facilitate interactions that result in monetary profit, something scholars are not necessarily in a position to offer-although we can frame the interview as an opportunity to be immortalized forever in book form, which could be appealing to comedians, whose ephemeral art is over once the applause ends (except for the parts that were added to the YouTube bank). A perceived challenge might be that comedians are always going for a laugh, so it could be difficult to convince comedians to drop the proverbial shtick when they're accustomed to interviewing for entertainment purposes rather than research (Plester and Orams). Similarly, a potential challenge to the interview method could be the reported inability of comedians to think intentionally and report clearly on decisions they make; this is an unfair assumption though, I would argue. The types of comedians who might be categorized under social activism or comedy with a conscience are plenty smart enough to do the kind of metacognitive work that's required for that. Ultimately, the affordances offered by interviewing comedians in order to capture their voice and perspective to describe their own work far outweigh the challenges.

\section{Interviewing Strategy}

With that goal in mind, I created questioning strategies through an iterative process that I first practiced with local comedians, like Dan Martin. I studied interviews with comedians that have already been published in book form (Fry \& Allen, Provenza, Sacks, Radulescu and Wilde) and documentary form (I Am Comic, Comedian). Shaped by the interview process presented in these examples, I formulated my questions to get at the crux of comedians' communication choices through language, informed by the research design descriptions by John W. Creswell, Cindy Johanek, and Thomas R. 
Lindlof and Bryan C. Taylor. These questions included framing some scholarly concepts for comedians and asking them to share their reactions and ideas based on that.

For example, I shared a brief, encapsulated overview of some of Otto’s findings about the tradition of fools and jesters having an ability to expose truths to leaders because they were coming from a place of "buffoonery" and therefore appeared to stand no personal gain, and then asked how they see that related or not related to the work that they do as comedians. I included questions about how they describe their process of determining which rhetorical moves to enact in order to influence audience's opinions and/or instigate change, and questions designed to elicit descriptions of how they may or may not see their stand-up as an authentic form of social activism.

My rationale for choosing this interviewing strategy was based on the rhetorical prowess of my subjects. In order to learn from them about how they saw themselves as rhetors and agents of social change, I wanted to set ideas up for them to react to rather than ask narrow, direct questions. An affordance of this approach was that the comedians I spoke with were all linguistically and intellectually nimble enough to expound on the ideas I presented without requiring strict parameters, allowing me to elicit full, rich responses from them on the topics at hand. A limitation ended up being that, in the relatively short amount of time I had for each interview, I was attempting to cover a lot of ground by asking them to speak to so many comparisons. As a result, some interviewees just naturally spoke more about one alignment than the others, which was fine with me.

\section{Preparing for the Interviews}


In order to have specific examples prepared to talk about with each comedian, I watched, transcribed, and coded multiple performances by them prior to the interview, organizing parts of their performances by the social topics being addressed and the rhetorical strategies being used. This served the purpose of helping me to make clear, direct connections to their personal work when asking about the comparisons I was interested in understanding more about. It also, frankly, did not hurt in the ego stroking department, since comedians are, after all, entertainers, and seemed encouraged by the mention of their own material. In all interviews, I asked for written permission to audio record our talk, and when given, I used those recordings to transcribe and code the interviews for the purposes of pulling quotes. The recordings were stored in a digitally safe, password protected place.

Learning how stand-up comedians themselves view the comparisons between their work and the work of Sophists, jesters, public intellectuals and social activists contributed to my own thinking about the major topics covered in my dissertation. It was incredibly instructive to get input from practicing comedians and use that to direct my work. Unsurprisingly, the comedians I interviewed had a lot of insightful takes on the alignments I was drawing; the opinions, experiences and information they shared with me served as a springboard for my writing. Additionally, they were able to offer astute assessments of their own styles of creating and workshopping their material.

\section{W. Kamau Bell: A Comedy Rhetorician for Emerging and Established Activists}

W. Kamau Bell shared his thinking on his own work as a stand-up comedian regularly addressing social issues through hismaterial. At the start of his CNN show United Shades of America, Bell says, "My name is W Kamau Bell. As a comedian, I've 
made a living finding humor in the parts of America I don't understand. And now I'm challenging myself to dig deeper. I'm on a mission to reach out and experience all the cultures and beliefs that add color to this crazy country.” The show did not begin until after my December 2014 interview with Bell, but that intro nicely encapsulates his stated mission as a comedian, as does his Twitter bio, “I tell jokes, but I'm not kidding,” which we discussed during our conversation together. When I mentioned the statement in his Twitter bio, Bell nodded vigorously and confirmed, “To me, that's what I’m doing.” I also asked about the significance behind some of his tour titles that suggest an activist bent, namely “The W. Kamau Bell Curve: Ending Racism in About an Hour” and "The Kamau Mau Uprising.” Although Bell tried to downplay the implications of those titles by merely offering, "Yeah, that was just the name of the tour, I just thought that was a funny title,” the rest of our interview clearly indicated that he puts more thought into his work and his representation than that.

We reviewed the five canons of rhetoric together, and Bell agreed that comedians “do all those things" but did not have a great deal to add to the alignment of comedians with Sophists, other than commenting about Kairos, "Yeah, it’s better when you're there. It can be good if you watch it, but it's never better at home than it is in the place.” On the ability of jesters to speak truth to power, Bell told me he thinks comedy is really a populist art form and every comic chooses which people they are trying to win the favor of. "Some comics choose to speak truth to power, which is never the way to make the most money,” he joked, “Certainly there’s comedy I hate, but I’m not saying just because you don’t speak truth to power you're a bad comedian; there’s a lot of 
comedians who don't speak truth to power necessarily — that's not their thing - that are hilarious.”

To follow up on the idea of different comedians choosing their which type of people to win the favor of, Bell made this statement:

I just think that sometimes when we talk about comedy, people talk about comedy in a monolithic way that you don’t talk about music. Like you don’t say “music speaks truth to power,” you would say “punk rock speaks truth to power," or "reggae speaks truth to power.” Or rap. Or even certain types of rap. I always feel like nobody’s cared enough to break comedy into categories. Some people have but it hasn’t taken off at a mass level, so people say things like, "I like stand-up comedy” in a way that you wouldn’t say "I like music.”

It was a concept I had confronted myself, along the way of attempting to define whom I would be studying and why, and while outlining full fledged categories or subgenres within stand-up comedy is a fascinating task I'd love to undertake, it will have to come at another point in my career as I continue to focus herein on stand-up comedians’ rhetorical agency.

As for Bell's decision about how to categorize his own material, he reported, "When people ask me to describe it, I say socio-political... I'm not talking about Washington for most of my act, but I think that there's a lot of identity politics, and I also care a lot about cultural movements and some of those are political and some aren't but they are also about society.” He described the importance of having different types of laughter in one comedy show to avoid becoming “predictable and didactic,” and also 
said that sometimes people come up to him and Hari Kondabolu, whom he has toured with in the past, and say that they didn't agree with something they said on stage, and "we're like, 'yeah, that's ok' ... to me, the messiness is a part of it.” About his process for writing and embracing the messiness, Bell said, "I think Seinfeld said any time you get angry, there's a joke there. I would extend that out to say any time you have an intense human emotion, there's a joke there somewhere. So a lot of my stuff comes from frustration or anger, when the outside world doesn't equal what I think it should.”

Now we were really getting somewhere. I wanted to learn more about how Bell developed comedic material out of moments when the world did not equal what he thought it should—essentially, he was finding the humor in the parts of America he didn't understand, as he would later announce at the start of United Shades of America. He elaborated, “All of comedy is communication. For me, a lot of it’s like, if I can figure out a way to explain to people why I'm frustrated about this, then that's the beginning of a joke.” In an effort to explain his frustration to people, he said he uses analogies, metaphors and allusions, and remarked that he feels successful when someone says, “Oh I didn’t see that as being like this, but now that you said that, I see those connections.” He did not, however, believe that laughter automatically implied agreement, and instead maintained that laughter just means “the comedian's a good comedian.”

Bell also reflected on how technology and social media have impacted his work as a stand-up comedian. Commenting about a time when someone in the audience recorded his whole set at a show in Houston and then posted it on YouTube and Facebook, he remarked that technology is making it harder for comedians to "hide their 
material until they're ready to show it to the world.” He talked about other comedians who have great material that they would not want to be recorded and shared, even in their own specials, like his friend and comic Bill Burr, who performed a bit onstage once about his dad: "I told him it was really funny and he goes, 'yeah, but I can never do it on the special,' and I go, 'why’ and he said, ‘Cuz I don't want it to live forever, like I don’t want my dad to see that!'” In a more general sense, Bell insisted on the importance of comedians deciding for themselves when to make material public because "comedians need to be able to fuck up on stage— and not even fuck up, just experiment, and finalize, and then decide.” When I told him I had recently written an article for Comedy Studies about technology and media changing the landscape of stand-up comedy, but that I obviously did not know as much about as he did because I'm not a stand-up comedian myself, Bell surprised me by saying, "Yeah but the people who study the thing often know more about it than the people in the thing," which struck me as humorously counterintuitive to the reason I was interviewing him in the first place, which was the belief that comedians themselves would know more about their strategic commitment to instigating change than I could abstractly philosophize about.

Of all my questions and all the topics I was able to discuss with Bell—in an interview that did end up being thirty minutes long, despite what Smith and White from Whitesmith Entertainment Inc. had said—social activism ended up being the richest, which would have been my prediction based on what I knew of Bell going into the interview. He seemed reluctant to cast himself in the role of a social activist, saying, "people have said that before and I totally accept it from the outside but it's kind of like you can't give yourself a black belt, somebody else has to—like, you get a black belt.” 
When I tried to give him a black belt by suggesting that his comedy posse "Laughter Against the Machine,” which he was in with fellow comics Hari Kondabolu, Nato Green and Janine Brito, was a way in which he used comedy as a tool for social activism, Bell shook his head and said, “I just don’t ever want a person who’s at a protest right now to feel like I'm somehow trying to surf off their activism with my jokes.” My understanding of what he meant by this is that, like Georgio, who deflected sentiments that his MLK Day tweets were worthy of praise, Bell does not want to accept credit where he isn't convinced credit is due.

In fact, Bell said he and the other comics started Laughter Against the Machine as a sort of "campfire for the revolution," for the people who were "doing the work" to sit down at the end of the day and not necessarily disconnect, but laugh and share stories; "we were like that campfire and we were like, 'sit down, now that you've done all that hard work,' and that's important, but it doesn't take the place of the work.” He added that he sometimes feels guilt for being credited with social activism when he has “activist friends who actually get up in the morning and are like, 'let's go flyer, let’s go protest.” Specifically, he said, “I feel guilt right now that I haven’t been to an Eric Garner Ferguson protest because I've been on the road, and when I go home I have two kids... so I was just like, I can't, but I feel good that there’s probably activists at this club, like people who come to the show who just want to hear somebody talk about the things in a new way.”

In addition to resisting the credit for being a social activist, Bell maintained that he wanted to be a comedian before he wanted to be "this type of comedian": 
I think because I am this type of comedian, people assume, and I think I've led them this way, "Oh do you have a degree in political science? You know, were you somebody who was like, 'How do I get the message to the people? I will use comedy!'” and it's like no, no, no, no, no, I was a little boy who watched comedy on TV and saw Eddy Murphy and Bill Cosby and Jerry Seinfeld and Janeane Garofalo, and all those people and was like, "I wanna do that."

Despite downplaying the extent to which he can be considered a social activist, Bell consistently demonstrates with his material that he is interested in influencing the opinions of his viewers, and, as his colleague from Laughter Against the Machine Nato Green stated in a 2012 interview on a San Francisco morning show, CBS’s Bay Sunday, "It’s comedy about ideas; it’s comedy for a thinking audience that wants to be challenged and provoked as well as entertained."

\section{John Fugelsang: A Comedy Rhetorician Devoted to the Process}

John Fugelsang is another comedian who challenges and provokes audiences, and when I interviewed him on October 12, 2015, we decided to dedicate the interview to a similar comedian, Dick Gregory, since it was the day after his birthday and Fugelsang had just recently done a cable special with him. Actually, Fugelsang had worked with many of the comedians we discussed—he'd even lived with one of them, Trayvon Free, a writer for The Daily Show. After reading the aforementioned list of comedians who have demonstrated a strategic, intentional commitment to addressing social issues through their material in an effort to enlighten audiences and/or instigate change, I asked Fugelsang if there were any glaring omissions, and he said I had "a good 
list right there,” adding that it sounded like I was interested in "political comics.” This prompted a useful discussion around honing the stated criteria for comedians researched and picked up the thread from my earlier conversation with Bell around subgenres of stand-up comedy. Fugelsang even made a similar comparison to music genres, citing hip hop and folk as examples.

After reviewing the five canons of rhetoric, Fugelsang said that he "absolutely" saw an alignment between them and his work, and after going over the role of the Sophists, he said stand-up comedians “certainly carry on that tradition.” When we arrived at the topic of jesters, he again said he saw a strong parallel, but this time with an important caveat: "The jester worked under the grace of the king... Now the jester is on his own mocking the king and the rulers ignore the jester at their own peril.” In his assessment, although it may have seemed like jesters from days of yore had been brave in daring to criticize the king, today's stand-up comedians are essentially taking on an even more daunting task, because while they are performing the same function, of using humor to point out critical flaws in leadership, it is no longer encouraged or invited, so the comedians do not enjoy the same protection to perform their criticism as the jesters did.

In Fugelsang’s own words, “even when the jester was the only person in court who could take on the ruler directly, it was always as a means of advising the ruler to make wiser decisions and the jester was often the only representative of the under classes so it was incumbent upon the king to, you know, maintain the favor of the people.” In that sense, he concluded, "the jester was an invaluable member of the court" whereas stand-up comedians aren’t afforded the same status. It seemed clear that 
Fugelsang had already given some thought to the connections between jesters and comedians, and wasn't confronting the parallel for the first time based on my question. He even added that he'd been planning to include a bit in his talk that evening "about how if Barack Obama had a cabinet position for Chris Rock, his poll numbers would be even higher.” Indeed, Fugelsang did include that line in his "Humor in Politics” talk that evening, along with so much more on the topic of jesters:

We need political comedians. Ok, so the character of the jester is one of the most common and widely recognized character types found in culture and mythology throughout the history of the world. Jesters were fools and entertainers, social and political critics, agents of change, for cultural and religious mores for their audiences. The jester was one of the few characters in court who could feely speak his conscience without causing offense. And they weren't just in Europe; they had jesters in Africa, India and China, and they all had the ability to speak their minds, through jokes, to question authority while others had to hold their tongue. And while the jester could tweak or mock the king, it was always in service of the king. Criticizing a policy in a joke was still supporting the ruler, trying to get him on the right track, and help right his judgement and protect his legacy. Today's comics are remote, freelance jesters. They no longer work directly for the rulers, but they use ridicule in ways to advise and guide, and the rulers are free to ignore them at their peril. I still wish we had the old dynamic; if Barack Obama had Chris Rock in his cabinet, he'd be doing a lot better in the polls. 
Cut to me, sitting in the audience at the Edwards Auditorium with my mouth hanging open, because Fugelsang had essentially demonstrated to an entire crowd that he could have written chapter three of my dissertation by himself, no problem. He had nailed the function of the jester, made a clear connection to stand-up comedians, and formulated an argument for the benefits of rulers acknowledging the usefulness of comic criticism.

It was clear to me from listening to Fugelsang's clear, confident talk about the importance of comedy in politics that he could have easily been a scholar and/or professor, sharing his well formulated ideas in a different arena than on his Sirius show “Tell Me Everything,” even though he had modestly opened by claiming that having him to speak at a university was like asking Willie Nelson for tax advice. During our interview though, Fugelsang had explained, "Making it funny is how you reach a wider audience. I mean, making it entertainment is the way I wanted to go rather than academia or politics. I think you get a lot further with the truth in a dick joke than just the truth.” Well that's one way to put it! Another way he put it, both in our interview and in his talk that evening, was, "Comedy is the lube that makes the gears of truth run." I was fascinated by Fugelsang's waxing philosophical about comedy as truth, as criticism, and as social commentary, because it so closely matched my own thinking on stand-up comedy, and it felt powerful to me that an actual practitioner, out there doing the work of stand-up comedy, could confirm what I saw as a major function of truth telling, idea sharing, mind changing and social activism.

Like Bell, Fugelsang seemed hesitant to fully ascribe social activism to his own work, saying that he tries to follow a formula: "Entertain first, inform second, preaching last, so if you make activism your goal, chances are you're going to be propaganda more 
than entertainment... I just think that preachiness is one of the enemies of funny, so one has to be very careful about that.” In addition to sharing his formula for crafting his sets, Fugelsang also provided a more general overview of how he creates and workshops material, telling me that his "devotion is to the process" and that "it's only in the repetition that you discover what works.” His insights made me reflect again on how much comedians could contribute to composition studies. While outlining and drafting tend to be typical components of a composition classroom, Fugelsang addressed alternate ways of brainstorming and editing, namely by practicing material out loud and in front of others:

For me, I'm no good at writing. I have to talk it out... you can be seduced by your own sense of self importance on the printed page. When you're saying it out loud, you instinctively know when something doesn't land. And this is what comics know all the time; you learn from your audiences... That's the wonderful thing about it—it's a beautiful chaos that requires a lot of trial and error.

After having learned from him that learning from his audience helped him to hone his material, I took particular notice during his evening talk when he would briefly jot something down, potentially about an audience's reaction or about another way he wanted to try making a similar point the next time he addressed it; in that way, comedians are constantly editing and reworking ideas and language.

In addition to his well formed argument about former jesters working directly for rulers and current comedians performing a similar role but as freelance critics, Fugelsang had a lot to say on the theme of comedy as a sort of sneak attack, non- 
combative form of persuasion. Reminding me of the Chris Bliss TED Talk quoted earlier about ideas sneaking in through the back door with comedy, Fugelsang declared: “The best political comedians disrupt the status quo by creating just enough discomfort to highlight issues others won't or can’t discuss because they cushion the bluntness of the blow with laughter.” He called on a quote from George Carlin’s book Last Words to make his point: "No one is ever more him/herself than when they really laugh. Their defenses are down. It's very Zen-like, that moment. They are completely open, completely themselves when that message hits the brain and the laugh begins. That's when new ideas can be implanted. If a new idea slips in at that moment, it has a chance to grow."

On the theme of stand-up comedy as a form of expression well suited for sharing truths, Fugelsang said:

Political comedy, when it's done right, is a delivery system for truth. The best political comics — the ones I admire—are our most effective cultural anthropologists and social critics. They document areas of knowledge, and bring ideas_-big notions, and often unarticulated but commonly felt feelings — to the conscious awareness of their particular audiences. Comedy can awaken us to critical thought patterns in a way people don't find threatening. Taking something many may already think or vaguely suppose, articulating it into words, and making it entertaining, helps a culture understand itself, and provides a context for others to understand that culture's humor. 
Here he brought in a scholarly source: “As Stephanie Kozinski wrote in 'The Standup Comedian as Anthropologist' in the Journal of Popular Culture, this is why we don't really find comedy of a previous generation, or a century ago, or foreign comedy, very funny, although that still doesn’t explain why French people like Jerry Lewis.”

Sticking with the term "political comedians" that he'd used frequently in our interview, Fugelsang made several strong statements about the important function performed by stand-up comedians, again starting off with the caveat that he was talking about when it was "done right.” Here he addressed humor as resistance and as social corrective, making me wish we had discussed Hurley, Dennett and Adams' theory of humor as an evolutionary error correction system:

When done right, humor, especially political humor, is entertainment that's also resistance to power and a way of confronting and deconstructing authority. In terms of social justice, humor is in many ways a social corrective. You'll see this in African American comedy, LGBT comedy, Latino comedy, religious humor, feminist humor... it validates shared experiences and it gets us to think more flexibly and reframes situations in this shared experience we call life. There's really an ancient human tradition of comedians critiquing the dominant powers of society, subverting authority, and exposing hypocrisy through wit instead of propaganda.

So there you have it. Fugelsang hit on multiple points I prioritized in my alignment of stand-up comedians with Sophists, jesters, public intellectuals, and social activists. He even highlighted their contributions to democratic societies to boot: "Political 
comedians in America are more important to democracy and the human spirit than ever. Laughter is essential to life and it's essential to politics. Humor, as you all know, helps us handle confusing and difficult life experiences.” Overall, my conversation with Fugelsang validated and strengthened the connections I was seeking to make, and the talk he gave that evening was the frosting on the cake.

\section{Aparna Nancherla: A Comedy Rhetorician Growing Into Her Political Identity}

My interview with Aparna Nancherla on July 24, 2016 was very interesting because at the time, she did not classify herself as among the group of what she called "overtly political comedians.” When we discussed the five canons of rhetoric, Nancherla nodded and said she felt like there were parallels between the canons and the "kind of comedy" she does, noting that her material is pre-arranged and not necessarily memorized, but that she generally uses the same wording and punchlines. When we went over the role of jesters though, she said, "I feel like maybe some more overtly political comedians addressing race or things that can be dicey-er and not everyone's on that side of the issue" would be similar to jesters, but that she did not cover "fringe or minority” issues as much in her own act. Later in the interview she did end up characterizing her material by saying, "Issues I end up talking about most are probably feminism and maybe being a woman of color.” She also mused that stand-up comedy provided an interesting "platform where you're able to challenge anything you want to when you're on stage.”

When asked about comedy's ability to subvert and resist, Nancherla actually pointed to Hasan Minhaj's speech at the 2015 Radio and Television Correspondents' Dinner as an example of a comedian doing the work of a jester, which was validating, 
since I had already tagged that performance to include in the chapter about jesters (as you saw earlier). She did say that she addresses imperialism in her own material, but laughed about how that wasn’t exactly a “current tension” to explore. I had seen a part of her act before where she says that she has white friends and whenever they say they're sorry to her, she just assumes they're apologizing for imperialism, so I knew the material she was referring to. She explained that there are parts of the country where “people aren’t jumping on the bandwagon right away” when she jokes about imperialism, but that Brooklyn was an example of a place where audiences tended to be on board right away.

In keeping with my questions for Bell and Fugelsang around process, I asked Nancherla if she could speak to her methods and techniques for coming up with and workshopping material. She described always writing down things she observes on a daily basis and then later sitting down to flesh them out into fuller ideas. For her editing process, she said she will workshop her ideas with friends or sometimes before audiences, and that it helps to run something by another comic. One challenge she identified was being her own goal setter without anyone looking over her shoulder; she described setting a goal of coming up with five minutes of material for a late show and working until she accomplished that. Like Bell and Fugelsang, Nancherla did not label herself a social activist, but it was only five short months after our interview that she penned the aforementioned article, "Comedians in the Age of Trump: Forget Your Stupid Toupee Jokes,” for The Village Voice, in which she argues, “As comedians, it is up to us to overturn and shake and deconstruct and weigh every system that governs life. 
This work, my work, feels more active now, more important. I feel driven to express my strong opinions and to challenge people's thinking, even when it's scary or inconvenient.”

It would appear as though Nancherla’s identity was growing toward one that might be included in the group of "overtly political comedians" that she initially did not align herself with when we spoke. Two months after her essay was published in The Village Voice, Nancherla did another interview, in which she said, "I think it’s gotten sort of increasingly surreal since the election and now that the presidency is official, the stuff that's happening with our government — it feels pretty unprecedented for my generation and probably for younger people, too” (Ciesielski). As a result, Nancherla said, "it’s definitely new ground for artists in terms of what they want to talk about and how they want to capture it, and also just like what freedom of speech even is right now how much longer it'll be around. It just feels like a more dark time than it has been at least in my lifetime” (Ciesielski). It’s possible to surmise from this timeline of events that while Nancherla may not have considered herself an “overtly political comedian” at one point, she has felt moved by current events to take advantage of her platform as a comedian to become socially active. This would make her similar to Bell, who noted that he had wanted to be a stand-up comedian first, and fallen into a more socially active role second. Interestingly, one of Nancherla's first jobs in comedy was actually as a writer on the FX show Totally Biased with W. Kamau Bell, so it's a small world!

One area in which Nancherla did seem confident to speak about in our interview was gender. A compelling comment she made during our interview was that "male comedians discuss male issues and everyone in the audience is supposed to be on board, but women's issues are 'niche.”' She said she didn’t know why this was the case, but 
that it's gratifying when material does resonate with people in the audience, because it seems like “they're glad you talked about that.” Generally speaking, Nancherla did not seem to be giving herself enough credit for the work that she does as a stand-up comedian, but that was in keeping with comments from Bell and Fugelsang as well, which made me wonder if another challenge to interviewing comedians might be their natural inclinations to downplay the importance of the work that they do. Despite their humility though, all three comedians offered excellent insights during our conversations, and I was grateful to have their firsthand accounts to consider in my writing on the topic of stand-up comedy. Since it would be impractical to interview every comedian I consider to be doing strategic, intentional, thoughtful work through the rhetoric of their stand-up material, for the reasons listed earlier in the methodology section as challenges as well as for the reason of time restrictions, I'm also grateful for the wealth of primary sources available, including others' interviews with comedians in video, article and book form.

\section{Speaking Seriously About the Craft}

Interviews with comedians conducted by journalists and first-person autobiographical or narrative accounts provide additional support to the claim that comedians operate with a rhetorical motive in mind. Contrary to the perceived challenge of comedians being unwilling to speak seriously about their craft, there are actually many excellent instances of comedians sharing nuanced reflections about their use of comedy to advance messages. In order to include the voices of stand-up comedians that I have already identified as crucial to understanding stand-up comedy from a producer-oriented approach, I will share multiple snapshots of comedians 
describing how they see their work. On the theme of comedy getting at essential truths through non-combative rhetoric, many examples of stand-up comedians have weighed in with their takes. Patton Oswalt, who majored in English in college and therefore is secretly one of us, said in an interview with Salon, "There has to be way less outrage, more fun and mocking and irreverence. It just feels like being outraged puts you in a position of not being powerful. You're so much more powerful when you're laughing and being forgiving and taking pity on someone” (Daley). In the same interview, he spoke to the idea of comedians extending who has access to ideas beyond the barrier of formal education when he said, “Comedians have always been the best conduit to the forgotten, to the outsiders, to the inarticulate. We speak for the underdogs, for the most part. That's what most comedians do" (Daley).

Comedians are well aware of their unique approach to truth-telling. In Make 'Em Laugh: The Funny Business of America, Billy Crystal addresses comedy as truth when he says, "Getting a laugh and getting at the truth are the same. We need comics to tell us when we're screwing up." This also harkens back to the computational theory of comedy as an evolutionary error correction tool. At his already-very-well-covered “Humor in Politics” talk, John Fugelsang addressed comedy as truth when he said, "We need comedians more than ever, not just to break the tension with laughter, but to tell the truth." Joan Rivers sees herself as filling that role when she announces, "If something outrages you, you must speak out about it, and comedy is the way to do it.... I think I'm a truth teller" (Make 'Em Laugh). In an episode of Louis CK's show Louie, Rivers offers yet another description of stand-up comedians’ work when she tells C.K.'s character, "What we do is a calling, my dear. We make people happy." 
Yet another comedian who touched on the idea of truth and honesty was Lenny Bruce, a comedian famous for his controversial social satire, who said, "The only honest art form is laughter, comedy. You can't fake it" (Rosen). Certainly we are beginning to see a pattern emerge of multiple comedians expressing the idea that what they do is connected to sharing truths. If we keep digging around, we'll also find examples of comedians commenting about the rhetorical, persuasive nature of their work. In one of his stand-up shows, Bill Hicks told his audience, “This is called logic, it won't hurt you, it'll set you free" (American), getting a laugh from the crowd while simultaneously letting them know that, like Bell, he was telling jokes, but he wasn't kidding. Michael Ian Black tweeted, "The best comedy is funny but also makes a serious point," once again reaffirming the notion that there's more to comedy than some chuckleheads tickling your funny bone.

Comedians recognize their work provide a release or relief from the pressures of everyday life. In 2011, HBO aired a one-hour special called Talking Funny, featuring Louis C.K., Chris Rock, Jerry Seinfeld and Ricky Gervais in an unscripted conversation about what it means to be a stand-up comedian. It's a great source for hearing about the work of stand-up comedy straight from the horses' mouths, and four of the most successful horses, at that. One notable quote from the discussion came when C.K. offered, "I think a great thing about comedy is taking people to places where they have fear and foreboding and making them laugh in that place; I think you help them.” Jim Norton made a similar statement when he was a guest on Totally Biased with W. Kamau Bell, in a conversation about whether or not joking about rape was ever acceptable: "The relief of comedy is it takes things that aren't funny and it allows us to laugh about them." 
Certainly, scholars from several fields have theorized about the relief theory of humor, but for me, hearing C.K. and Norton describe how they see their work packs a more impactful punch.

Tina Fey describes her own experiences working in the comedy world in The New Yorker's “Lessons from Late Night.” Responding to the idea that male and female comedic writers might be different, she argues that they are different, because "the men urinate in cups” and leave them around their offices. On the topic of comedy providing relief for the producer, Fey says, "Maybe we women gravitate toward comedy because it's a socially acceptable way to break rules and a relief from our daily lives." The Green Room with Paul Provenza, a talk show on Showtime featuring panel discussions by comedians on a variety of topics, is another excellent source for firsthand reflections by comedians. In one episode, Bo Burnham expands on the idea of comedy as a means of relief for the humor producer when he says, “The absolute 'comedy comes from pain' limits what comedy is, because I think comedy comes from love, it comes from fear, it comes from hate.”

\section{Examining the Human Experience}

Yet another place to look for comedians offering their experienced perspective would be documentaries about stand-up comedy. In one such documentary, Why We Laugh: Black Comedians on Black Comedy, Chris Rock calls his job "examining the human experience." And you thought it was telling jokes! In the same documentary, Sommore says, "If you want to know what's going on in our community, watch our comedy," suggesting that stand-up comedians shape and reflect the thinking and behavior of social groups. Again, researchers like Mintz and Kozinski have staked 
similar claims, but it is significant to hear it from a comedian herself, in an earnest, informal tone. Likewise, it is significant to hear from comedians themselves about their processes and experiences. Bell, Fugelsang and Nancherla were kind enough to share some of their strategies and approaches with me, and their input caused me to reflect on how there is no one way to accomplish the invention, arrangement, style, memory, and delivery required of a comedian. In other words, as comedian Myq Kaplan once said, "Here's the thing... The comedian's job is to talk, to say things, to get across ideas, to be funny. It’s not required to look a certain way."

According to Jerry Seinfeld though, it might sound a certain way. In an interview for The Guardian, Seinfeld is described as "a scientist of comedy, painstakingly calibrating his equipment [whose] extreme professionalism crosses over into a kind of absurdist Zen” (Burkeman). Seinfeld tells Burkeman, "The timbre of it, the shape of it, the length of it - there's so much information in a laugh. A lot of times, you could play me just the laughs from my set and I could tell you, from the laugh, what the joke was. Because they match." Chris Rock shares his feedback involving audience and process in an interview with New York Magazine: "The thing about comedians is that you're the only ones who practice in front of a crowd." This matches what Chris Bliss says in his aforementioned TED Talk, "Comedy as Translation”: "Feedback is instant and intimate," because in both cases, the audience’s reactions to material provides the comedians with real-time, genuine evaluation.

Thinking back to Aamer Rahman's reverse racism bit covered in chapter two, we'll have a context for when he tells interviewer Brian Logan that what makes it funny is how the long list of things that would have to happen, with the assistance of a time 
machine, in order for reverse racism to be a possibility, conveys the exhaustion of having to explain to anyone that the concept of racism involves an unequal standing of two groups, and therefore joking about white people not being able to dance cannot be considered to be on par with a joke targeting a person of color. It is essentially a more detailed explanation of why the unwritten rules of comedy require comics to punch up toward those in power rather than tear down the already-vulnerable. Both Rahman's explanation and the punching up concept reinforce the evolutionary and computational error correction theory of humor that suggests we are drawn to consume comedy in service of identifying which ideas we encounter are rationally or ethically flawed.

Comedy sheds insight on human nature and human foibles in a way that can have transformative impact. Rahman reports, "The number-one feedback I get from the clip is, 'I've been trying to explain this to my friend, or a colleague, for years - and now I just send them your video.' And I get emails from university professors who play it in their classes. They say, 'I didn't have to write a lecture; I just played this and the kids argued about it for the next 60 minutes."' (Logan). Rahman’s experience is a literal representation of stand-up comedy's shift toward the general public without the barrier of formal education; according to their professors, students were better able to access an important idea about race through Rahman's three-minute stand-up performance than through a lecture by their professor-and not only were they able to access and understand it, but they were compelled to spend an hour engaged with the idea, discussing it with each other in class.

Working Out Life Crises Through Comedy 
Continuing with our effort to include multiple voices from the field, we will now move on to Amy Schumer, one of the most popular comedians in contemporary culture. Since her work straddles multiple genres, it’s worth noting that Schumer, like Stewart and others, started out as a stand-up comedian before crossing over into television and movies. She now has her own show on Comedy Central called Inside Amy Schumer, which follows a structure similar to The Dave Chappelle Show in that it includes both sketch comedy and stand-up comedy. Schumer has also worked in film, starring in movies like Trainwreck and Snatched. This presents the same challenge we've confronted all along here, which is that we will first have to untangle her stand-up comedian persona from other types of comedy and zero in on that. Helpfully, Schumer has consistently toured and performed as a stand-up comedian, throughout her forays into television and film. In an interview with Molly Young from New York Magazine in 2013, Schumer gave us an insight into her process when she said her "writing routine is to work backward from an uncomfortable premise" and then try to make it both funny and palatable.

Another comedian who has worked backward from uncomfortable premise by creating and performing comedic material about a painful personal experience is and personally painful premises to arrive at comedy is Sasheer Zamata, who described her motivations and processes for stand-up comedy when she guested on NPR's This American Life. You may recognize Zamata’s name from Saturday Night Live. Actually, if you watch that show, you could try a quick thought exercise where you ask yourself if you heard her name in the SNL announcer's voice when you read it, and then you could reflect a little on the auditory connections a voice like that creates for a viewer. Either 
way, the important thing to note is that Zamata is a stand-up comedian too, although she may be more well known for her role on $S N L$, and in the segment she did for This American Life, Zamata was describing an incident that happened to her on the streets of Florida that she has turned into material for her stand-up act over the years. She was walking with a friend, who was another black woman. Host Ira Glass, I should add at this point, cautioned listeners that Zamata was going to be using a racial slur in her story, so perhaps I should similarly add that here. And look at that, I have.

Anyway, Zamata and her friend were walking down the street when a large truck bearing a confederate flag vanity plate approached them. A red-faced man (which was as "politically correct” as she could be in describing him, Zamata told us) leaned out the window and yelled, "y'all niggas need to take yo' black asses back to Africa." Zamata says she did something she doesn't often do when she's upset; she called her mom. She goes on to provide a background and context for her mother's relationship with white people: when her mother was school-aged in the 1960s, she was sent to an integrated school in Forrest City, Arkansas. Zamata says that her mother had never shared any of this information with her when she was growing up; the most she would get out of her mom could be defined by an incident where her mother was driving and had stopped to let an older white couple walk across the street. Her mother let out this "this deep sigh like, ehh, white people,” and Zamata said, “I was like, 'Uhh, they're not even talking to us right now. What's the issue?"” And her mother just said, “memories.”

It wasn’t until after Zamata had the experience with the slur-yelling truck driver that she thought to really ask her mother about her experiences with white people growing up. At that point, Zamata’s mother Ivory actually joined to tell the story with 
her daughter. Ivory described going to the integrated school because her mother had chosen to send her children there when the option of racial integration became available, saying that she wanted her children to interact with white people so they didn't grow up afraid of them. Ivory and her six siblings would ride the bus to school—in the front, where their mother had told them to sit so that if a problem arose, the bus driver could witness it. The bus driver did witness the problems that arose - other children on the bus hurled slurs at Ivory and the other black children on the bus, but he said nothing to protect them. The school principal witnessed white children pelting rocks and bananas at Ivory and did nothing.

These two stories—of getting hate speech yelled at Zamata and of her mother getting rocks and bananas thrown at her—don't seem that funny, do they? But Zamata says that she worked through the experience with the truck driver on stage, through the development of her material for stand-up performances. She says she's been talking about it for a few years now in her act; she describes the man and his truck to audiences as a caricature of racism, as if the man had walked into a store and said, "I need to look as racist as I feel!” She says this last part in a deep voice with a southern accent, and I can picture her on stage, holding the microphone and gesticulating with her hand and making her eyes bigger when she says it, staring up over the top of the audience for this quick impersonation as part of her bit.

I haven’t actually seen Zamata do this bit, so she may or may not hold her arm the way I imagined it when she's on stage, or look where I imagine her looking. But I have watched enough stand-up comedy to have made some observations about the way comedians hold their bodies and use their voices and their gaze to elicit laughter out of 
audience members. You have too probably, if you think about it. Or maybe you haven’t; I don't know you so you might be someone who settles in for a nice documentary about the food industry or the failing education system on a Friday night, but chances are you've seen some standup comedy routines. Regardless of how much stand-up you've consumed, consider this: creating and performing comedic material about a painful experience helped Zamata work through complicated feelings about racism so she could arrive at a place where she has wrestled that experience into something that she has power over. And she's not the only one who has done this.

In this chapter, I have intentionally and comprehensively called upon stand-up comedians’ own words in order to uncover a rhetorical motive in their work, where one is often not recognized. When Louis C.K., Jim Norton, Bo Burnham, W. Kamau Bell, Michael Ian Black, Patton Oswalt, Joan Rivers, Aamer Rahman, Billy Crystal, Amy Schumer, and Sasheer Zamata all make similar statements about either the healing power comedy has on audiences or the spotlight it can shine on injustices or the validation of working through a painful personal experience by working it into stand-up material, we should listen to them, because they're the ones up there with the microphones doing the job.

Comedian Dan Martin describes his performances as boxing matches_-he cuts audiences with a less offensive joke here so he can follow up with a power punch there that addresses something serious, then he gives them some water with a one-liner or a side comment. He says he's the coach and the opponent. If this section was like a water break because it included interesting-to-read statements from comedians themselves, put 
your mouth guard back in, because we need to enter into the final round of this match, the aptly titled "punchline" chapter. 


\section{CHAPTER 5}

\section{THE PUNCHLINE}

\section{A Review of the Argument}

In this dissertation, I began with an overview of the five canons of rhetoric and how they are represented in a stand-up comedian's work. Next, we reviewed what some academic and non-academic writers in different fields have had to say about humor in general and stand-up comedy in particular to date, noting that there is an opportunity for rhetoric and composition scholars to contribute meaningfully to this topic. In particular, ties to early thinkers and concepts in rhetoric, like Aristophanes and kairos, are useful in setting up our field's clear connection to stand-up comedy. To set the scene for how and why humor is used to shape opinions and shift mindsets, I shared the evolutionary and computational theory of humor presented by Matthew M. Hurley, Daniel C. Dennett and Reginald B. Adams, Jr. in Inside Jokes: Using Humor to Reverse-Engineer the Mind. According to those three, we are wired to derive pleasure from the act of recognizing errors in our systematic thinking — hence our sense of humor.

Before moving on from that first chapter, I included a brief disclaimer about the intentional decision to incorporate a less formal approach to word choice and writing style, and explained the connection between one of the ideas we'd be exploring - that comedians are able to reach larger audiences in part because of the way their casual tone lowers the barrier of entry into ideas — and how the ideas are expressed. I also gave a 
heads up that due to the nature of the material we'd be encountering, you might come across some less savory language, and I think I made good on that caution, don't you?

In the second chapter, we dug into a deep comparison between Sophists and stand-up comedians, starting with a summary what we know to be true of the Sophists and how they've been reread and revived by rhetoric and composition scholars like Crowley, Jarratt, Crick, and Jaeger. I outlined the similarities between Sophists and stand-up comedians, beginning with the baseline congruence of their roles centering on traveling and selling speech. We saw how Sophists represented a shift from nobility to wealth, and stand-up comedians, in turn, represent a shift away from the prerequisite of formal education. Using an example from Ellen Degeneres’ 2000 comedy special The Beginning, in which she dismantles an argument against same sex marriage by imagining life married to a goat, we drew a parallels to how Crowley characterizes Sophists as "unsettling pupils” away from unsatisfactory positions toward more useful ones. Just as the Sophists used their speeches and interactions with listeners to help them “identify and negotiate differences among social groups,” we examined how Aamer Rahman forced recognition of social differences in his act when he outlined what would have to take place in order for "reverse racism" to be real. And last but not least, we considered the similar "bad raps" assigned to both Sophists and stand-up comedians, and ultimately I argued that we should reread stand-up comedians just as we’ve reread Sophists.

In the second part of chapter two, we tackled another important comparison, this time between jesters and stand-up comedians. Looping back to the notion that comedy is a delivery system for truth, as Fugelsang says, we looked at how jesters were able to 
speak truth to power by delivering damning criticism to rulers in the form of funny barbs, leveraging a perceived buffoonery and an earnest absence of having anything to gain politically by pointing out imperfections in the leader. In order to see how stand-up comedians today accomplish the feat of speaking truth to power, and to the general public, we delved into the concepts of subversion and resistance, assisted by the work of scholars like Domnica Radulescu, Barry Sanders, Helene Shugart and Joseph Boskin and comedians like Richard Pryor, Margaret Cho, and D.L. Hughley.

Having aligned stand-up comedians with Sophists and jesters, we moved on to comparisons with public intellectuals and social activists next in chapter three. After considering definitions of public intellectuals offered by Nathan Crick, Alan Lightman, and Edward Said, I looked for ways in which stand-up comedians fit that bill. Reminder: There were many. And plenty of non-academic publications had furnished us with some thoughts on that comparison from writers like Megan Garber, Marisa Kabas, and Francie Latour, who analyzed comedy by Amy Schumer, Michael Ian Black, and Louis C.K., respectively, to draw comparisons between stand-up comedians and public intellectuals.

The documentary Stand-up Planet was instrumental in understanding why one might call a stand-up comedian a social activist, as it shows Hasan Minhaj traveling to Mumbai, India and Sowetto, South Africa to meet comedians there who are harnessing the power of comedy to change the conversation around pressing local issues like poverty, sanitation, and AIDS epidemics. Minhaj ultimately concludes that the revolution will be hilarious, and an impact evaluation by Caty Borum Chattoo reveals that viewers were more moved to higher rates of awareness, concern and intended action by Stand-up Planet than by a similar-length documentary about global poverty presented 
in a more traditional, less humorous way, suggesting that stand-up comedy can be an effective tool for social activism.

That brings us to chapter four, in which I emphasized the importance of including comedians’ perspectives and voices and laid out my methodology for securing and conducting interviews with comedians W. Kamau Bell, John Fugelsang, and Aparna Nancherla. From my transcripts of those three interviews, I shared the comedians’ thinking on their use of the five canons of rhetoric, the alignment of stand-up comedians to Sophists, jesters, public intellectuals, and comedians, and their process for crafting and delivering material. Determined to incorporate as many sound bytes by stand-up comedians reflecting on their own work as possible, I covered a broad landscape of comedians' statements from written and recorded interviews and discussions across multiple platforms and publications. It turned out, when we listened to comedians, they had a lot to say. From Patton Oswalt's characterization of comedians as "the best conduit to the forgotten, to the outsiders, to the inarticulate” to Aamer Rahman's recounting of professors telling him that showing his reverse racism bit worked better than delivering a lecture to get their students engaged with complicated concepts of race and quality to Sommore's assertion that comedy reflects what's going on in a community, their statements and observations about the work of being stand-up comedians contributed colorfully and meaningfully to our consideration of comics.

Last but not least, as part of our rehashing of what's been covered thus far, let's take a look back at a few social experiments I included in there like an Easter egg hunt. For starters, I asked you, dear readers, to consider the tone of the writing in this document and reflect on whether the high interval training method of heavy critical 
thinking lifting interspersed with bursts of leg-stretching whimsy running impacted the understanding of the material—did it keep you engaged? Did it offer intermittent reprieval? Did it distract from an overall credibility factor that comes with consistently formal, scholarly writing? Secondly, I asked you to consider watching Stand-up Planet and reflecting on whether, as Caty Borum Chattoo surmised in her impact evaluation, the humorous presentation of material does, as she suggests, make for a higher likelihood of engaging the public in concepts of poverty and social inequity. For extra credit, you could extend that reflection to consider other ways in which engagement and impact may be strengthened by humorous presentations of material. I also suggested that you imagine the name Sasheer Zamata being announced by the $S N L$ voiceover guy and picture Gaston from Beauty and the Beast as a jester. Dissertations don't usually come with homework for the reader, but in an effort to emulate the interactive quality of stand-up comedy, in all its Kairos and you-had-to-be-there-ness, sprinkling in a handful of social experiments seems apropos.

\section{My Identity as a Writer, Researcher, and Comedy Consumer}

A good researcher will make transparent her identity as it relates to the work she presents. At the start of this dissertation, I referenced Gloria Anzaldúa’s statement about how identity can't be reduced to a "bunch of little cubbyholes," and listed some of the aspects of myself that my identity flows between and over, like my experience as a high school teacher and my consumption of stand-up comedy. As the saying goes, when you're a hammer, everything looks like a nail, and perhaps it is my training in the field of rhetoric and composition through this doctoral program that originally caused me to see stand-up comedy so decidedly as an important topic for rhetoricians to handle, but 
the more I poked and prodded at the many overlaps, the more convinced I became that rhetoricians’ understandings and frameworks should be brought to bear on stand-up comedy.

As for my appreciation of comedy, a potential critique of my work could be that I am a tourist in this area, as a non-comedian myself. In an effort to "get into character," so to speak, for the writing and researching of this project, I have very minorly dabbled in the practice of stand-up comedy, including - and also limited to, really - a comedy workshop in 2013 facilitated by Spark Arts Entertainment, a Last Ram Standing competition, also in 2013, and an improv workshop as part of a humor symposium in 2014. It's worth mentioning that I actually organized all three of these events as part of a yearlong initiative at URI to investigate comedy and social change, and the reason it's worth mentioning is that it helps to paint a picture of my identity as an appreciator of comedy, but not a passive enjoyer.

Inevitably, a person who does not regularly engage in stand-up comedy production yet writes about stand-up comedy and, specifically, argues for a produceroriented approach to studying stand-up might be administered some side-eye with a “Where do you get off making this type of claim” look, which is why I’ve elected to point out the ways in which I have actively sought the firsthand experience of creating and presenting stand-up comedy material. My participation in this activity, however limited, has contributed to a more well rounded perspective of stand-up comedy as an art, science, and techne. Feeling the blood pound in my ears, and knowing that all eyes and ears were on me up on stage- and that nobody else could save me from having to perform for those eyes and ears and hopefully not mess up but also make the whole 
thing look effortless, like a good comedian does—gave me a taste of the pressures and the exhilaration that come with being a stand-up comedian.

To imagine that on top of figuring out how to present themselves as nonchalantly cool story sharers in front of large groups on a regular basis, stand-up comedians might also be doing the important work of error detection through message delivery to wide audiences without the barriers of formal education... Let's just say that I developed a great respect for the work that stand-up comedians do, but I made a conscious effort not to let that fangirl identity cloud my judgments about how they were performing their roles. As someone who would rather go out to a stand-up show than a to a concert or movie, I recognized that my personal enthusiasm for comedy could influence my research interests, but should not dictate my scholarly investigations. I should also mention that I did win second place in the competition, if for no other reason than to brag.

\section{Implications for Research in Writing and Rhetoric}

Implications, implications, where to start. It's always a good idea to wrap up a dissertation with a few well formed, well worded, well meaning recommendations for what to do with this new research or this new take on something or this new tiny blip in the outside of the circle of human knowledge that the somewhat self-important video, “An Animated Guide to a Ph.D.,” suggests doctoral work concludes in. Accordingly, I have a few.

Academics must take popular culture seriously. If the academic world and the comedy world can be brought closer together by this work, a new, enjoyable genre worthy of study will open up to researchers and students. An aim of mine has been to 
examine how messages are shared by comedians and draw some conclusions about what other groups can learn from them about making information palatable and entertaining without sacrificing content and integrity. Rhetoric and composition scholars shouldn't continue to ignore “entertainment.” Instead, we could be capitalizing on the energy, enthusiasm, and rhetorical strength that comedic writing and its wide swath of subgenres can bring to our field. If a handful of educators were to ever, in some universe, get a hold of this dissertation and decide to take five minutes of class time to show a clip of stand-up comedy as an introduction into a lesson or assign students to select from five pre-determined segments on the same topic, including one or more stand-up excerpts, and ask them to write about the similarities and differences of learning about the same topic through different modes, or involve stand-up comedy in some other way of their choosing, I would smile and put a check mark next to this particular implication, which we'll affectionately call: More stand-up comedy in the classroom, please.

There is much of value outside the scholarly literature and rhetoric and composition researchers should look carefully at this growing body of work. The nonacademic articles we've surveyed in this dissertation show us that non-academics can feel compelled to write intelligently about comedy. Let's use that in our classes and ask our students to write intelligently about comedy. It may be just the hook that some of them need to turn on their critical thinking. The obvious benefit of pulling stand-up comedy into our classrooms would be engagement. Beyond the mere interest factor though, stand-up comedy could be especially invaluable in light of Hurley, Dennett and Adams' computational and evolutionary theory of humor. By putting students in contact with stand-up comedy material, we are not only keeping them interested, but potentially 
providing opportunities for them to confront or confirm latent committed beliefs through the reward of laughter.

It's possible that in the future, we will feel as foolish for overlooking the importance of stand-up comedians as rhetors as everyone in the field has been made to feel about selling the Sophists short. I've made clear my stance that stand-up comedians need to be recovered, rewritten, re-watched, and restored, which brings me to my second implication: Let's pay more attention to the ways in which stand-up comedians fit the history of Sophists, the tradition of jesters, and the function of speaking truth to power through rhetorical agency, thereby recovering the rhetorical place of importance that stand-up comedians should have. A vast landscape of possibilities stretches before us of all the different ways rhetoric and composition scholars could contribute to the study of stand-up comedy, but first we need to acknowledge all the different that stand-up comedians intersect with other figures of stature and social change, now and in the past.

One of the reasons I pulled non-scholarly texts into my work here is, as I indicated, people without higher education institutional attachments to their names can still offer clear-headed, contemplation-worthy investigations and explanations about stand-up comedy. Another reason though is the relatively slim pickings in the academic arena on which I could rely. Meier and Schmitt's very recent book Standing Up, Speaking Out: Stand-Up Comedy and the Rhetoric of Social Change is certainly a promising signal that the topic could be picking up steam out here, and they even make a similar call for paying more attention to stand-up in the academic community: "Although we are not suggesting that stand-up should be regarded as a panacea, its ability to speak truth to power, speak the unspeakable, and consider the world not as it is 
but as it should be cannot be ignored as a potentially powerful rhetorical resource for social change.”

Comedy makes a difference in the world by having real impact. Winston Churchill told us, "A lie gets halfway around the world before the truth has a chance to get its pants on,” and a cleverly crafted, memorably delivered stand-up comedian bit can circulate much more widely than a drily delivered, if carefully written, scholarly article. We might then surmise that thinking more about sharing information in humorous ways could go a long way in disseminating messages of our own, and that would result in a third implication: Let's learn from stand-up comedians' successes in getting large audiences to listen to what they have to say. In academia, we sometimes talk of the “impact factor” of a journal, as measured by the number of citations of articles in it. In one disappointing analysis, it was revealed that "some $90 \%$ of papers that have been published in academic journals are never cited” and “as many as 50\% of papers are never read by anyone other than their authors, referees and journal editors” (Lokman). Yikes. Even if we were to generously assume that these figures are way off, and immediately assign graduate students across the country to quadruple the number of articles they're reading, we'd still have a pretty dismal outlook on the majority of papers published in academic journals. This is sad, to put it simply, which you may have noticed I'm in favor of doing, because academics put a lot of blood, sweat and tears, or at the very least, a lot of time and energy into the things they publish. That's why I've been fascinated by the impact factor of stand-up comedians, who climb up on stage and regularly address sizable crowds, sharing opinions and ideas that they haven’t run 
through the editing mill of an academic journal, but nevertheless can often be strikingly sharp, insightful, and artfully delivered.

Academic scholarship cannot afford to be insular. Beatrice Otto asks if "scholarship [has] become too obsessed with growing prize onions in the garden plot while ignoring the beckoning fecundity of fields beyond the fence,” and I worry that the answer might be yes (Otto xvii). Of course, I have seen some examples of academics publicly reflecting on their professional connections to stand-up comedy, though not many. Dr. Kelli Marshall of DePaul University shared a post about how live comedy shows have contributed to her professional, scholarly work. First she lists the comedians she's seen live, and then she reflects on how seeing those live performances has impacted her professional life, from book chapters and journal articles she’s published about comedians to college courses she’s designed around comedians and their work, like "Stand-up Comedy on TV" and "Stand-up Comedy Documented." As Marshall acknowledges, there are larger social implications of stand-up comedians' work that are important enough to warrant discussion and exploration and the sharing of ideas.

Perhaps comedy can help academics to be better public intellectuals. There are even examples of academics taking on the persona of stand-up comedians in order to share their research, which is not necessarily what I'm suggesting we should try on for size, but it’s interesting nonetheless. A movement called "Bright Club” in London brings professors into pubs and night clubs to present their research in a series of comedy nights. It was inspired by Steve Cross, "a former geneticist who is completely serious in his crusade to find new ways for academics to interact with the public" 
(Guttenplan). At the 2015 International Society for Humor Studies conference, I actually encountered several professors who regularly participate in Bright Night in London, and Sophie Scott, who spoke at URI’s 2015 Honors Colloquium, has participated as well. The tagline for Bright Club is "researchers become comedians for just one night,” and again, I am not suggesting that this is the way academics can learn from stand-up comedians' rhetorical strategies and engagement techniques (although I I'm not not suggesting we have one at URI), but it does at least represent a recognition that we can learn something important from comedians about how to hook an audience.

Critical analysis of standup comedy may engage and motivate learners. In K-12 education and higher ed, we have occasionally recognized that humor is a powerful rhetorical tool capable of transmitting ideas and engaging students in them, as the professors professed to Rahman when the said that his stand-up comedy routine worked better than their lectures. Haphazardly, inconsistently, and without a great deal of (or any?) prompting from the powers that be in state and federal departments of education, in the case of K-12, or from department chairs or deans, in the case of higher ed, educators have pulled comedy into their classrooms at varying levels, dependent entirely on their own personal interest in and commitment to doing so. Why wouldn't more of us feel motivated to pull mirth and laughter into our classrooms? Moreover, why would we want to stamp it out of students with standardized curriculum and assessment?

I wouldn't want to suggest a wholesale standardization or requirement of incorporating comedy into classrooms across the board, because, while I don't think E.B. White was right about analyzing humor being like dissecting a dead frog, I do think establishing "mandatory comedy incorporation” would almost always stamp out any joy 
that might come with its inclusion. Furthermore, it would be way too broadly impossible to posit that humor should infiltrate education. However, on a much tinier, more explicit level, I do posit that stand-up comedy, specifically, should be pulled into the fold of rhetoric and composition, both as a form to study and analyze for discourse and as a prompt for students to engage with ideas, ethics, and opinions. Tarez Samra Graban points to key intersections between the field and humor studies in "Beyond 'Wit and Persuasion': Rhetoric, composition and humor studies,” but most are rooted in the theory of rhetoric and cultural production, and few intersections between comedy and composition as a practice, and as a course, are found.

\section{Kairos and Comedy}

Comedians are beings in time. Tragedies, love stories, and other great works of literature that generally receive academic respect and attention easily, without having to clamor for it, speak to feelings, which can be universal across time and space, and that makes sense when we consider how important it is to feel connected to others through recognizing similar feelings in them. Comedy, however, is harder to canonize in the same way as great literature, and lends itself less easily to long-term studying and debate, because it can be so time- and audience- bound. Coming back to that concept of Kairos, a well thought out, designed and delivered stand-up performance may not be as easy to capture and repeat and mull over as a play about love, because so much of the thinking involved in finding the stand-up performance satisfying is not the same for the second or third or thousandth retelling. We can count on feelings to stay pretty universal over time and across space, but we cannot say the same for matters of the mind, and if jokes or humorous utterances or artfully crafted and captivatingly performed stand-up sets can be 
said to appeal to the mind (and we've seen that they can be said to do just that), then it's no wonder we don't have the same general agreement that we should commit to consuming them critically, appreciating them professionally, and bringing them into our classrooms as texts to hold up to the light for reading, understanding and discussing.

If we did agree, as a field, that stand-up comedy sets and the rhetors who create and perform them are worth continued attention, what might our research look like, and our findings from that research? What might our classrooms look like? What would our students gain from the natural enjoyment of encountering humor during learning, and from the strong messages of power and human behavior and social constructs conveyed by the comedians? One thing they might benefit from is the creativity, flexible thinking, and problem solving that stand-up comedy inspires. One study indicated that when challenged with two tasks generally regarded as requiring creative ingenuity, people who watched a short comedy video were 3.75 times more likely to demonstrate improved performance (Isen, Daubman and Nowicki).

The truth is, if I am spending the amount of time writing and thinking that I am, in fact, spending at this time on this particular work of scholarship, it would feel uncomfortable and even irresponsible to not at least connect to current events in some way. Otherwise, I would worry that I was writing in a vacuum, and a vacuum is not where I wish to be. It's a natural fit, given the overall goals of this dissertation, to emphasize the function of stand-up comedy as resistance for our final implication. If, as Sophie Quirk tells us in Why Stand-up Matters, “jokes have the advantage of being eminently repeatable and thus able to spread ideas to a much wider audience,” then 
stand-up comedy is a very appropriate medium through which to resist, because it can carry important ideas to the multitudes.

Understanding, as we do, that humor can accomplish what Chris Bliss calls a “verbal magic trick," by seducing us into a different way of thinking when the endorphins bring down our defenses, now is an especially important time for us to pay attention to the power of stand-up comedians. Dissertations, by nature, are not particularly political, but paying attention to context just as we've explicitly paid attention to arrangement and audience, it is worth mentioning that at the time that parts of this dissertation were written, Donald Trump had just become the $45^{\text {th }}$ president of the United States. (For other parts, Barack Obama was president and that, this writer opines against the rules of dissertation writing, was a better time.)

In a time of anti-intellectualism — as some may argue we are now in, given the disdain the current president has shown for academic "elites”- stand-up comedians are well positioned to act as heroes, delivering information and ideas to people from outside what is traditionally thought of as intellectualism. Edward Said addressed the associations of "ivory tower" and "sneer" with the word "intellectual," stating that the public role of the intellectual is actually "as outsider, 'amateur,' and disturber of the status quo” (Said x). Stand-up comedians certainly qualify as “outsiders” to the ivory tower, and from their outside vantage point, they are better able to disturb the status quo without invoking the dismissiveness sometimes ascribed to academic elites. Since audiences are more open to hearing their message, stand-up comedians can take on the role of resisters and truth tellers—-while not giving up their positions as merry makers. 


\section{BIBLIOGRAPHY}

1. @michaelianblack. “Hey Washington: how about a Secretary of Getting Stuff Done?! The best comedy is funny but also makes a serious point.” Twitter, 10 Oct. 2013, 7:11pm.

https://twitter.com/michaelianblack/status/388441685119610880.

2. Abbey-Lambertz, Kate. “Anne Frank Center: Trump 'Is Driving Our Nation Off a Moral Cliff.'” Huffington Post, 25 Sep. 2017.

http://www.huffingtonpost.com/entry/anne-frank-center-donald-trumpdiscrimination_us_58890c18e4b0024605fd7ed2.

3. Amburn, Brad. “The World’s Top 20 Public Intellectuals.” Foreign Policy, 7 Oct. 2009. Web. http://foreignpolicy.com/2009/10/07/the-worlds-top-20-public$\underline{\text { intellectuals/ }}$

4. American: The Bill Hicks Story. Dirs. Matt Harlock and Paul Thomas. Jackamo Productions, 2011. Film.

5. Anzaldúa, Gloria. “To(o) Queer the Writer.” InVersions: Writing by Dykes, Queers, and Lesbians, edited by Betsy Warland, Pr Gang Pub, 1991, pp. 251-264.

6. Armstrong, Archibald. The Ass Race: Or the Secret History of Archy Armstrong, Fool to King Charles I. 1740.

7. Bakhtin, Mikhail. Rabelais and His World. Translated by Hélène Iswolsky. Bloomington: Indiana University Press, 1984. 
8. Barreca, Gina. They Used to Call Me Snow White... But I Drifted: Women's Strategic Use of Humor. Lebanon: University Press of New England, 2013.

9. Barrett, Harold. The Sophists: Rhetoric, Democracy, and Plato's Idea of Sophistry. Chandler \& Sharp, 1987.

10. Belanger, Jillian. “Comedy Meets Media: How Three New Media Features Have Influenced Changes in the Production of Stand-up Comedy.” Comedy Studies 6.2 (2015), 141-7.

11. --. "I have an academic crush on Gloria Anzaldúa.” https://paperwithpencil.wordpress.com/2015/03/07/i-have-an-academic-crush$\underline{\text { on-gloria-anzaldua/ }}$

12. Bell, W. Kamau. Personal interview. 6 Dec. 2014.

13. Berger, Phil. The Last Laugh: The World of Stand-up Comics. Lanham: Cooper Square Press, 2000.

14. Bilington, Sandra. A Social History of the Fool. New York: St. Martin’s, 1984.

15. Birnbaum, Henrik. “Laughter, Play and Carnical in Old Rus.” Words and Images: Essays in Honour of Professor (Emeritus) Dennis Ward. Nottingham: Astra Press, 1989, pp. 30-31.

16. Bizzell, Patricia and Bruce Herzberg. The Rhetorical Tradition: Readings from Classical Times to the Present. $2^{\text {nd }}$ ed., Bedford/St. Martins, 2001.

17. Bliss, Chris. “Comedy is Translation.” Ted Talk. Dec 2011.

18. Borum Chattoo, Caty. "Entertainment, Storytelling \& Social Change in Global Poverty: An Impact Evaluation of Stand Up Planet.” Center for Media \& Social Impact, American University, 2015. Web. 
http://archive.cmsimpact.org/sites/default/files/documents/entertainmentdocumentary_storytelling-social_change_in_global_poverty_-

_stand_up_planet_impact_report_february_2015.pdf.

19. --. "The Serious Role of Comedy in Social Change.” Frank Conference for Public Interest Communication, Feb. 2016. https://vimeo.com/156780810.

20. Boskin, Joseph. Rebellious Laughter: People's Humor in American Culture. Syracuse: Syracuse University Press, 1997.

21. Bruce, Lenny. How to Talk Dirty and Influence People. New York: Touchstone, 1965.

22. Burke, Kenneth. A Rhetoric of Motives. Berkeley: University of California Press, 1969.

23. Burkeman, Oliver. "Jerry Seinfeld on How to Be Funny Without Sex and Swearing.” The Guardian, 5 Jan. 2014. https://www.theguardian.com/culture/2014/jan/05/jerry-seinfeld-funny-sexswearing-sitcom-comedy.

24. Carrell, Amy. "Historical Views of Humor.” The Primer of Humor Research (Ed. Victor Raskin). Berlin: Mouton de Gruyter, 2008. 303-32.

25. Ciesielski, Jenni. "Q \&A with Comedy Arts Comedian Aparana Nancherla." Daily Tarheel, 16 Feb. 2017. http://www.dailytarheel.com/article/2017/02/qawith-comedy-arts-comedian-aparna-nancherla.

26. Cixous, Hélène. “The Laugh of the Medusa.” Signs 1.4 (1976): 875-93.

27. Cohen, Ted. Jokes: Philosophical Thoughts on Joking Matters. Chicago: University of Chicago Press, 2001. 
28. Colletta, Lisa. "Political Satire and Postmodern Irony in the Age of Stephen Colbert and Jon Stewart.” Popular Culture, vol. 42, no. 5, Oct. 2009, pp. 856874.

29. Comedian. Dir. Christian Charles. Bridgnorth Films, 2002. Film.

30. Compton, Joshua, and Miller, B. "Image Repair in Late Night Comedy: Letterman and the Palin Joke Controversy.” Public Relations Review vol. 37, 2011, pp. 415-21.

31. Compton, Joshua, and Miller, B. "Image Repair in Late Night Comedy: Letterman and the Palin Joke Controversy.” Public Relations Review vol. 37, 2011, pp. 415-21.

32. Conley, Thomas M. Rhetoric in the European Tradition. The University of Chicago Press, 1990.

33. Creswell, John W. Research Design: Qualitative, Quantitative, and Mixed Method Approaches. Thousand Oaks: Sage Publications, Inc., 2009.

34. Crick, Nathan. "The Sophistical Attitude and the Invention of Rhetoric." Quarterly Journal of Speech vol. 96, no. 1, 2010, pp. 25-45.

35. Critchley, Simon. On Humour: Thinking in Action. London: Routledge, 2002.

36. Crowley, “A Plea for the Revival of Sophistry.” Rhetoric Review vol. 7, no. 2, 1989, pp. 318-34.

37. Cushman, Ellen. The Rhetorician as an Agent of Social Change. College Composition and Communication, Vol. 47, No. 1, Feb. 1996, pp. 7-28.

38. Daley, David. “Salon’s Patton Oswalt Peace Summit.” Salon, 11 Mar. 2015. www.salon.com/2015/03/11/salons_patton_oswalt_peace_summit/. 
39. Degeneres, Ellen. The Beginning. Dir. Joel Gallen. HBO, 2000. Film.

40. Deggans, Eric. “Inside Amy Schumer, Some Surprising Commentary.” NPR, All things Considered, 22 Apr. 2014.

http://www.npr.org/2014/04/22/305952940/inside-amy-schumer-somesurprising-commentary.

41. Dessau, Bruce. The Bluffer's Guide to Stand-up Comedy. London: Bluffer's, 2014.

42. DiCioccio, Rachel, ed. Humor Communication: Theory, Impact, and Outcomes. Dubuque: Kendall Hunt Publishing, 2013.

43. Double, Oliver. Stand-Up! London: Heinemann, 1997.

44. --. Getting the Joke: The Inner Workings of Stand-up Comedy. New York: Bloomsbury Methuen Drama, 2005.

45. Douglas, Mary. Implicit Meanings: Essays in Anthropology. Boston and London: Routledge and Kegan Paul, 1975.

46. “Drunk History Serves an Educational Cocktail, with Comedic Twist.” NPR, Morning Edition, 2 Jul. 2014.

http://www.npr.org/2014/07/02/327079981/drunk-history-serves-an-educationalcocktail-with-comedic-twist.

47. Emerson, Ralph Waldo. “The American Scholar.” Phi Beta Kappa. Society. 31 Aug. 1837. Cambridge, MA. Speech.

48. Episode 23. Totally Biased with W. Kamau Bell: Season 1. FX, 30 May 2013.

49. Erasmus, Desidirius. Praise of Folly. Penguin Classics, 1994.

50. Fey, Tina. “Lessons from Late Night.” The New Yorker, 14 Mar. 2011. 
51. Freud, Sigmund. The Joke and Its Relation to the Unconscious. New York: Penguin Classics, 2003.

52. Fry, William F., and Melanie Allen. Creating Humor: Life Studies of Comedy Writers. Piscataway: Transaction Publishers, 1997.

53. Fugelsang, John. Personal interview. 13 Oct. 2015.

54. Gagarin, Michael. "Did the Sophists Aim to Persuade?” Rhetorica: A Journal of the History of Rhetoric vol. 19, no. 3, 2001, pp. 275-91.

55. Garber, Megan. "How Comedians Became Public Intellectuals.” The Atlantic, 28 May 2015. http://www.theatlantic.com/entertainment/archive/2015/05/howcomedians-became-public-intellectuals/394277/

56. Gere, Anne Ruggles. "Kitchen Tables and Rented Rooms: The Extracurriculum of Composition." College Composition and Communication vol. 45, no. 1, 1994, pp. 75-92.

57. Goodnow, Trischa, et. al. The Daily Show and Rhetoric: Arguments, Issues, and Strategies. New York: Lexington Books, 2011.

58. Gotham Writers. Gotham Writers Workshop, Inc., 2017. www.writingclasses.com.

59. Graban, Samra Tarez. "Beyond 'Wit and Persuasion’: Rhetoric, Composition, and Humor Studies." The Primer of Humor Research (Ed. Victor Raskin). Berlin: Mouton de Gruyter, 2008. 399-448.

60. Green, Melanie C., and Timothy C. Brock. "The Role of Transportation in the Persuasiveness of Public Narratives.” Journal of Personality and Social Psychology 79.5 (2000): 701-21. 
61. Green, Michelle. “The Mouth of Texas.” People, 9 Dec. 1991.

http://people.com/archive/the-mouth-of-texas-vol-36-no-22/.

62. Greenbaum, Andrea. “Stand-up Comedy as Rhetorical Argument: An Investigation of Comic Culture.” Humor 12.1 (1999): 33-46.

63. Greenbaum, Andrea. “Stand-up Comedy as Rhetorical Argument: An Investigation of Comic Culture.” Humor vol. 12, no. 1, 1999, pp. 33-46.

64. Guttenplan, D.D. “Academics Making Forays Into Stand-up Comedy.” The New York Times, 19 Dec. 2010.

http://www.nytimes.com/2010/12/20/world/europe/20iht-educLede20.html.

65. Hariman, Robert. "Political Parody and Public Culture. Quarterly Journal of Speech 94.3 (2008): 247-72.

66. Harper, Robyn. “When I Get Married, Will It Be a ‘Gay Marriage’?” Huffington Post, 6 June 2012. http://www.huffingtonpost.com/robynharper/marriage-equality_b_1572611.html

67. Havelock, Eric. The Liberal Temper in Greek Politics. New Haven: Yale University Press, 1957.

68. Hawhee, Debra. “Bodily Pedagogies: Rhetoric, Athletics, and the Sophists' Three Rs.” College English, Vol. 65, No. 2, 2002, pp. 142-62.

69. Holcomb, Christ. “A Man in a Painted Garment: The Social Function of Jesting in Elizabethan Rhetoric and Courtesy Manuals.” HUMOR: International Journal of Humor Research vol. 13, no. 4, 2000, pp. 429-56.

70. --. “Anyone Can Be President: Figures of Speech, Cultural Forms, and Performance.” Rhetoric Society Quarterly 37.1 (2007): 71-96. 
71. Huckin, Thomas, et al. "Critical Discourse Analysis and Rhetoric and Composition.” College Composition and Communication vol. 64, no. 1, 2010, pp. 107-29.

72. Hughley, D.L. Unapologetic. HBO, 2007. Film.

73. Hurley, Matthew M., Daniel C. Dennett, and Reginald B. Adams, Jr. Inside Jokes: Using Humor to Reverse-Engineer the Mind. Cambridge: MIT Press, 2011.

74. I Am Comic. Dir. Jordan Brady. Uber Content, 2010. Film.

75. “It'll Make Sense When You're Older.” This American Life. NPR, WBEZ, 25 Mar. 2016. https://www.thisamericanlife.org/radioarchives/episode/583/transcript.

76. Isen, Alice M, Kimberly A. Daubman, and Gary P. Nowicki. "Positive Affect Facilitates Creative Problem Solving.” Journal of Personality and Social Psychology, vol. 52, no. 6, Jun. 1987, pp. 1122-1131.

77. Isocrates. Against the Sophists and Antidosis. Translated by George Norlin. Cambridge: Harvard University Press, 1929.

78. Jaeger, Werner. Paideia: The Ideals of Greek Culture. New York: Oxford University Press, 1943.

79. Jarratt, Susan C. Rereading the Sophists. Carbondale: Southern Illinois University Press, 1998.

80. Jenkins, David M. “Was It Something They Said?: Stand-up Comedy and Progressive Social Change.” Dissertation, University of South Florida, 2015. 
81. Johanek, Cindy. Composing Research: A Contextualist Paradigm for Rhetoric and Composition. Logan: Utah State University Press, 2000.

82. Kabas, Marisa. "Michael Ian Black and the Golden Age of Idiocy.” The Daily Dot, 11 Jan. 2016, http://www.dailydot.com/layer8/michael-ian-black-gunviolence/?tw=dd.

83. Knoedelseder, William. I'm Dying Up Here: Heartbreak and High Times in Stand-up Comedy’s Golden Era. New York: Perseus Book Group, 2010.

84. Koestler, Arthur. The Act of Creation: A Study of the Conscious and Unconscious in Science and Art. New York: Dell, 1964.

85. Koziski, Stephanie. “The Standup Comedian as Anthropologist.” Journal of Popular Culture vol. 18, 1984, pp. 57-76.

86. Krefting, Rebecca. “Punching Up.” New America, 22 Sep. 2016. Web, https://www.newamerica.org/weekly/edition-135/punching/.

87. --. All Joking Aside: American Humor and Its Discontents. Baltimore: John Hopkins University Press, 2014.

88. Latour, Francie. “Wise Guy: Wrapped in Louis C.K.’s Stand-up Material Are Powerful Insights on Race.” Boston.com, 8 Dec. 2013. http://www.boston.com/jobs/jobs-news/2013/12/08/wise-guy

89. Lewis, Paul. Cracking Up: American Humor in a Time of Conflict. Chicago: University of Chicago Press, 2006.

90. Lichter, Robert, Jody C. Baumgartner, and Jonathan S. Morris. Politics Is a Joke: How TV Comedians Are Remaking Political Life. 
91. Lichter, Robert. “Study: Leno’s Top Joke Target Was Bill Clinton.” The Center for Media and Public Affairs at George Mason University, 4 Feb. 2014.

92. Lightman, Alan. "Public Intellectuals and the Academy.” MIT Communications Forum. 2 Dec. 1999. MIT, Cambridge, MA. Colloquium remarks. http://www.mit.edu/ saleem/ivory/epil.htm

93. Limon, John. Stand-up Comedy in Theory, or, Abjection in America. Durham: Duke University Press Books, 2000.

94. Lindlof, Thomas R. and Taylor, Bryan C. Qualitative Communication Research Methods. $3^{\text {rd }}$ ed. Los Angeles: Sage Publications, 2011.

95. Lockyer, Sharon, and Michael Pickering. Beyond a Joke: The Limits of Humour. New York: Palgrave Macmillan, 2005.

96. Logan, Brian. “Shock Value: How Aamer Rahman’s ‘Reverse Racism’ Joke Saved His Career.” The Guardian, 4 Jun. 2014. Web, https://www.theguardian.com/stage/2014/jun/04/aamer-rahman-reverse-racismcomedy-tour.

97. Lynch, Owen H. “Humorous Communication: Finding a Place for Humor in Communication Research.” Communication Theory vol. 12, no. 4, 2002, pp. 42345.

98. Make 'Em Laugh: The Funny Business of America. Dir. Michael Kantor. PBS, 2009. Comedy series.

99. Marshall, Kelli. “Comedians I’ve Seen Live.” Medium, 2 Jun. 2015, https://medium.com/@KelliMarshall/comedians-i-ve-seen-live43028205e468\#.g99rzgert. 
100. McGee, Michael Calvin. “Text, Context, and the Fragmentation of Contemporary Culture.” Western Journal of Speech Communication 54.3 (1990): 274-89.

101. Meho, Lokman I. "The Rise and Rise of Citation Analysis.” Physics World, Jan. 2007, pp. 32-36.

102. Meier, Matthew R., and Casey R. Schmitt, editors. Standing Up, Speaking Out: Stand-up Comedy and the Rhetoric of Social Change. Routledge, 2016.

103. Mendrinos, James. The Complete Idiot's Guide to Comedy Writing. New York: Alpha Books, 2004.

104. Meyer, John C. "Humor as a Double-Edged Sword: Four Functions of Humor in Communication. Communication Theory 10.3 (2000): 310-31.

105. Might, Matt. “The Animated Guide to a Ph.D.” YouTube, uploaded by ElicaTeam, 4 Jan. 2014, https://www.youtube.com/watch?v=We760YM5-iM. 106. Miller, Geoffrey. The Mating Mind: How Sexual Choice Shaped the Evolution of Human Nature. New York: Doubleday, 2000.

107. Mintz, Lawrence E. “Standup Comedy as Social and Cultural Mediation.” American Quarterly Special Issue: American Humor vol. 37, no. 1, 1985, pp. 7180.

108. ---, ed. Humor in America: A Research Guide to Genres and Topics. Wesport: Greenwood, 1988.

109. Moms Mabley: I Got Somethin’ To Tell You. Dir. Whoopi Goldberg. Whoop/One Ho Productions, 2013. Film. 
110. Murphy, Sheila T., Lauren B. Frank, Meghan B. Moran, and Paula PatnoeWoodley. "Involved, Transported, or Emotional? Exploring the Determinants of Change in Knowledge, Attitudes, and Behavior in Entertainment-Education.” Journal of Communication 61.3 (2011) 407-31.

111. Murphy, Sheila. "Stories Are Better Than Lectures At Teaching Us About Health.” The Conversation, 3 Feb., 2017. http://theconversation.com/stories-arebetter-than-lectures-at-teaching-us-about-health-71682.

112. Nachman, Gerald. Seriously Funny: The Rebel Comedians of the 1950s and 1960s. New York: Pantheon, 2003.

113. Nancherla, Aparna. Personal interview. 24 Jul. 2016.

114. --. "Comedians in the Age of Trump: Forget Your Stupid Toupee Jokes.” The Village Voice, 13 Dec. 2016.

115. Oliver, John, and Andy Zaltman. "Close to the Edge.” The New Statesman, 22 Aug. 2005.

116. Olson, Stephanie Koziski. "Standup Comedy.” Humor in America: A Research Guide to Genres and Topics. Wesport: Greenwood, 1988.

117. Onishi, Norimitsu. "Nigeria’s Comics Pull Punch Lines from Deeper Social Ills.” The New York Times, 5 Dec. 2015. https://www.nytimes.com/2015/12/06/world/africa/nigerias-comics-pull-punchlines-from-deeper-social-ills.html? _r=0.

118. Otto, Beatrice K. Fools Are Everywhere: The Court Jester Around the World. Chicago: The University of Chicago Press, 2001. 
119. Pearson, Kyra. "Words Should Do the Work of Bombs: Margaret Cho as Symbolic Assassin.” Women and Language 32.1 (2009): 36-43.

120. Plester, Barbara, and Mark Orams. "Send in the Clowns: The Role of the Joker in Three New Zealand IT Companies.” HUMOR: International Journal of Humor Research, vol. 21., no. 3, 2008, pp. 253-281.

121. Porter, James E. Audience and Rhetoric: An Archaeological Composition of the Discourse Community. Englewood Cliff: Prentice Hall, 1992.

122.Poulakos, John. "Toward a Sophistic Definition of Rhetoric."

123. Provenza, Paul. Satiristas: Comedians, Contrarians, Raconteurs and Vulgarians. Scranton: Harper Collins It Books, 2010.

124. Pryor, Richard. Craps (After Hours), 1971.

125. Quirk, Sophie. “Containing the Audience: The 'Room' in Stand-up Comedy.” Participations: Journal of Audience \& Reception Studies, vol. 8, no. 2, Nov. 2011, pp. 219-238.

126. Radulescu, Domnica. Women's Comedic Art as Social Revolution: Five Performers and the Lessons of Their Subversive Humor. Jefferson: Mcfarland, 2011.

127. Rahman, Aamer. "Reverse Racism.” YouTube, uploaded by Fear of a Brown Planet, 28 November 2013, https://www.youtube.com/watch?v=dw_mRaIHb-M.

128. Raskin, Victor. The Primer of Humor Research. Berlin: Mouton de Gruyter, 2009.

129. “Rest Easy, Bill: After 4,000 Jokes, Leno’s Run Wraps Up.” NPR All Things Considered. 2014. 
130. Rich, Frank. “In Conversation: Chris Rock.” New York Magazine, 1 Dec. 2014.

131. Rosen, Ralph. "Efficacy and Meaning in Ancient and Modern Political Satire: Aristophanes, Lenny Bruce, and Jon Stewart.” Politics and Comedy 79.1 (2012): $1-32$.

132. Rossing, Jonathan P. “Critical Race Humor in a Postracial Moment: Richard Pryor’s Contemporary Parrhesia.” Howard Journal of Communications, vol. 24, no. 1, 2014, pp. 16-33.

133. Rutter, Jason. "Stand-up as Interaction: Performance and Audience” Dissertation, University of Salford, 1997.

134. Sacks, Mike. Poking a Dead Frog: Conversations with Today's Top Comedy Writers. New York: Penguin Books, 2014.

135. Said, Edward. Representations of the Intellectual: The 1993 Reith Lectures. New York: First Vintage Books, 1994.

136. Sanders, Barry. Sudden Glory: Laughter as Subversive History. Boston: Beacon Press, 1996.

137. Sankey, Jay. Zen and the Art of Stand-Up Comedy. London: Routledge, 1998.

138. Scott, Sophie. “Science of Laughter.” URI Honors Colloquium, 27 Oct. 2015, Edwards Auditorium, Kingston, RI. Guest lecture.

139. Sher, Aubrey. The Stand-up Comedy Festival: Send in the Clowns. Bloomington: XLIBRIS, 2013.

140. Shugart, Helene A. "Postmodern Irony as Subversive Rhetorical Strategy." Western Journal of Communication vol. 63, no. 4, Fall 1999, pp. 433-455. 
141. Sims Bishop, Rudine. "Mirrors, Windows, and Sliding Glass Doors.” Perspectives: Choosing and Using Books for the Classroom 6.3 (1990): ix-xi.

142. Smith, Stephen A. "Humor as Rhetoric and Cultural Argument.” Journal of American Culture 16.2 (2004): 51-64.

143. Stone, Laurie. Laughing in the Dark: A Decade of Subversive Comedy. New York: The Ecco Press, 1997.

144. Tafoya, Eddie. The Legacy of the Wisecrack: Stand-up Comedy as the Great American Literary Form. Boca Raton: Brown Walker Press, 2009.

145. Talking Funny. Dir. John Moffit. HBO, 2011. Television special.

146. The Green Room with Paul Provenza. Season 1, Episode 2. Showtime, 14 Jul. 2011.

147. Thomas, Justin. "How Laughter Reconnects Us with Life’s Simple Truths.” The National, 25 Oct. 2015. Web. http://www.thenational.ae/opinion/comment/howlaughter-reconnects-us-with-lifes-simple-truths.

148. Totally Biased with W. Kamau Bell: Season 1, Episode 23. FX, 30 May 2013.

149. Turner, Victor. "Frame, Flow and Reflection: Ritual and Drama as Public Liminality.” Performance in Postmodern Culture. Eds. Michael Benamou and Charles Caramello. Madison: University of Wisconsin Press, 1977. 465-99.

150. Vitanza, Victor J. Negation, Subjectivity, and the History of Rhetoric. Albany: State University of New York Press, 1997.

151.Volpe, Michael. “The Persuasive Force of Humor: Cicero’s Defense of Caelius.” Quarterly Journal of Speech 63 (1977): 311-23. 
152. Waisanen, Don. "Standing-Up to the Politics of Comedy." Communication and Language Analysis in the Public Sphere. Ed. Roderick P. Hart. Austin: IGI Global, 2014. 426-42.

153. --. "Comedian-in-Chief: Presidential Jokes as Enthymematic Crisis Rhetoric.” Presidential Studies Quarterly, vol. 45, no. 2, Jun. 2015, pp. 335-360.

154. --. "Laughing or Learning with the Chief Executive? The Impact of Exposure to Presidents’ Jokes on Message Elaboration.” Humor, vol. 30, no. 1, Nov. 2016, pp. 23-41.

155. Watkins, Mel. On the Real Side: Laughing, Lying, and Signifying: The Underground Tradition of African-American Humor that Transformed American Culture, from Slavery to Richard Pryor. New York: Simon and Shuster, 1994. 156. Why We Laugh: Black Comedians on Black Comedy. Dirs. Robert Townsend and Quincy Newell. Codeblack Films, 2009. Documentary.

157. Wilde, Larry. Great Comedians Talk About Comedy. Mechanicsburg: Executive Books, 2000.

158. Willett, Cynthia, Julie Willett, and Yael D. Sherman. “The Seriously Erotic Politics of Feminist Laughter.” Social Research, vol. 79, no. 1, Spring 2012, pp. 217-246.

159. Women in Comedy. Directed by Heidi Ewing and Rachel Grady, 2015.

160. Young, Molly. “57 Minutes with Amy Schumer.” New York Magazine, 1 Apr. 2013. 
161.Zarya, Valentina. “President Obama Gets ‘Choked Up’ While Giving Ellen DeGeneres the Highest Civilian Honor.” Fortune, 23 Nov. 2016. http://fortune.com/2016/11/23/obama-ellen-degeneres-medal/.

162.Zoglin, Richard. Comedy at the Edge: How Stand-up in the 1970s Changed America. New York: Bloomsbury, 2008.

163.Zupancic, Alenka. The Odd One In: On Comedy. Cambridge: The MIT Press, 2008. 